$$
\begin{gathered}
\text { UNIVERSIDADE DE SÃO PAULO } \\
\text { INSTITUTO DE FISICA DE SÃO CARLOS } \\
\text { DEPARTAMENTO DE FÍSICA E INFORMÁTICA }
\end{gathered}
$$

ERNANNI DAMIÃO VIEIRA

\title{
RESSONÂNCIA MAGNÉTICA ELETRÔNICA NO ESTUDO DE SISTEMAS DE INTERESSE BIOLÓGICO
}

São Carlos

2009 



\section{ERNANNI DAMIÃO VIERA}

\section{RESSONÂNCIA MAGNÉTICA ELETRÔNICA NO ESTUDO DE SISTEMAS DE INTERESSE BIOLÓGICO}

Tese apresentada ao Programa de PósGraduação em Física do Instituto de Física de São Carlos da Universidade de São Paulo, para obtenção do título de Doutor em Ciências.

Área de Concentração: Física Aplicada. Orientador: Prof. Dr. Antonio José da Costa Filho

São Carlos

2009 
AUTORIZO A REPRODUÇÃO E DIVULGAÇÃO TOTAL OU PARCIAL DESTE TRABALHO, POR QUALQUER MEIO CONVENCIONAL OU ELETRÔNICO, PARA FINS DE ESTUDO E PESQUISA, DESDE QUE CITADA A FONTE.

Ficha catalográfica elaborada pelo Serviço de Biblioteca e Informação IFSC/USP

Vieira, Ernanni Damião

Ressonância magnética eletrônica no estudo de sistemas de interesse biológico / Ernanni Damião Vieira.; orientador Antonio José da Costa Filho.-- São Carlos, 2009.

$140 \mathrm{p}$.

Tese (Tese em Ciência - Área de concentração: Física Aplicada) - Instituto de Física de São Carlos da Universidade de São Paulo.

1. RPE. 2. Superparamagnetismo. 3. Nicotina. 4. Surfatante pulmonar. 5. Células-tronco. I.Título. 


\section{FOLHA DE APROVAÇÃO}

Ernanni Damião Vieira

Tese apresentada ao Instituto de Física de São Carlos da Universidade de São Paulo para obtenção do título de Doutor em Ciências. Área de Concentração: Fisica Aplicada.

Aprovado em: 01/06/2009

\section{Comissão Julgadora}

Prof. Dr. Antônio José da Costa Filho

Instituiçăo: IFSC/USP

Assinatura

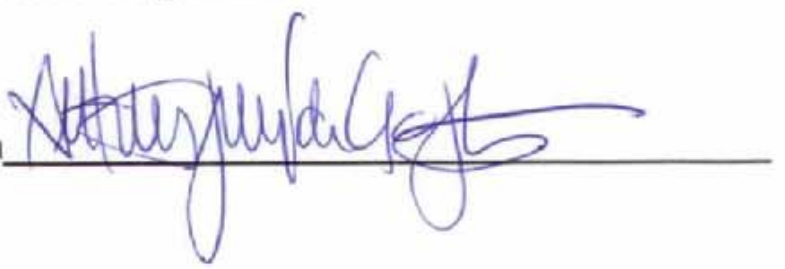

Prof. Dr. Amando Siuiti Ito

Instituição: FFCLRP/USP

Assinatura

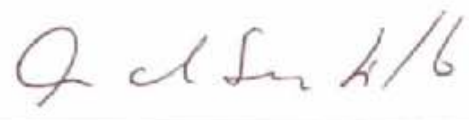

Prof. Dr. Jose Pedro Donoso Gonzalez

Instituiçâa: IFSC/USP

Assinatura

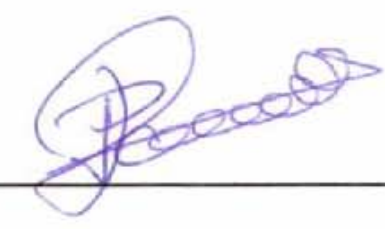

Prof. Dr. Lionel Fernel Gamarra Contreras Instituição: SBIBHAH

Assinatura

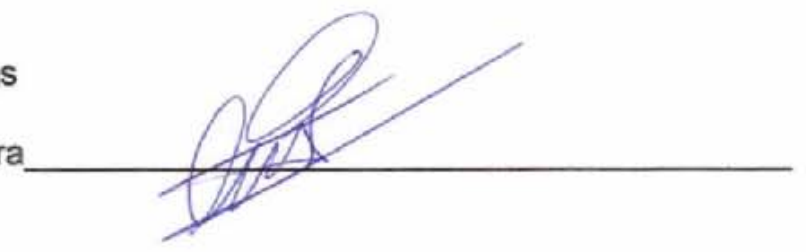

Profa. Dra. Eliane Wajnberg Instituição: CBPF

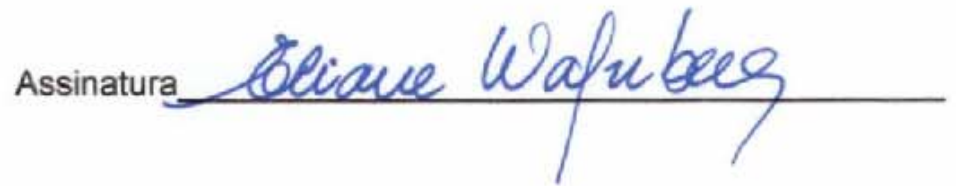


Este trabalho científico é dedicado à memória de minha mãe, por tudo que sou e tudo que tenho conquistado.

À minha LINDA Rezinha, luz dos meus olhos e afago da minha alma, pelos os maravilhosos momentos que temos vividos juntos.

Ao Prof. Otaciro Rangel Nascimento, meu pai científico, quem me acolheu no grupo de Biofísica na árida época da graduação, instruiu-me na técnica de RPE mostrando-me a arte de realizar uma boa medida.

Ao meu pai Damião Vieira, à dona Maria, aos meus irmãos Ivanildo e Edson, aos meus sobrinhos Rian, Clemerson e Vitória; as minhas cunhadas Simone, Margarida e Queite. 


\section{Agradecimentos}

Agradeço ao professor Dr. Antonio José da Costa Filho pela orientação continuada desde o meu mestrado há exatos sete anos, por mais uma oportunidade e pela amizade.

Ao Dr. Lionel Gamarra Contreras, pela amizade, pela valiosa colaboração, pelo empenho e impagável ajuda com que tem me prestado principalmente no final desta tese.

A minha competente professora de inglês Solange Maimoni, pela amizade e empenho com que tem me alfabetizado na língua inglesa, especialmente na escrita. Ao meu companheiro e amigo Luís Guilherme (militar) pelas nossas proveitosas discussões sobre RPE.

As minhas Princesinhas: Deinha e Yasmin, por tudo que representam pra mim.

À minha inesquecível professora de ciências Célia Ribeiro.

A minha amiga Jane, Dona Zoraide, primo Pedro, Mário Gaziro,

As pessoas do Grupo de Biofísica:

Prof. Zucolotto, Prof. Magon, Andressa, Profa. Ana Paula, minha amiga Sheila, Profa. Leila, Beto, Ana Paula (Paulette), Fernando Lima, Fernando Melo, Débora, Leandro, Zé Luis, Assuero, Baiano, Rony, Lia, Possato, Bel, Profa. Nelma, Joci, Luis argentino, Camila, Débora-IC, Tatiana, Júlia, Dona Graça, Pámela, Natália, Estér, Gigi...

Ás Bibliotecárias, pela simpatia e competência no atendimento, especialmente a Neusa e Mara que tem me ajudado na formatação desta tese.

Ás Tias e Tios do "bandejão", quem nos dão de comer todos os dias da semana.

Aos meus Tios e Tias, primos e primas.

Às funcionárias, funcionários, professoras e professores do IFSC.

À FAPESP, CNPq e CAPES pelo apoio financeiro e científico ao longo de desenvolvimento deste trabalho. 
A mais longa jornada começa com um passo.

Provérbio Chinês

Antes tarde do que NUNCA! Provérbio "Carriês" 


\section{Resumo}

VIEIRA, E. D. Ressonância magnética eletrônica no estudo de sistemas de interesse biológico. 2009. 140 p. Tese (Doutorado) Instituto de Física de São Carlos, Universidade de São Paulo, São Carlos, 2009.

Neste trabalho de tese aplicamos a espectroscopia de Ressonância Paramagnética Eletrônica (RPE) junto com a chamada técnica do "grupo repórter", aliada a simulação espectral por meio do programa NLSL, para investigar a interação da nicotina dependente com membranas. Também empregamos Ressonância Ferromangnética (RFM), que é uma técnica similar em muitos aspectos ao RPE, para investigamos células-tronco marcadas com nanopartículas superparamagnéticas de óxido de ferro (NSOF), previamente preparada no laboratório de nanotecnologia do Instituto Israelita de Ensino e Pesquisa Albert Einstein (IIEPAE). Os resultados relativos à primeira parte da tese, mostraram que a nicotina quando em meio ácido interage com a região da cabeça polar dos fosfolipídios estudados e tem ação penetrante em meio básico. A interação da nicotina com o DPPC resulta em uma desestabilização da fase gel do fosfolipídio. Este fato pode estar relacionado com a ocorrência de doenças respiratórias em tabagistas devido ao fato de que o DPPC é o maior constituinte do complexo surfatante pulmonar. Na segunda parte, fomos capazes de marcar células-tronco com nanopartículas superparmangéticas e também quantificá-las pelo cálculo da área, dupla integral do espectro de RFM das NOSF. Finalmente, fizemos uma caracterização das nanopartículas por meio de experimentos de RFM dependente da variação de temperatura, que confirmaram o comportamento superparamagnético das NOSF.

Palavras Chaves: RPE, Superparamagnetismo, Nicotina, Surfatante pulmonar, Células-tronco. 


\section{Abstract}

VIEIRA, E. D. Electron magnetic resonance in studies of biologicallyrelevant systems. 2009. 140 p. Tese (Doutorado) - Instituto de Física de São Carlos, Universidade de São Paulo, São Carlos, 2009.

In this work, we made use of the Electron Paramagnetic Resonance (EPR) spectroscopy along with the so-called reporter group technique and extensive spectral simulations by means of the software NLSL to investigate the interaction of nicotine with model membranes. Besides that we also employed Ferromagnetic Resonance (FMR), which is a technique similar in many aspects to EPR, to investigate stem cells labeled with superparamagnetic nanoparticles of iron oxide (NSOF) previously made at the Nanotechnology Laboratory of the Instituto Israelita de Ensino e Pesquisa Albert Einstein (IIEPAE). The results concerning the first part of our work showed that nicotine in acidic $\mathrm{pH}$ value interacts with the polar headgroup region of the phospholipids under investigation, whereas it penetrates the model membrane in alkaline $\mathrm{pH}$ value. Also, the interaction of nicotine with DPPC resulted in destabilization of the phospholipid gel phase. This fact could be related to some of the effects of nicotine in respiratory diseases since DPPC is the major constituent of the pulmonary surfactant complex. In the second part of our work, we were able to successfully label stem cells with the superparamagnetic nanoparticles and also quantify that labeling by calculating the area under the double integrated NSOF FMR spectra. We also performed a characterization of the nanoparticles by means of temperature-variation FMR experiments, which showed that the iron oxide nanoparticled indeed had a superparamagnetic behavior.

Key Words: EPR, Superparamantism, Nicotine, Lung Surfactants, Stem Cell 


\section{Sumário}

1 Introdução Geral 10

1.1 Interações de Nicotina com Modelos de Membrana 14

1.2 Materiais e Métodos 20

1.2.1 Materiais 20

1.2.2 Preparação de Amostras 21

1.2.3 Medidas de RPE 22

1.2.4 Simulações de Espectros de RPE 23

1.3 Resultados e Discussão 29

1.3.1 Vesículas do Fosfolipídio DPPC com e sem nicotina
monitoradas por 5-PCSL e 16-PCSL

1.3.2 Vesículas do fosfolipídio POPC com e sem nicotina
monitoradas com marcadores 5-PCSL e 16-PCSL em pHs ácido ( 6) e básico ( 10) 45

1.3.3 Discussão geral dos resultados 66

2 Nanopartículas superparamagnéticas de óxido de ferro como marcadores celulares $\quad 72$

2.1 Fundamentos Teóricos 72

2.1.1 Introdução

2.1.2 Ferrofluidos 76

2.1.3 Células tronco CD133 ${ }^{+} \quad 80$

2.1.4 Ressonância Ferromagnética 83

2.1.3 Características Físico-Químicas dos Óxidos de Ferro:
Magnetita e Maghemita

2.2 Materiais e Métodos 89

2.2.1 Marcador magnético: Descrição da amostra 89

2.2.2 Células-Tronco CD133 ${ }^{+} \quad 90$

2.2.3 Metodologia de quantificação das NSOF 91

2.2.4 Detecção das células marcadas - Citometria de Fluxo 93

2.2.5 Visualização qualitativa das $\mathrm{CD}_{133^{+}}$: Microscopia

2.2.6 Medidas de Ressonância Ferromagnética 94

2.3 Resultados e Discussão 95

2.3.1 Caracterização Magnética do marcador celular 95

2.3.2 Detecção das Células Marcadas: Citometria de Fluxo 102

2.3.3 Visualização Qualitativa das Células Marcadas: MET 103

2.3.4 Construção da curva de calibração 105

2.3.5 Quantificação por FMR das células marcadas por NSOF 106

3 Conclusão 110

Referências $\quad 114$

Apêndice A $\quad 126$

Apêndice B $\quad 134$ 


\section{Introdução Geral}

Projetos que se baseiam no estudo de problemas de interesse biológico, em geral, envolvem sistemas complexos constituídos por uma grande quantidade de entes e de graus de liberdade. Nos casos em que se busca o entendimento de fenômenos em nível molecular, soma-se a essas dificuldades, a impossibilidade de visualização direta dos processos sob investigação. É neste ponto que o uso de técnicas que nos permitam obter informações moleculares de sistemas intrincados assume seu papel de relevância dentro do que costumamos chamar de Biofísica Molecular.

Dentre essas técnicas, ganharam destaque e ampla aplicabilidade aquelas que se baseiam na utilização da interação entre radiação, nas mais diversas faixas do espectro eletromagnético, e matéria. Por matéria entendemos sistemas que podem ir desde os blocos fundamentais constituintes de macromoléculas biológicas (aminoácidos, por exemplo), as próprias macromoléculas, até células e tecidos. Cada metodologia experimental acaba por monitorar eventos distintos em certa situação, originando dados também distintos e/ou complementares. Assim, várias são as técnicas que têm gerado contribuições significativas para o entendimento de problemas biológicos como a fluorescência, dicroísmo circular, difração de raios $X$, infravermelho e absorção óptica, para citar apenas algumas.

No caso particular em que se insere nosso interesse de pesquisa e dentro do qual se encaixa o presente trabalho de tese, restringimos nossa atenção à obtenção de informações de sistemas microscópicos através de métodos que empregam uma propriedade intrínseca das partículas que compõem a matéria, o seu spin. Estamos, portanto, no campo de atuação das técnicas conhecidas como 
Ressonâncias Magnéticas (RM). Em nosso caso, estamos interessados no spin de elétrons desemparelhados em amostras como proteínas, membranas ou compostos de íons de metais de transição. Em outros casos, o mesmo spin, mas não eletrônico e sim nuclear, constitui a base da Ressonância Magnética Nuclear $(R M N)$, método que tem dado contribuições inigualáveis e que vão desde a determinação da estrutura tridimensional de moléculas como proteínas até o uso clínico em exames de tomografia por RMN.

Concentrando-nos no spin eletrônico, estamos portanto escolhendo a Ressonância Magnética Eletrônica (RME). Esta, até meados da década de 50, era quase exclusivamente área de atuação de físicos, com aplicações rotineiras a uma variedade de problemas em química e biologia se estabelecendo gradualmente. No que diz respeito a seu uso específico em problemas biológicos, contribuições significativas foram dadas por George Feher (EUA), que introduziu a técnica de ressonância dupla conhecida como ENDOR ${ }^{(1)}$, e Jack Freed (EUA), que realizou os primeiros experimentos de ressonância eletrônica por Transformada de Fourier ${ }^{(2)}$.

A técnica de RME em seu regime de onda contínua (CW) vem sendo aplicada a estudos de sistemas de interesse biológico há muitos anos, sendo que as contribuições daí provenientes são muito diversas. Vão desde a caracterização de sítios de ligação de metais em materiais com possíveis aplicações biológicas/médicas, passando por estudos da estrutura e dinâmica de membranas biológicas e chegando ao estudo de processos reacionais em proteínas. Grande parte de tais aplicações encontra-se descrita nos vários volumes da série Biological Magnetic Resonance, editada por L.J. Berliner (Plenum, New York), ${ }^{(3)}$ na qual os trabalhos relacionados servem para dar uma 
idéia da vasta contribuição de RME ao estudo de sistemas de interesse biológicos.

Uma das maneiras mais eficazes de aliar a técnica de ressonância magnética e os referidos problemas de interesse biológico consiste no uso de sondas paramagnéticas conhecidas como marcadores de spin. Marcadores de spin têm sido usados freqüentemente na busca por informações estruturais e dinâmicas em macromoléculas, ${ }^{(3)}$ mas a falta de sítios paramagnéticos ou com afinidade por eles em muitos desses sistemas fez com que a sua aplicação fosse sempre limitada. No entanto, o surgimento de moléculas como, por exemplo, fosfolipídios marcados, via ligação covalente, com um radical do tipo nitróxido ou a possibilidade de se realizar uma marcação de spin sítio dirigida conferiram à RME um ampla aplicabilidade em problemas envolvendo modelos para membranas fosfolipídicas e proteínas. Além desses fatores, RME ainda possui resolução temporal compatível com aquela na qual normalmente ocorrem fenômenos como mudanças conformacionais em membranas biológicas e em estruturas de proteínas e a possibilidade da escolha de um marcador de spin que melhor se adéqüe a um problema específico. É nesta modalidade de uso da RME que se encontra a primeira parte de nosso trabalho e que envolve mudanças na estrutura de modelos de membrana quando da presença de moléculas de baixo peso molecular e quando da alteração de parâmetros externos como a temperatura.

Outro objeto central de pesquisa em nosso grupo tem sido os estudos de centros metálicos em sistemas de interesse biológico. Estes projetos têm um caráter diferente em termos de abordagem necessária, mesmo que tal abordagem seja também feita primordialmente através da técnica de ressonância magnética. No caso de centros contendo íons de metais de transição, como ferro 
e cobre, as medidas de ressonância magnética envolvem experimentos, em geral, a temperaturas criogênicas e o sistema em si pode variar consideravelmente seu estado de spin. A interpretação dos resultados experimentais obtidos muda consideravelmente. Assim sendo, em relação aos sistemas caracterizados pela presença de íons de metais de transição, temos trabalhado intensamente com a caracterização via técnicas de ressonância magnética de nanopartículas contendo íons de ferro e sua possível aplicação médica. Neste caso, as nanopartículas de óxido de ferro possuem momentos magnéticos de grande magnitude e são, portanto, chamadas de superparamagnéticas. Este trabalho é resultado de uma colaboração entre nosso grupo e o grupo do Dr. Lionel Gamarra, atualmente pesquisador do Hospital Israelita Albert Einstein (São Paulo).

Baseado no exposto acima, podemos afirmar que os resultados apresentados têm como linha central métodos de ressonância magnética para o estudo de sistemas de interesse biológico. Os objetivos específicos e resultados alcançados até o momento estão descritos nos capítulos subseqüentes. Para maior clareza da apresentação, os objetos de estudo estão descritos separadamente em duas partes da seguinte maneira: a parte 1 versa sobre os estudos utilizando modelos de membrana biológica e a parte 2 descreve nossas atividades no estudo de nanopartículas de ferro com potencial aplicação em problemas biomédicos. 


\subsection{Interações de Nicotina com Modelos de Membrana}

Pulmões de mamíferos são bolsas membranosas divididas em alvéolos, pequenos sacos em forma de bolha com alta elasticidade que aumentam bastante a área de superfície no momento das trocas gasosas. No processo de troca gasosa, o oxigênio flui dos alvéolos para os capilares sanguíneos e o gás carbônico deixa os capilares e difunde nos alvéolos. Neste processo, há condensação de vapores resultando em uma tensão superficial na superfície interna do alvéolo. Sem um mecanismo de defesa interno, o pulmão tende a colapsar. Esta tendência é minimizada pela presença de substâncias que reduzem a tensão superficial no interior da superfície interna do alvéolo para valores muito baixos. ${ }^{(1)}$ A substância que tem o papel de diminuir a tendência de formação de gotículas e, consequentemente, diminui a tensão superficial de líquidos formados na superfície dos alvéolos pulmonares dos mamíferos é chamada de surfatante pulmonar. Este é composto principalmente de lipídios e proteínas específicas, chamadas proteínas surfatantes. ${ }^{(4,5,6)}$ A massa de lipídios que compõe o complexo surfatante pulmonar corresponde a aproximadamente $90 \%$ do total, entre os quais $40 \%$ é formado por dipalmiltoilfosfatidilcolina (DPPC), $\quad 30 \%$ de palmitoiloleolilfosfatidilcolina (POPC), $10 \%$ de palmitoiloleolilfosfatidilglicrol (POPG), $8 \%$ de outros fosfolipídios e $2 \%$ de lipídios naturais. As proteínas surfatante desempenham um papel importante na estrutura, função e metabolismo dos surfatantes. Quatro proteínas específicas têm sido descritas: ${ }^{(4)}$ SP-A (5\%), SP-B(2\%), SP-C (2\%) e SP-D (1\%). Estas proteínas são sintetizadas e excretadas pelas células epiteliais tipo II dos alvéolos pulmonares e são classificadas como hidrofílicas (SP-A e SP-D) e 
hidrofóbicas (SP-B e SP-C). SP-A e SP-B têm papel importante na primeira linha de defesa contra agentes patogênicos, bem como função regulatória na formação da monocamada que diminui a tensão superficial. ${ }^{(5)}$

Para abaixar a tensão superficial, a monocamada torna-se enriquecida do fosfolipídio 1,2-dipalmitoil-sn-glicero-fosfatidilcolina (DPPC) que pode ocorrer por processo de inserção durante a adsorção ou durante exclusão de outros componentes do filme durante a redução de sua área. Além da função principal de diminuir a tensão superficial, outras funções estão creditadas às proteínas surfatantes: ativação de macrófagos alveolares, formação do tubo de mielina secreção de fosfolipídios pelas células tipo II na monocamada, regulação e ordenamento dos fosfolipídios e defesa contra bactérias e vírus. ${ }^{(4)}$

Síndrome da angústia respiratória constitui a principal causa de enfermidade ou morte em recém-nascidos oriundas da diminuição na produção de surfatantes pelas células tipo II alveolares. ${ }^{(7,8)}$ Estudos mostraram que esta enfermidade tem alta incidência em crianças recém-nascidas de mães fumantes. ${ }^{(9)}$ Ademais, tem sido mostrado que o hábito de fumar diminui os níveis de surfatante associado aos fosfolipídios na lavagem brônquio-alveolar. ${ }^{(10)}$

Aproximadamente 1,3 milhões de tabagistas consomem anualmente, cerca de 73 mil toneladas de nicotina embaladas em cigarros, principalmente nos países em desenvolvimento. ${ }^{(11)}$ No combusto do tabaco, a nicotina é o componente mais importante. Distúrbios cardiovasculares, impotência, doença de Parkinson, doença de Alzheimere e vários tipos de câncer são consequências do uso de nicotina em tabagistas. ${ }^{(12)}$ O tabaco contém cerca de 70 substâncias cancerígenas distribuídas em três grupos principais: hidrocarbonetos aromáticos policíclicos, aminas aromáticas e nitrosaminas. A nicotina participa da carcinogênese atuando como intermediária através da sua nitrosação, 
produzindo nitrosaminas específicas. As nitrosaminas derivadas da nicotina formam-se durante o processo de preparo do tabaco. Dentre as quatros principais nitrosaminas [NNK2-4-(metilnitrosamina)-1-(3-piridil)-1-butanona, NNN-N'-nitrosonornicotina, NAB-N'-nitrosoanabasina e NAT-N'nitrosoanabatina], a nitrosamina NNK2 possui maior potencial cancerígeno no estômago, pâncreas, fígado, pele e pulmão. ${ }^{(12)}$ Em tabagistas, a nitrosação se processa pela ação de enzimas, tal como a hidroxilização do sistema citrocômico P450 de fígado e do pulmão. ${ }^{(13,14)}$ No metabolismo da nicotina os chamados macrófagos são ativados liberando aril-hidroxilase-hidrocarbonetos, os quais decompõem nitrosaminas, aminas aromáticas e hidrocarbonetos aromáticos policiclos em metabólitos chamados epóxitos. Estes produzem adutos no DNA com alto potencial mutagênico e cancerígeno. ${ }^{(15)}$

A nicotina é um alcalóide vegetal produzido pela planta do tabaco (Nicotiana tabacum) originária das Américas. Esta é uma amina terciária composta de anéis de piridina e pirolidina como mostrada na Figura 1.1.1.

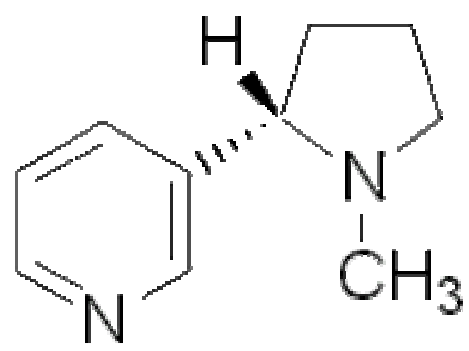

Figura 1.1.1 Estrutura molecular da nicotina: (-)-1-Methyl-2-(3-pyridyl)pyrrolidine

Apesar de uma extensa literatura a respeito de muitas doenças relacionadas com o consumo do tabaco, principalmente o câncer de pulmão, quase não há estudos sobre os efeitos da interação direta da nicotina com os componentes constituintes dos surfatantes pulmonares. O estudo de sistemas com base na composição de surfatantes pulmonares tem significância em 
patologia, bioquímica e biofísica principalmente para se aprender acerca das interações em nível molecular.

O estudo de estruturas biológicas do tipo membrana é, no entanto, de difícil execução dada a sua complexidade estrutural e a sua obtenção não-trivial. Uma das estratégias para enfrentar este problema é utilizar-se das chamadas membranas modelo, cuja composição simples e de fácil controle permite a investigação de propriedades específicas (por exemplo, composição de lipídios ou ligação de drogas e fármacos, peptídeos e proteínas) das membranas biológicas presentes em células vivas.

Neste sentido, a espectroscopia de Ressonância Paramagnética Eletrônica (RPE) aliada à técnica de "grupo repórter"(16) tem contribuído bastante para o entendimento de sistemas biológicos. Especificamente, RPE é absorção de radiação de microondas pelos elétrons desemparelhados quando estes estão na presença de um campo magnético externo. Tais sistemas físicos ocorrem em íons ou átomos de alguns metais de transição, em radicais livres ou em sondas bioquímicas especiais chamadas marcadores de spin, largamente usados em aplicações biológicas.

A base física da técnica é a interação entre o momento magnético associado ao spin de um elétron desemparelhado e os campos magnéticos externos e aqueles existentes na amostra. Espectros de RPE são usualmente mostrados como a primeira derivada da absorção do espectro. Um espectro é caracterizado por quatro parâmetros principais: intensidade, largura de linha, fator g (definido pela posição da linha) e estruturas de multipletos. A intensidade do espectro de RPE em solução pode fornecer informações a respeito da concentração, a largura de linha está relacionada aos processos dinâmicos, o fator $\mathrm{g}$ ao ambiente imediatamente próximo ao elétron desemparelhado e a 
estrutura de multipletos (caracterizado pela constante de desdobramento A) informa sobre a interação dos spins dos elétrons desemparelhados com os spin dos núcleos vizinhos.

Ressonância Paramagnética Eletrônica tem sido largamente usada para se obter informações da dinâmica molecular de polímeros. A estratégia adotada se baseia na introdução de um radical estável com a finalidade de se investigar as mudanças estruturais, dinâmicas e anisotrópicas no seu entorno. O radical nitróxido tem sido o mais usado, sobretudo em estudos sobre dinâmica de sistemas miméticos de membranas celulares.

O espectro de RPE do radical nitróxido é sensível a processos de reorientação por causa da anisotropia oriunda das interações magnéticas entre o momento magnético associado ao elétron desemparelhado e campo local, ou seja, o campo magnético aplicado somado ao campo produzido pelo momento magnético associado ao spin nuclear $\left({ }^{14} \mathrm{~N}\right)$ da molécula de nitróxido. ${ }^{(3)}$ Ademais, a dinâmica experimentada pelo radical nitróxido modula as interações magnéticas e define, assim, uma escala de tempo e um tempo de correlação típico $\tau_{c}$ (tempo necessário para que a molécula "esqueça" sua última orientação espacial) que caracteriza os regimes de movimento da moléculas repórter. Esses regimes de movimento para o radical nitróxido são definidos pelo tempo $\tau_{\mathrm{c}}$ e pela largura em frequência $(\Delta \omega)$ do espectro: quando $\tau_{c} \cdot \Delta \omega \approx 1$, o regime é dito lento (slow motion) para uma frequência dada; para tempos de correlação extremamente curtos, o regime é dito rápido (fast motion); quando o tempo de correlação é extremamente longo (sistema sem dinâmica, equivalente a amostra sólida), o regime é dito limite rígido. ${ }^{(17)}$

Um dos métodos empregados para obter as informações dos espectros do radical nitróxido é aquele baseado na solução da equação estocástica de Liouville 
(stochastic Liouville equation - SLE), ${ }^{(18)}$ que pode ser considerado como uma generalização semi clássica da equação máster de difusão. ${ }^{(19)}$ Nesta descrição, os spins eletrônico e nuclear são tratados como entidades quânticas, enquanto que o movimento de reorientação é tratado classicamente e parametrizado em termo de constantes de difusão rotacional. Para sistemas de membranas modelos, como o descrito neste estudo, o marcador nitróxido está ligado covalentemente em posições estratégicas da cadeia acila de um fosfolipídio que funciona como repórter. Neste sistema, há dois parâmetros chave para a interpretação física dos espectros: o parâmetro de ordem $S_{0}$ que está relacionado com o potencial de orientação sentido pelo radical e o tensor de difusão rotacional $\mathbf{R}$ que reflete a dinâmica sentida pelo grupo NO. Este tensor pode ser escrito em simetrias diversas, em nosso caso simetria axial $\left(R_{p r p}\right.$ e $\left.R_{p l l}\right)$, e suas componentes estão relacionadas com os tempos de correlação. ${ }^{(17)}$ As informações quantitativas com respeito a ambos os parâmetros $S_{0}$ e $R_{\text {ptp }}$ estão relacionadas com as fases que os lipídios organizados em vesículas podem assumir com relação à variação de temperatura, $\mathrm{pH}$ e composição. $\mathrm{O}$ parâmetro $\mathrm{R}_{\mathrm{prp}}$ ainda está relacionado com a energia de ativação de fase quando a variável termodinâmica é a temperatura. Assim é possível estimar a energia relacionada com uma fase lipídica e comparála com aquela que vem da interação de lipídios com moléculas de interesse biológico.

No presente estudo, usamos espectroscopia de RPE de marcadores de spin com o grupo repórter nitróxido aliada a um extenso processo de simulações espectrais baseadas no pacote de programas $\mathrm{NLSL}^{(19)}$ para investigar os efeitos dependentes da temperatura e pH da interação da nicotina sobre as propriedades físico-químicas de modelos de membrana constituídos por fosfolipídios componentes dos surfatantes pulmonares. Mais especificamente, estudamos 
vesículas multilamelares constituídas de fosfolipídios zwitterônicos Dipalmitiilglicerolfosfatidilcolina (DPPC) e Palmitoiloleoilglicerolfosfatidilcolina (POPC). O marcador de spin com o grupo repórter em diferentes posições da cadeia acila do fosfolipídio palmitoil-steroil(n-DOXIL)glicerolfosfatidilcolina [nPCSL; $n=5$ e 16] foi adicionado às vesículas para monitorar as mudanças na estrutura dinâmica da cadeia hidrofóbica dos fosfolipídios. Ademais faremos uma análise comparativa entre a solução do combusto retido no filtro de um cigarro de uma marca comercial disponível no mercado e o fosfolipídio POPC, relacionando os efeitos da interação não específica da nicotina sobre os fosfolipídios acima descritos.

\subsection{Materiais e Métodos}

No presente capítulo são apresentados os procedimentos de preparação de amostras para medidas de RPE, processamento dos dados e simulação dos espectros obtidos.

\subsubsection{Materiais}

Os fosfolipídios 1,2-Dipalmitoil-sn-Glicero-3-fosfocolina (DPPC), 1-Palmitoil-2Oleoil-sn-Glicero-3-fosfocolina (POPC) e (1-Palmitoil-2-Oleoil-sn-Glicero-3fosfoglicerol (POPG), assim como os marcadores de spin 1-palmitoil-2-(n-doxil 
stearoil) fosfatidilcolina ( $\mathrm{n}=5$ e $16 ; 5-, 16-\mathrm{PCSL})$ foram adquiridos junto à empresa Avanti Polar Lipids, Inc. (Alabaster, AL) e a nicotina [(-)-1-Metil-2-(3piridil)pirrolidina, (-)Nicotina] da empresa Sigma Chem. Co. (St. Louis). Cigarro adquirido comercialmente da marca Marlboro (king size), fabricado por Phillips Morris Brasil Ind. e Com. LTDA, com as seguintes especificações: mistura de tabaco, açucares, papel de cigarro, extratos vegetais e agentes de sabor, alcatrão (10 mg), nicotina $(0,8 \mathrm{mg})$ e monóxido de carbono (10 mg).

\subsubsection{Preparação de Amostras}

O procedimento aqui descrito é geral e vale para todas as amostras usadas nos experimentos de RPE. Soluções estoque de lipídios em clorofórmio e marcadores de spin em clorofórmio foram misturadas em tubo de vidro. A massa total de lipídios em cada preparação foi de $1 \mathrm{mg}$ e a concentração de marcador de spin foi sempre mantida em 0,5 mol\% dos lipídios presentes na amostra. Uma vez misturados lipídios e marcador de spin, a solução final foi evaporada em fluxo de $\mathrm{N}_{2}$, com os lipídios secos formando um filme fino nas paredes do tubo de vidro. A fim de se garantir a completa eliminação de resíduos de clorofórmio das amostras, estas são mantidas algumas horas em ultra-centrifugação sob vácuo (Savant Speedvac plus-Thermo Quest). A seguir, a amostra é hidratada em volume adequado de água milli-Q $(\mathrm{pH} \mathrm{6),} \mathrm{MiLLI-Q} \mathrm{Plus-Millipore} \mathrm{industria} \mathrm{e}$ comércio LTDA e ou tampão acetato-borato-fostofato, $20 \mathrm{mM}$ e pH 10 ( especialmente para as medidas de POPC marcadas com 16-PCSL). Os lipídios são, então, raspados das paredes do tubo, agitados em vórtex e a solução 
sonicada por três minutos para cada um dos três ciclos de banhos quente e frio. Em seguida, foi adicionado às amostras um volume específico de nicotina $\left(1: 10^{3}\right)$; agitados em vórtex e mantidos em repouso a temperatura ambiente por pelo menos 1 hora para hidratação das membranas. Após a hidratação, as amostras são centrifugadas até que se forme um "pellet" razoável para a transferência das vesículas do tubo de vidro para um capilar adequado (I.D. 1,5 $\mathrm{mm})$.

O procedimento para extrair a nicotina do cigarro usada no experimento de RPE seguiu o protocolo: um cigarro como descrito acima foi fumado até muito próximo do seu filtro através de uma seringa de sucção de $20 \mathrm{~mL}$ por aproximadamente cinco minutos. O filtro foi incubado durante $16 \mathrm{~h}$ em $10 \mathrm{~mL}$ de água Milli-Q. A solução foi agitada, centrifugada e uma fração do sobrenadante foi usada para determinar a concentração de nicotina através de seu coeficiente de extinção.

\subsubsection{Medidas de RPE}

Os espectros de RPE foram medidos em um espectrômetro Varian modelo E-109, operando em banda $X(9,4 \mathrm{GHz})$ e equipado com uma cavidade retangular. A variação de temperatura foi alcançada através do uso de um sistema controlador de temperatura Varian E257-X. Os parâmetros de operação do equipamento comuns a todas as amostras foram: frequência de modulação, $100 \mathrm{KHz}$; tempo de varredura, 3 minutos; constante de tempo, $128 \mathrm{~ms}$; varredura do campo magnético, 100 ou 150 G dependendo do mardador ; 
potência de microondas, $15 \mathrm{~mW}$ e amplitude de modulação máxima do campo, 0,5 G. A temperatura foi monitorada com um termopar ferro-constantan, conectado a um potenciômetro Fluke (2100A Digital Thermometer).os capilares com as amostras foram colocadas em tubos de quartzo em banho de óleo mineral comercial posicionados no centro da cavidade de ressonância. Este procedimento foi necessário para garantir a estabilização da temperatura da amostra dentro do capilar.

\subsubsection{Simulações de Espectros de RPE}

A quantificação da estrutura dinâmica dos modelos de membrana nas várias situações encontradas no presente trabalho foi feita através de uma abordagem de simulação espectral para a obtenção de parâmetros de ordem e da taxas de difusão rotacional que caracterizem a dinâmica e a estrutura da membrana na qual o marcador de spin encontra-se inserido. Isso é possível através do pacote de programas NLSL desenvolvido Freed e colaboradores. $(20,18,19)$

Esses programas baseiam-se na teoria estocástica de Liouville para cálculo de espectros de EPR no regime de movimentos lentos, que para radicais nitróxidos ocorre quando os tempos de correlação são da ordem de $10^{-7}$ até $10^{-9}$ $S^{(17)}$

A idéia principal para resolver o problema do cálculo de espectros de RPE no regime de movimento lentos reside em se assumir que as flutuações na orientação de uma molécula, definida por coordenadas $\Omega$, podem ser tratadas 
classicamente usando-se um operador $\Gamma_{\Omega}$ (operador de Markov) que é independente do tempo. A equação de difusão para a probabilidade $P(\Omega, t)$ de se achar a orientação $\Omega$ em um tempo $t$ é:

$$
\frac{\mathrm{dP}(\Omega, \mathrm{t})}{\mathrm{dt}}=-\Gamma_{\Omega} \mathrm{P}(\Omega, \mathrm{t}) \text {. }
$$

Com essa hipótese, a equação de movimento do operador matriz densidade $\rho(\Omega, t)$ podia ser dada por: (21-24) $^{2}$

$$
\frac{d \rho(\Omega, t)}{d t}=-i[H(\Omega, t), \rho(\Omega, t)]-\Gamma_{\Omega} \rho(\Omega, t) .
$$

onde $H(\Omega, t)$ é o hamiltoniano de spin, que depende da orientação da molécula e $\Gamma_{\Omega}$ é o operador de relaxação representando a difusão rotacional molecular que, no caso de membranas lipídicas, normalmente é definida em termos de um tensor de difusão rotacional com simetria axial $\left(R_{\mathrm{prp}}\right.$ e $\left.R_{\mathrm{pll}}\right)$. A resolução da eq 1.1.2 no regime estacionário fornece os elementos da matriz densidade $\rho(\Omega, t)$ para o problema em questão que, por sua vez, estão relacionados com o espectro de RPE.

Muito mais útil em termos práticos do que o método em si para resolução da eq 1.2.2 é o entendimento dos parâmetros usados durante os ajustes e seus significados em termos da estrutura do modelo de membrana. Assim, uma descrição semiqualitativa dos princípios básicos envolvidos nas simulações espectrais certamente auxiliará na interpretação dos resultados obtidos. Primeiramente, faz-se necessária a descrição dos diversos sistemas de referência relevantes para as simulações em questão. Há quatro sistemas de coordenadas: o sistema de difusão rotacional molecular $\left(x_{R}, y_{R}, z_{R}\right)$, o sistema do diretor local $\left(x_{d}, y_{d}, z_{d}\right)$, o sistema magnético $\left(x_{m}, y_{m}, z_{m}\right)$ e o sistema de laboratório $\left(x_{L}, y_{L}, z_{L}\right)$ 
Os sistemas de referência mais triviais de serem definidos e visualizados são o sistema magnético $\left(\mathrm{x}_{\mathrm{m}}, \mathrm{y}_{\mathrm{m}}, \mathrm{z}_{\mathrm{m}}\right)$ e o de laboratório, sendo este último, como é usual, definido pela direção $z$ do campo magnético estático. Em relação ao sistema magnético são definidos os tensores $\vec{g}$ e $\vec{A}$. Os eixos $x_{m}$ e $z_{m}$ são definidos paralelos às direções da ligação $\mathrm{N}--\mathrm{O}$ e do orbital $2 p_{z}$ do átomo de nitrogênio, respectivamente; como mostrado na Figuras 1.2.1. O eixo $y_{m}$ é definido de maneira a formar um sistema dextrogiro ortogonal com os outros dois eixos.

O sistema do diretor local $\left(\mathrm{x}_{\mathrm{d}}, \mathrm{y}_{\mathrm{d}}, \mathrm{z}_{\mathrm{d}}\right)$ é definido pela normal à superfície da membrana em cada ponto da mesma (vetor diretor local). A normal é, então, chamada de eixo $z_{d}$, com ( $x_{d}$ e $y_{d}$ arbitrariamente escolhidos). O diretor local é usado para definir os ângulos $\psi$ referentes ao efeito MOMD descrito abaixo.

Para a definição do sistema molecular $\left(x_{R}, y_{R}, z_{R}\right)$, notar-se que a mobilidade rotacional de um marcador de spin é caracterizada por duas taxas de difusão rotacional, $R_{\text {prp }}$ e $R_{\text {pll, }}$ que representam os valores principais de um tensor de difusão com simetria axial. Na verdade, $R_{\text {prp }}$ e $R_{\text {pll }}$ representam uma aproximação para os modos internos de rotação da cadeia e para o movimento geral da mesma. O sistema de difusão molecular $\left(x_{R}, y_{R}, z_{R}\right)$ é, portanto, aquele no qual essas duas taxas são definidas. Mais especificamente, o eixo $z_{R}$ é tomado como paralelo ao eixo principal de simetria do segmento da molécula onde encontra-se ligado o radical nitróxido. Portanto, $R_{\mathrm{p} \| l}$ e $R_{\mathrm{prp}}$ são as taxas de difusão rotacional em torno do eixo $z_{R}$ e de um eixo perpendicular a ele, respectivamente. Em marcadores do tipo n-PCSL ( $n$ é a posição do radical NO ao longo da cadeia lipídica, por exemplo 5 , ou 16 ), $z_{R}$ é paralelo ao diretor local $z_{d}$ 
(i.e., à própria cadeia lipídica) e $R_{\text {prp }}$ representa o movimento oscilatório da respectiva porção da cadeia lipídica.

Em relação ao sistema de difusão molecular são definidos, ainda, os parâmetros de ordem do sistema. Estes parâmetros representam o potencial orientador presente em membranas biológicas e que restringe a amplitude do movimento rotacional das cadeias lipídicas. Isto é, quanto maior o potencial orientador, menor será o intervalo de orientações disponível para o movimento rotacional das cadeias. Mais precisamente, o potencial $\mathrm{U}(\Omega), \Omega$ representa os ângulos de Euler dos eixos de difusão no sistema diretor, dá origem a uma distribuição de moléculas ao longo de várias orientações em torno do eixo de ordenamento local da membrana (diretor local). No caso de vesículas, existe, ainda, uma distribuição desse diretor local representando cada um dos segmentos da membrana na vesícula.

O parâmetro de ordem mais comumente usado $S_{0}$ é definido como:

$$
S_{0}=\left\langle D_{00}^{2}\right\rangle=\left\langle\frac{1}{2}\left(3 \cos ^{2} \theta-1\right)\right\rangle=\frac{\int d \Omega \exp \left(-U / k_{B} T\right) D_{00}^{2}}{\int d \Omega \exp \left(-U / k_{B} T\right)},
$$

onde $\mathrm{k}_{B}$ é a constante de Boltzmannn, $\mathrm{T}$ é a temperatura absoluta. Esse parâmetro indica o quanto o eixo molecular $z_{R}$ está alinhado com o vetor diretor local $z_{d}$. Um segundo parâmetro de ordem pode ser também definido

$$
S_{2}=\left\langle D_{02}^{2}+D_{0-2}^{2}\right\rangle=\left\langle\sqrt{\frac{3}{2}} \sin ^{2} \theta \cos 2 \phi\right\rangle .
$$

e indica o desvio da simetria cilíndrica do alinhamento molecular relativo à superfície da membrana, ou seja, mede até que ponto há uma preferência de alinhamento dos eixos moleculares $x_{R}$ vs. $y_{R}$ com relação ao diretor local. 0 potencial $\mathrm{U}(\Omega)$ é usualmente representado como uma expansão em harmônicos esféricos generalizados, 


$$
\begin{aligned}
& -\frac{\mathrm{U}(\theta, \phi)}{\mathrm{k}_{\mathrm{B}} T}=\mathrm{C}_{20}\left(\frac{3 \cos ^{2} \theta-1}{2}\right)+\mathrm{c}_{22} \sqrt{\frac{3}{2}} \operatorname{sen}^{2} \theta \cos 2 \phi+\mathrm{C}_{40}\left(\frac{35 \cos ^{4} \theta-30 \cos ^{2} \theta+3}{8}\right)+ \\
& +\mathrm{C}_{42} \sqrt{\frac{5}{8}}\left(7 \cos ^{2} \theta-1\right) \operatorname{sen}^{2} \theta \cos 2 \phi+\mathrm{c}_{44} \sqrt{\frac{35}{32}} \operatorname{sen}^{4} \theta \cos 4 \phi
\end{aligned}
$$

onde $\Omega=(\theta, \phi)$ são os ângulos polar e azimutal do eixo de difusão $z_{R}$ em relação ao sistema diretor local. ${ }^{(18)}$ Os coeficientes $\mathrm{C}_{20}, \mathrm{C}_{22}, \mathrm{C}_{40}$ e $\mathrm{C}_{42}$ são parâmetros adimensionais representando a energia potencial de cada orientação.

Em espectros de vesículas lipídicas, o efeito de "Microscopic $\underline{\text { Order and }}$ Macroscopic Disorder" $(\text { MOMD })^{(17,18)}$ é levado em consideração durante as simulações. Isto quer dizer que diferentes segmentos da membrana lipídica estão aleatoriamente orientados em relação ao eixo $z$ do laboratório (direção de aplicação do campo magnético estático). O espectro no modelo MOMD pode ser visto, então, como o espectro de uma amostra policristalina, sendo, portanto, representado por uma superposição de espectros oriundos de todos os fragmentos e que pode ser escrito como: ${ }^{(17)}$

$$
S_{c \pm}^{M O M D}=\int S_{c \pm}(\psi) \operatorname{sen} \psi d \psi
$$

onde $S_{c \pm}(\psi)$ é o espectro de um fragmento da membrana cujo vetor diretor faz um ângulo $\psi$ com o eixo $z$ do laboratório. Nas simulações aqui apresentadas, 0 espectro teórico final foi sempre obtido pela média sobre cinqüenta diferentes valores de $\psi$. Na Figura 1.2.1 fazemos um resumo esquematizado do que foi dito acima em relação aos sistemas de eixos e estrutura geral das membranas. Na primeira são apresentados os sistemas magnéticos $\left(\mathrm{x}_{\mathrm{m}}, \mathrm{y}_{\mathrm{m}}, \mathrm{z}_{\mathrm{m}}\right)$ e moleculares $\left(x_{R}, y_{R}, z_{R}\right)$ para o marcador de spin 16-PCSL. Daí conclui-se que é possível dizer que 16-PCSL tem uma $z$-ordem $\left(z_{d} / / z_{R}\right)$. Portanto, os valores do parâmetro de ordem $S_{0}$ dão uma medida de quanto os respectivos eixos $Z_{R}$ (16-PCSL) alinhamse com o diretor local $z_{d}$. 


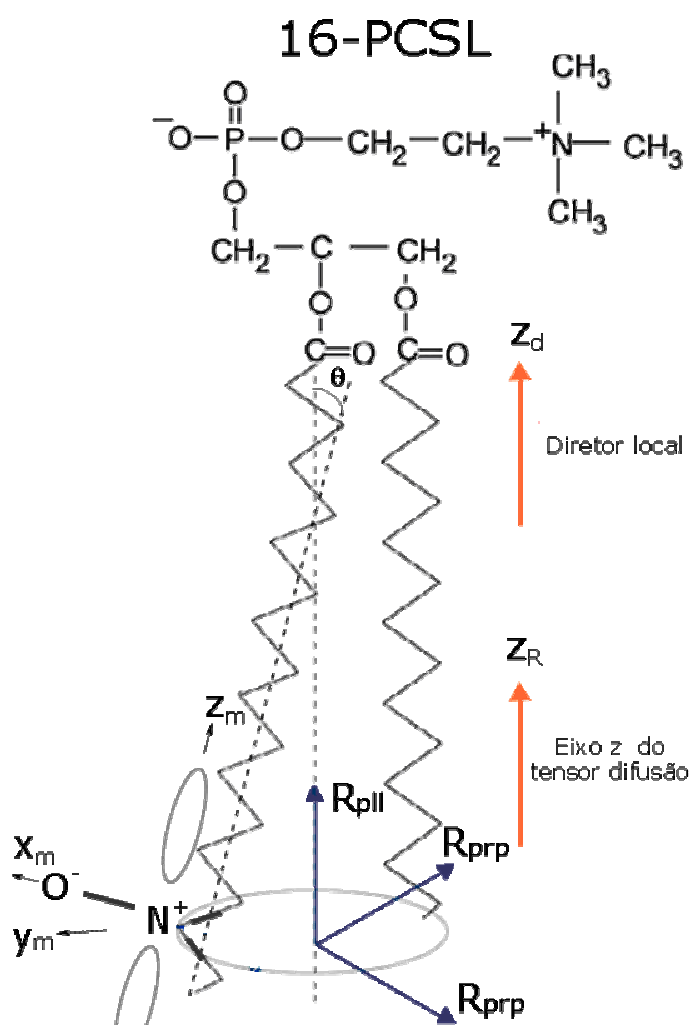

Figura 1.2.1 Representação esquemática de alguns eixos dos sistemas de coordenadas usados nas simulações dos espectros do marcador de spin 16-PCSL em membranas lipídicas. O eixo $\mathrm{z}_{\mathrm{d}}$ é o diretor local da membrana, $\mathrm{z}_{\mathrm{R}}$ é o eixo de simetria da cadeia acila e, neste caso, é paralelo ao diretor local, $\mathrm{R}_{\mathrm{pll}} \mathrm{e}$ $\mathrm{R}_{\text {prp }}$ são os valores principais do tensor de difusão, $\theta$ é o ângulo de inclinação da cadeia acila relativo ao eixo $z_{R}$ e está relacionado com o parâmetro de ordem e $x_{m}, y_{m}$ e $z_{m}$ são os eixos magnéticos do radical nitróxido. Adaptado de BASSO, L. G. M. ${ }^{(29))}$

Na Figura 1.2.2 visualiza-se a definição do ângulo de "tilt" $\psi$ do vetor diretor em relação à direção do campo magnético estático (eixo $\mathrm{z}_{\mathrm{L}}$ ) e que leva ao chamado efeito MOMD. O primeiro passo para a realização de uma simulação utilizando o pacote de programas NLSL consiste na escolha de valores de partida razoáveis para as grandezas $\mathrm{R}_{\mathrm{prp}}, \mathrm{R}_{\mathrm{pll}}, \mathrm{C}_{20}, \mathrm{C}_{22}, \mathrm{C}_{40}$ e $\mathrm{C}_{42}$ e $\Delta_{\mathrm{G}}$ (alargamento inomogêneo Gaussiano), onde o último é um parâmetro de largura de linha adicional e que, essencialmente, representa a contribuição devido às interações super-hiperfinas com prótons do solvente. Vale notar que nem todos coeficientes da expansão do potencial $\mathrm{U}(\Omega)$ são necessariamente usados. Em amostras de fosfolipídios marcados com 16-PCSL a expansão do potencial de orientação $U(\Omega)$ até $c_{20}$ é suficiente para se ter uma bom ajuste, já as marcadas com 5-PCSL a 
expansão do potencial com os coeficientes $c_{20}$ e $c_{40}$ é suficiente. Ademais os valores de entrada para os tensores $\breve{g}$ e $\breve{A}$ são usados de trabalhos anteriores. ${ }^{(28)}$

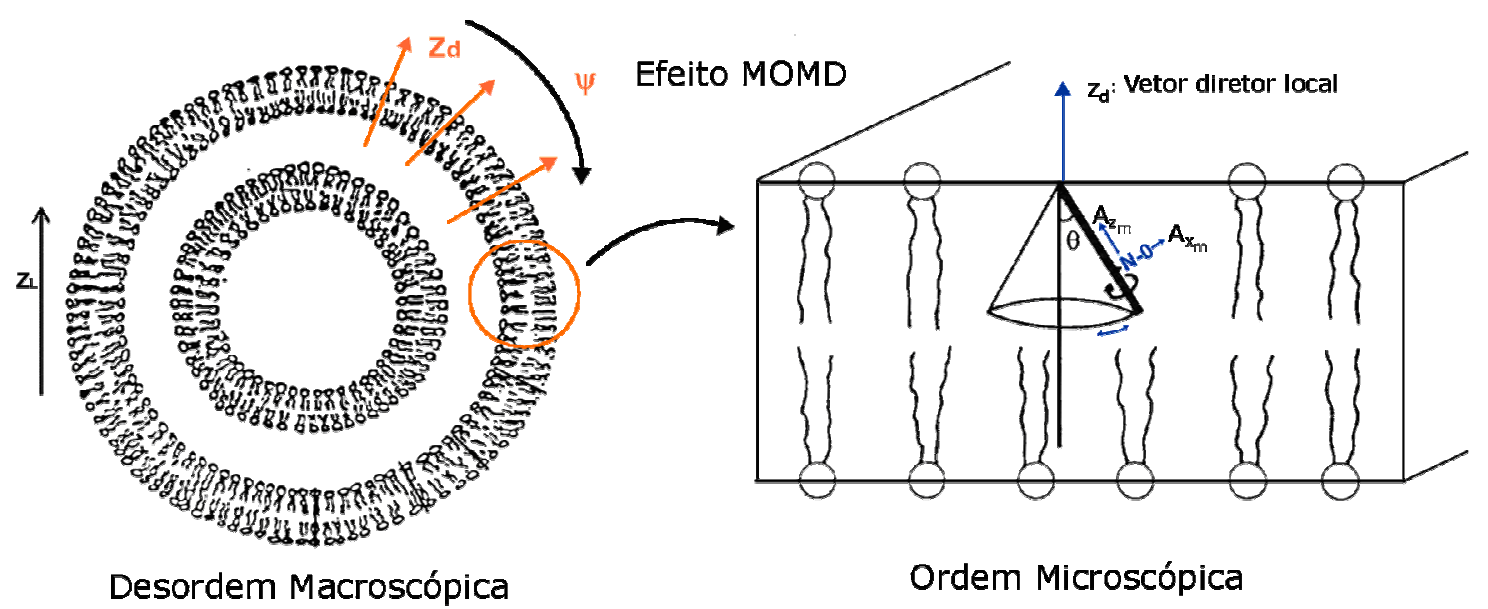

Figura 1.2.2 Representação esquemática de um domínio de membrana que apresenta ordenamento molecular microscópico (ampliação de uma seção da bicamada à direita), mas que, globalmente, está orientado aleatoriamente com relação ao eixo $\mathrm{Z}_{\mathrm{L}}$ do laboratório. Nesta figura também é apresentada a definição do ângulo de tilt $\psi$, que é o ângulo entre o diretor local de cada domínio e o eixo de aplicação do campo magnético externo. (Figura adaptada das referências $(25,26)$

\subsection{Resultados e Discussão}

Neste capítulo, apresentamos os resultados obtidos a partir das medidas de RPE de amostras contendo modelos de membranas constituídas de fosfolipídios DPPC e POPC, na ausência e na presença da molécula de nicotina. O objetivo foi investigarmos o efeito desta última sobre o comportamento termotrópico dos modelos de membranas através do uso de sondas paramagnéticas conhecidas como marcadores de spin (5-PCSL e 16-PCSL). Os experimentos foram realizados em $\mathrm{pH}$ ácido $(\sim 6)$ e, em um dos casos, também 
em pH básico ( 10$)$. Em pH 6, a nicotina encontra-se na sua forma monoprotonada, enquanto que em pH 10, está na forma não-ionizada. ${ }^{(29)}$

Junto com os espectros experimentais são apresentados espectros calculados a partir de simulações espectrais com base no método desenvolvido por Freed e colaboradores (Nonlinear Least-Squares Analysis - NLSL). ${ }^{(18,19)}$ As simulações são baseadas na solução da equação estocástica de Lioville, assumindo-se o modelo de ordenamento microscópico, mas desordenado macroscopicamente (Microscopic Order Macroscopic Disorder - MOMD). ${ }^{(17)}$ Este modelo é bastante apropriado para descrever fluidos anisotrópicos do tipo fosfolipídios dispersos em excesso de água ou tampão. Os marcadores de spin desempenham o papel de reportar mudanças estruturais no seu entorno.

\subsubsection{Vesículas do Fosfolipídio DPPC com e sem nicotina monitoradas por 5-PCSL e 16-PCSL}

\section{5-PCSL}

Quando bicamadas lipídicas preparadas de fosfolipídios puros estão sujeitas à variação térmica sob pressão atmosférica, frequentemente, sofrem múltiplas transições de fase termotrópicas dependendo do intervalo de temperatura em que se efetuam as medidas. Essas transições podem ser detectadas por uma variedade de técnicas física. Dados oriundos de calorimetria diferencial de varredura (DSC) mostram que o fosfolipídio DPPC exibe uma sub- 
transição em torno de $19,0^{\circ} \mathrm{C}$, pré-transição em $35,0^{\circ} \mathrm{C}$ e transição principal com temperatura principal $\left(T_{m}\right)$ em $41,5^{\circ} \mathrm{C}^{(30,31)}$ Nestas condições, quatro fases lamelares são distinguíveis no intervalo de $0^{\circ} \mathrm{C}$ até $50^{\circ} \mathrm{C}$ : Lamelar cristalino $\left(L_{C}\right)$, gel tilted $\left(\mathrm{L}_{\beta^{\prime}}\right)$, gel rippled $\left(\mathrm{P}_{\beta^{\prime}}\right)$ e líquido-cristalino $\left(\mathrm{L}_{\alpha}\right)$.

Com a finalidade de se verificar como a nicotina interage com vesículas compostas pelo fosfolipídio DPPC em pH ácido $(\sim 6)$ e quais os efeitos sobre a fluidez e transição de fase do fosfolipídio, foram realizadas medidas de RPE, na ausência e na presença de nicotina, monitorada por moléculas marcadas na posição 5 (5-PCSL) e 16 (16-PCSL) da cadeia acila do fosfolipídio. Os espectros de RPE foram medidos em vesículas multilamelares, dispersas em excesso de água mili-Q, de DPPC e DPPC/nicotina na razão molar 1000/1. A Figura 1.3.1 mostra alguns espectros experimentais para o marcador 5-PCSL em vesículas de DPPC no intervalo de temperatura desde $6,9^{\circ} \mathrm{C}$ até $69,9^{\circ} \mathrm{C}$, enquanto que a Figura 1.3.2 exibe os espectros oriundos de vesículas de DPPC/nicotina com o mesmo marcador de spin e no intervalo de temperatura entre $8,5^{\circ} \mathrm{C}$ e $64,2^{\circ} \mathrm{C}$.

Uma análise qualitativa dos espectros experimentais no intervalo de $25,6^{\circ} \mathrm{C}$ até $43,0^{\circ} \mathrm{C}$ (Figura 1.3.1) para o sistema 5-PCSL/DPPC exibe mudanças na forma da linha de campo central no intervalo entre $25,6^{\circ} \mathrm{C}$ e $27,0^{\circ} \mathrm{C} ; 38,5^{\circ} \mathrm{C}$ e mudanças na linha de campo baixo entre $38,5^{\circ} \mathrm{C}$ e $40,2^{\circ} \mathrm{C}$. Analogamente, a Figura 1.3.2 mostra uma alteração na linha de campo central entre $25,6^{\circ} \mathrm{C}$ e $26,9^{\circ} \mathrm{C}$ e na de campo baixo entre $39,7^{\circ} \mathrm{C}$ e $40,3^{\circ} \mathrm{C}$ para 5 -PCSL/DPPC/Nicotina. Isto sugere transição entre as fases lamelares $L_{c}$ e $L_{\beta} / P_{\beta}$ no intervalo térmico $\left(25,6^{\circ} \mathrm{C}\right.$ e $\left.27,0^{\circ} \mathrm{C}\right)$ bem como $\mathrm{P}_{\beta} \cdot$ e $\mathrm{L}_{\alpha}$ no intervalo $38,5^{\circ} \mathrm{C}$ e $40,2^{\circ} \mathrm{C}$ para a amostra 5-PCSL/DPPC. Para 5-PCSL/DPPC/nicotina não há deslocamento apreciável de fases entre os intervalos análogos aos da amostra 5-PCSL/DPPC. 
A fim de obtermos uma descrição quantitativa das mudanças observadas nos espectros do marcador 5-PCSL incorporado a vesículas de DPPC e DPPC/nicotina, procedemos com um processo de simulação espectral através do programa NLSL. ${ }^{(19)}$ O objetivo principal neste tipo de abordagem está na caracterização da estrutura e dinâmica de um dado sistema mimético e suas alterações frente a variações de parâmetros como a composição, temperatura e ligação de moléculas. Para tanto, são utilizados os coeficientes de um potencial restaurador (v. capítulo 1.2) e que resultam em um parâmetro de ordem $\left(\mathrm{S}_{0}\right)$, que fornece o grau de alinhamento da cadeia acila dos fosfolipídios em relação ao vetor normal à bicamada lipídica, e uma taxa de difusão rotacional $\left(R_{\text {prp }}\right)$. Os espectros calculados usando-se o referido programa estão também mostrados, em linhas vermelhas, na Figura 1.3.1 para 5-PC/DPPC e na Figura 1.3.2 para 5PC/DPPC/nicotina. Os ajustes apresentaram, em geral, boa concordância com os espectros experimentais para as várias temperaturas medidas. Nota-se que, quanto mais baixa a temperatura, mais difícil o processo de simulação com consequente piora na qualidade dos espectros calculados. 

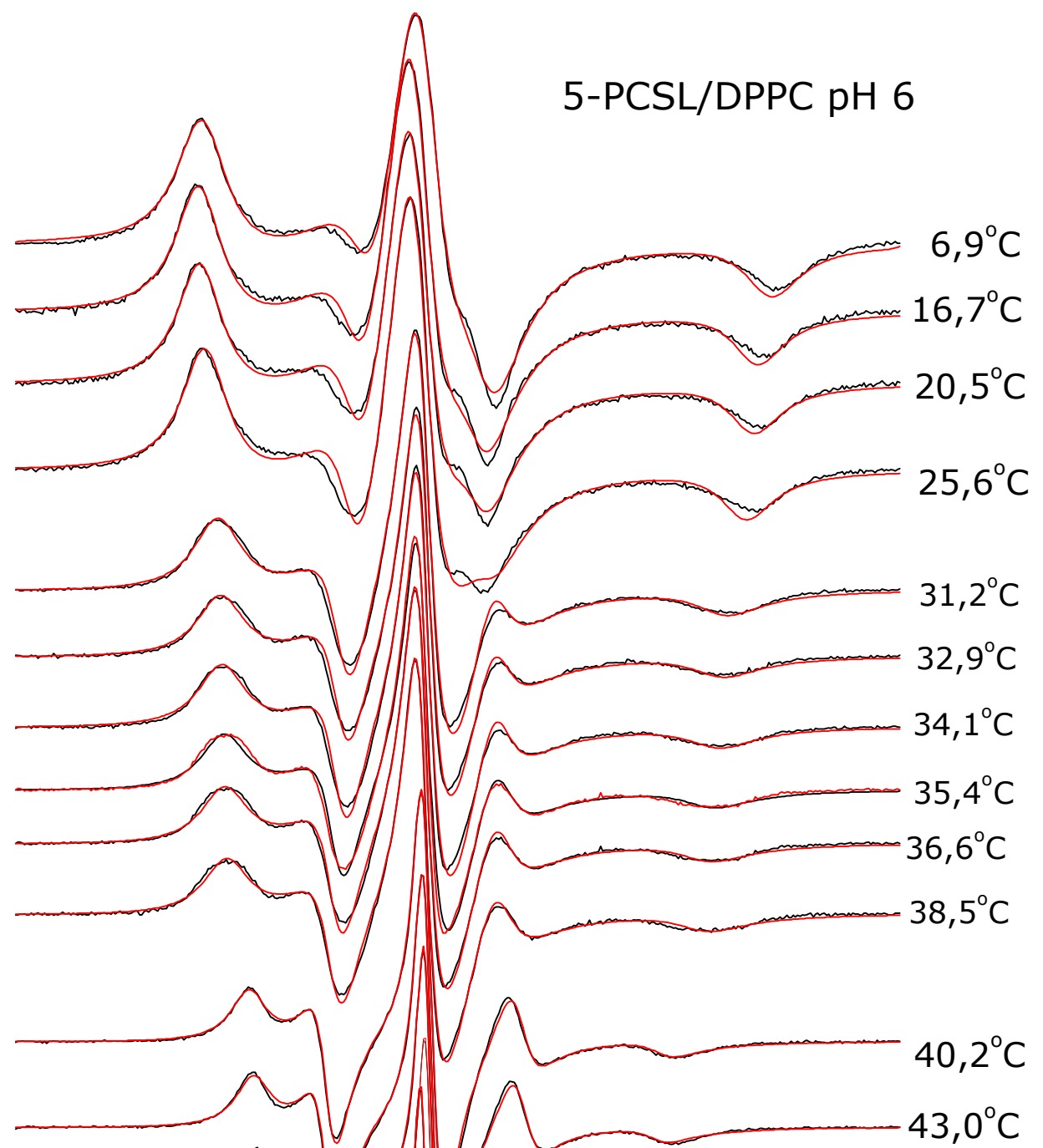
$43,0^{\circ} \mathrm{C}$ $49,8^{\circ} \mathrm{C}$ $59,9^{\circ} \mathrm{C}$ $69,9^{\circ} \mathrm{C}$

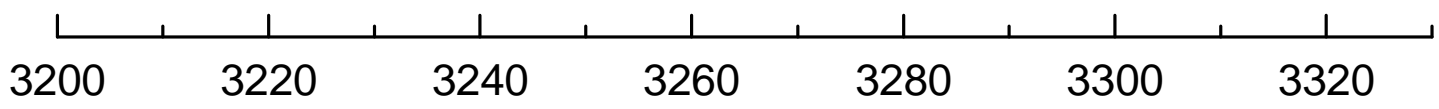

Campo Magnético (Gauss)

Figura 1.3.1 Espectros experimentais (linha preta) de RPE e seus respectivos espectros simulados (linha vermelha) medidos em vesículas de DPPC marcadas com 5-PCSL. 


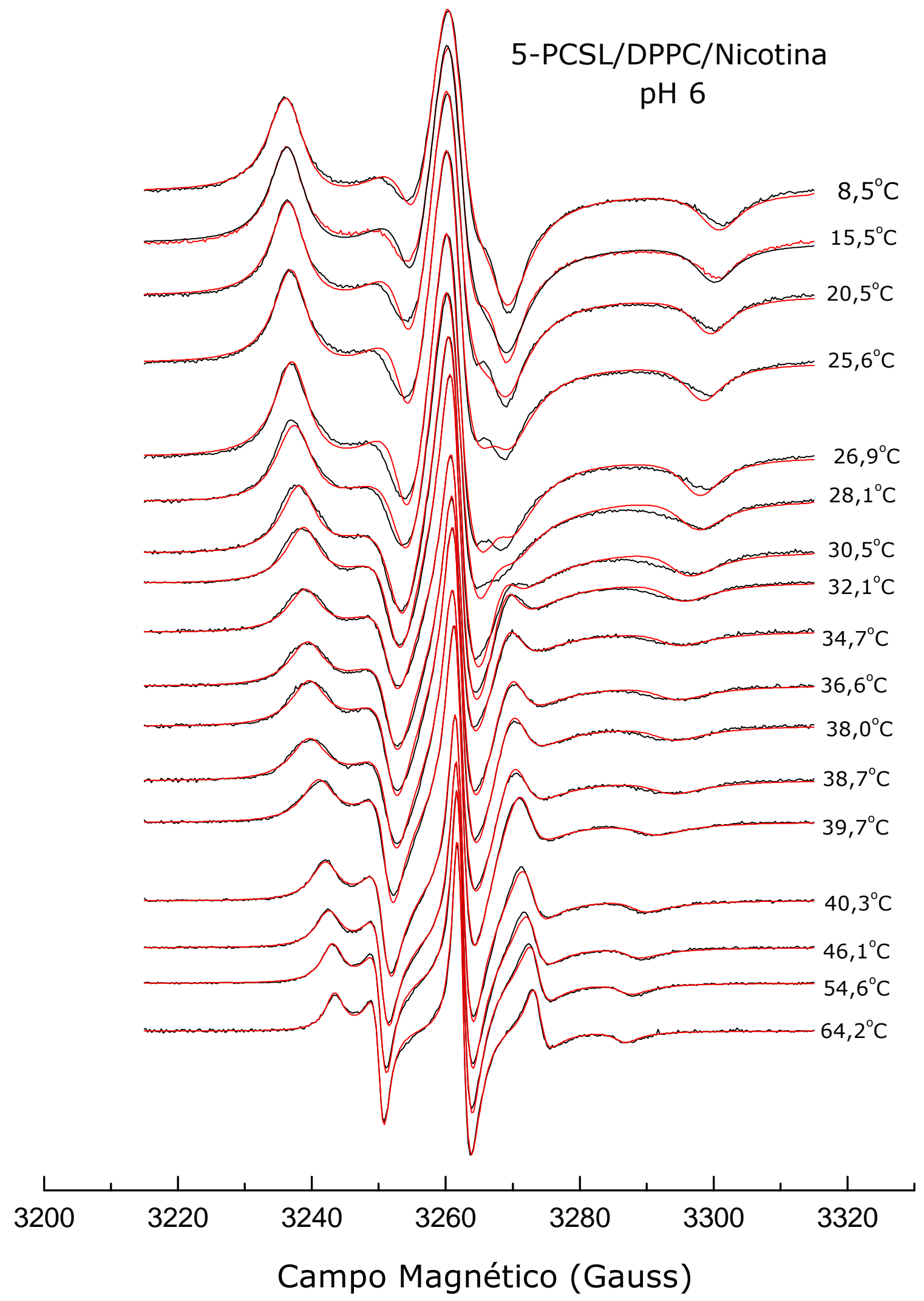

Figura 1.3.2 Espectros experimentais (linha preta) de RPE e seus respectivos simulados com uma componente (em vermelho) medidos em vesículas de DPPC/nicotina marcadas com 5-PCSL. 
O comportamento da membrana modelo em função da temperatura é, portanto, refletido nos parâmetros estruturais calculados pelo programa NLSL. A Figura 1.3.3 mostra a dependência do parâmetro de ordem $S_{0}$ em função da temperatura e indica a existência de duas transições distinguíveis no intervalo de temperatura medido tanto para a amostra 5-PCSL/DPPC como para 5PCSL/DPPC/Nicotina.

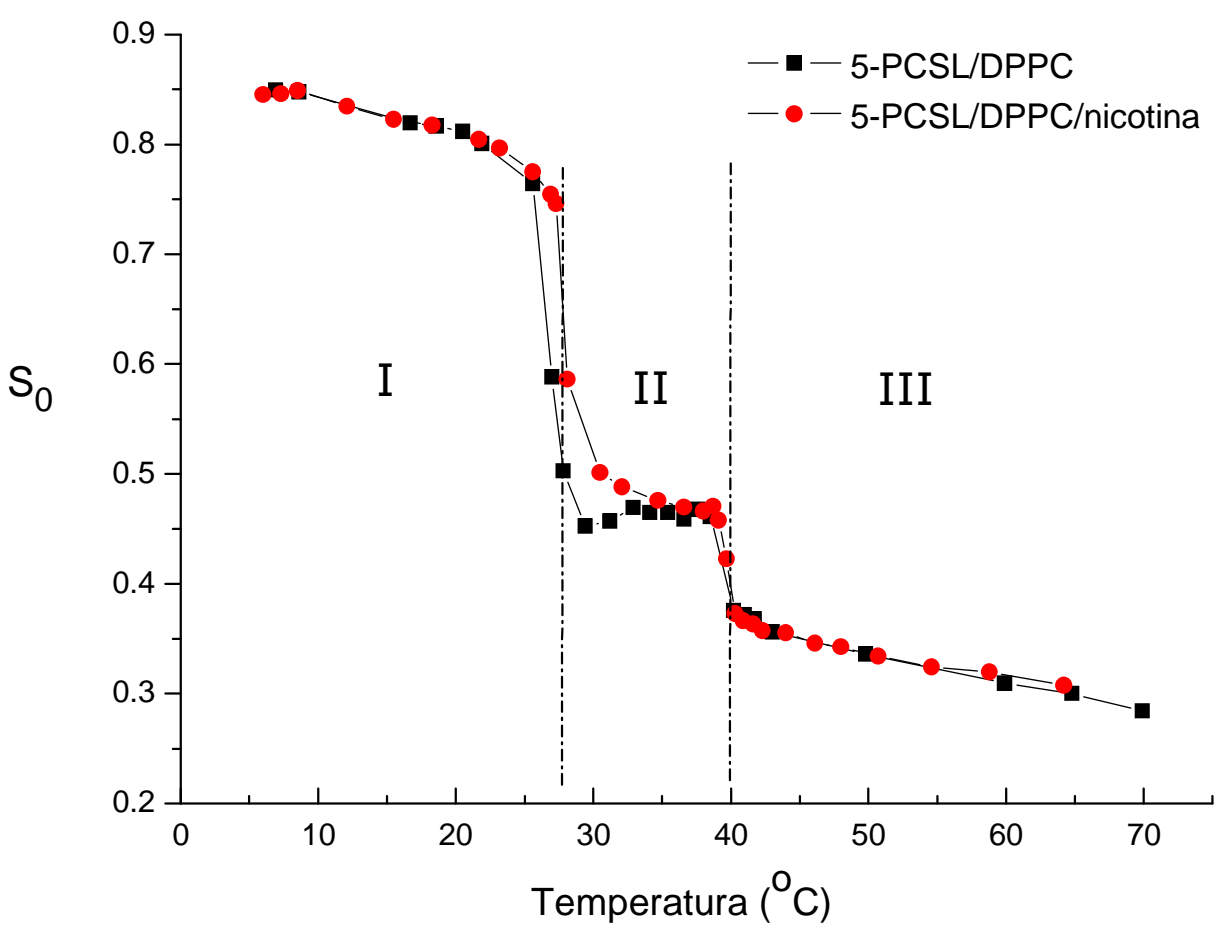

Figura 1.3.3 Dependência do parâmetro de ordem $S_{0}$ com a temperatura obtido a partir dos ajustes espectrais das amostras 5-PCSL/DPPC (quadrados) e 5-PCSL/DPPC/nicotina (círculos). As barras verticais mostram possíveis transições de fases.

A taxa de difusão rotacional, que está relacionada com a dinâmica do sistema através do parâmetro $R_{p r p}$ é mostrada na Figura 1.3.4. O parâmetro $R_{p r p}$ sofre um decréscimo abrupto em torno de $30^{\circ} \mathrm{C}$ e uma segunda mudança 
marcante é observada na vizinhança de $40^{\circ} \mathrm{C}$, onde há um acréscimo também abrupto.

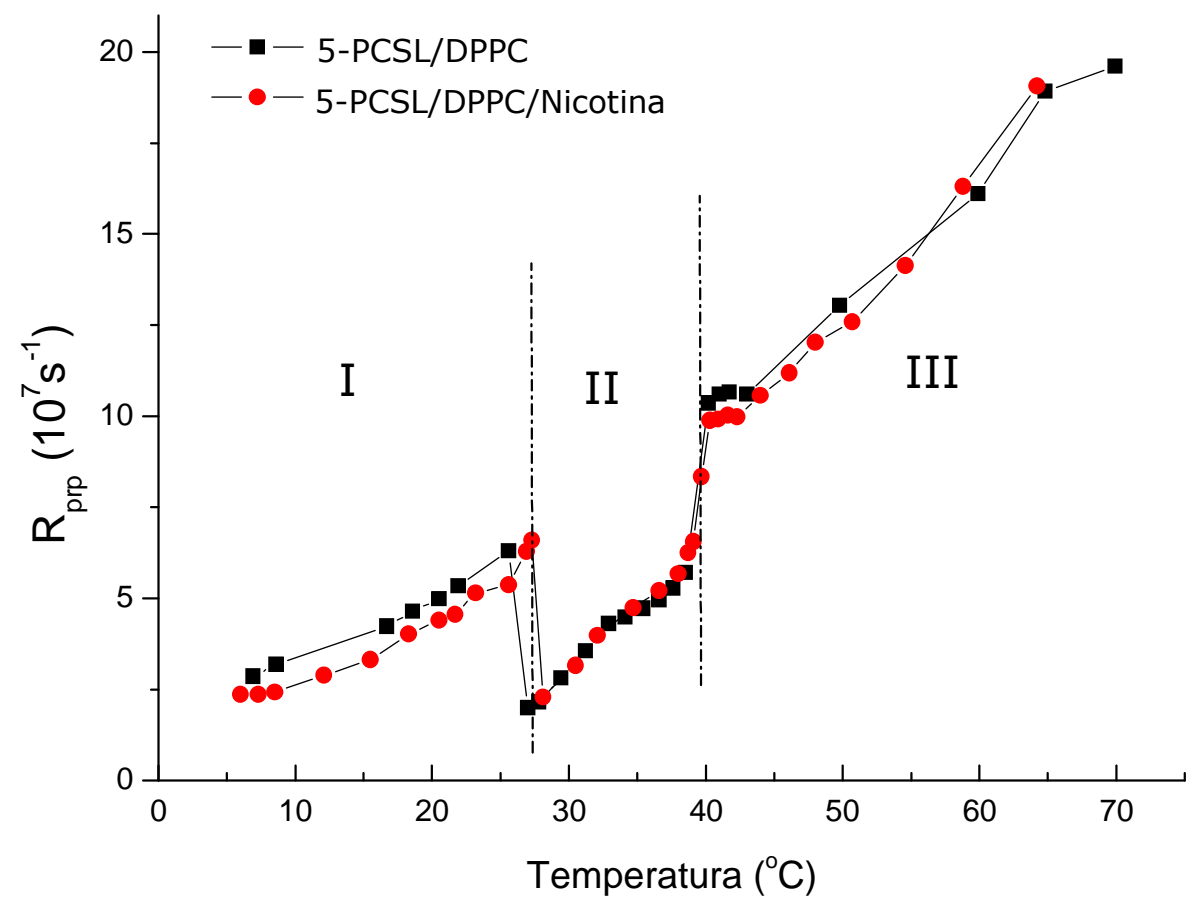

Figura 1.3.4 Dependência de $\mathrm{R}_{\text {prp }}$ com a temperatura obtida a partir dos ajustes espectrais das amostras: 5-PCSL/DPPC (quadrados) e 5-PCSL/DPPC/nicotina (círculos). As barras verticais mostram possíveis transições de fases.

Para os dois parâmetros calculados no caso de vesículas de DPPC, pH ácido, na ausência e presença de nicotina e monitoradas pelo marcador 5-PCSL, localizado em uma região próxima à cabeça polar, não há mudanças significativas no intervalo de temperatura medido. Em ambos os casos $\left(S_{0} e\right.$ $\mathrm{R}_{\mathrm{prp}}$ ), duas mudanças abrutas dos parâmetros em questão são observadas (cerca de 30 e de $40^{\circ} \mathrm{C}$ ) atribuídas à pré-transição e à transição principal do sistema modelo. Acreditamos que os espectros do marcador 5-PCSL, naturalmente largos e de baixa resolução, não permitem distinguirmos com clareza fases como a de subgel $(L C)$ e de gel $\left(L_{\beta^{\prime}}\right)$. Sendo assim, nas Figuras 1.3.3 e 1.3.4 atribuímos a região I à fase subgel $\left(L_{c}\right)$ e gel $\left(L_{\beta^{\prime}}\right)$, a região II à fase gel rippled $\left(P_{\beta^{\prime}}\right)$ e a região III à fase líquido cristalino $\left(L_{\alpha}\right)$ 
Em relação aos efeitos da presença de nicotina em modelos de DPPC ( $\mathrm{pH}$ ácido) e sentido pelo marcador 5-PCSL (Figuras 1.3.3 e 1.3.4), temos que poucas mudanças significativas são observadas, exceto por um leve acréscimo de aproximadamente $1,5{ }^{\circ} \mathrm{C}$ na temperatura da pré-transição quando da adição da nicotina.

\section{6-PCSL}

De forma análoga ao procedimento executado para as amostras marcadas com 5-PCSL, as amostras marcadas com 16-PCSL passaram pelo mesmo tratamento tanto de execução de medidas como de ajuste espectral. As Figuras 1.3.5 e 1.3.6 exibem os espectros experimentais e seus respectivos ajustes para a amostra 16-PCSL/DPPC medidos em temperaturas que vão de $6,8{ }^{\circ} \mathrm{C}$ até 65,0 ${ }^{\circ} \mathrm{C}$ e $16-\mathrm{PCSL} / \mathrm{DPPC} /$ nicotina $\left(7,0^{\circ} \mathrm{C}\right.$ até $\left.63,5^{\circ} \mathrm{C}\right)$.

Neste caso, os espectros experimentais oriundos da região da fase gel (entre as duas transições encontradas acima) apresentam claramente características de espectro de duas componentes. De fato, os espectros relativos à amostra 16-PCSL/DPPC medidos em $27,3^{\circ} \mathrm{C}$ e $29,4^{\circ} \mathrm{C}$ apresentam mudanças marcantes em suas formas de linhas, sobretudo nas linhas de campo baixo e de campo alto (setas na Figura 1.3.5). Estas mudanças podem ser interpretadas como o aparecimento de uma segunda componente nos espectros medidos nesse intervalo de temperatura. Ademais, uma análise cuidadosa nos espectros medidos em $30,5^{\circ} \mathrm{C}$ e $33,5^{\circ} \mathrm{C}$ nos permite concluir que há também uma mudança nos espectros, sobretudo na linha de campo alto. De modo semelhante ao que 
foi constatado nos espectros da amostra 16-PCSL/DPPC, as amostra 16PCSL/DPPC/nicotina apresentam espectros com característica de duas componentes a partir do espectro medido em $30,1^{\circ} \mathrm{C}$ até $41,2{ }^{\circ} \mathrm{C}$.

A existência de duas componentes em um espectro de RPE indica que o marcador de spin sente, em média, dois ambientes estruturalmente distintos e que é acessível dentro de uma escala de tempo lenta comparada com os tempos característicos da técnica utilizada, neste caso algo na faixa de micro a nanossegundo. O espectro resultante é, portanto, uma soma de duas contribuições, com cada contribuição multiplicada pela respectiva população relativa. O espectro do marcador $16-\mathrm{PCSL}$, localizado no final da cadeia acila, e normalmente constituído de linhas muito estreitas apresenta resolução suficiente para que mudanças dessa natureza sejam sentidas.

Além de alterações qualitativamente apresentadas acima, determinamos a variação com a temperatura do parâmetro de ordem $\mathrm{S}_{0}$ e da taxa de difusão rotacional $R_{\text {prp }}$ obtidas a partir das simulações dos espectros de RPE. As Figuras 1.3.7 e 1.3.8 mostram estes resultados para as amostras 16-PCSL/DPPC e 16PCSL/DPPC/nicotina em pH ácido. Além do parâmetro de ordem e difusão, apresentamos ainda na Figura 1.3 .9 os dados referentes à variação com temperatura das populações de cada componente espectral. 


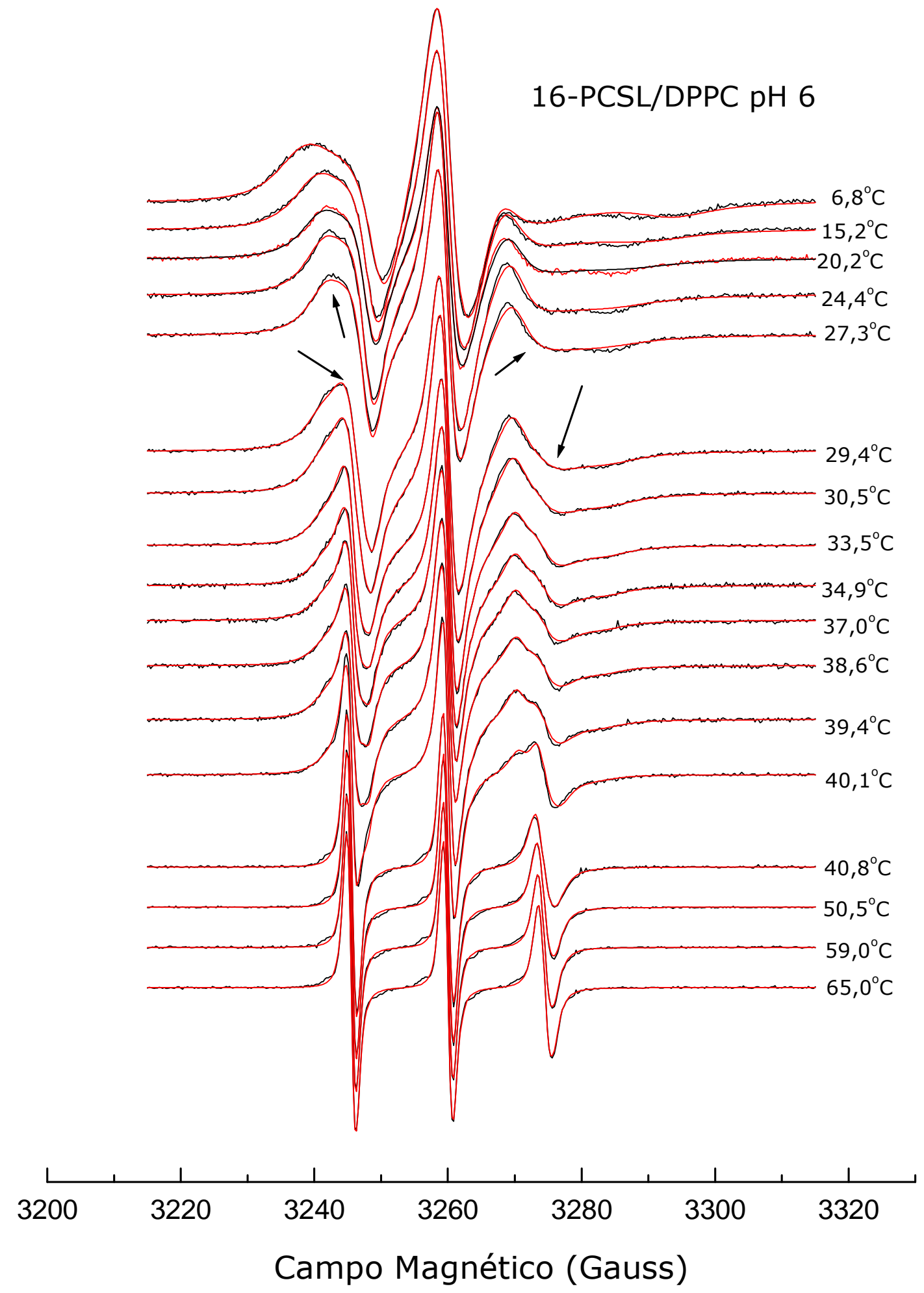

Figura 1.3.5 Espectros experimentais (linha preta) de RPE e seus respectivos simulados com duas componentes (em vermelho) medidos em vesículas de DPPC marcadas com 16-PCSL. As setas apontam para as mudanças na forma de linha nos espectros medidos em $27,3^{\circ} \mathrm{C}$ e $29,4^{\circ} \mathrm{C}$. 


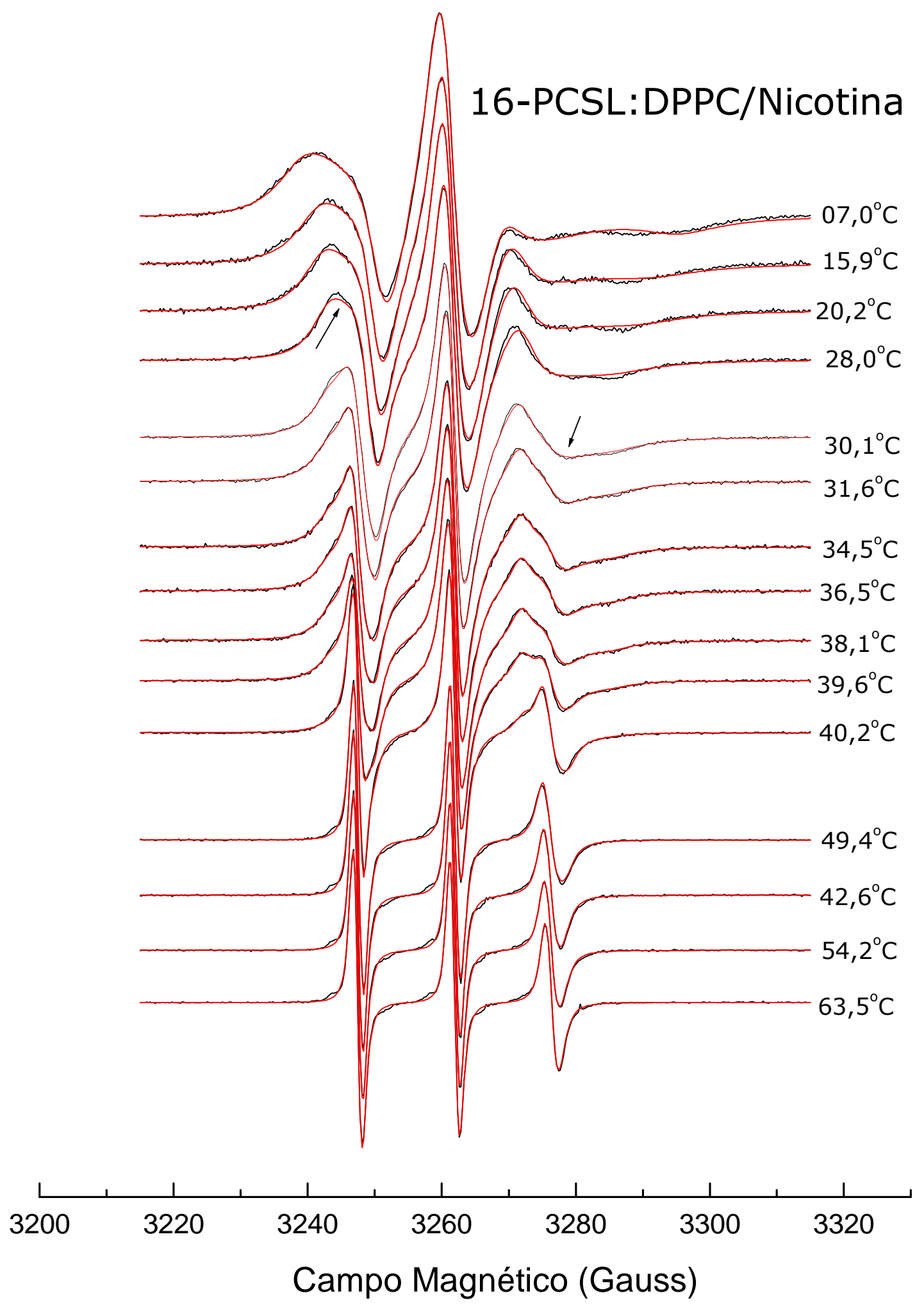

Figura 1.3.6 Espectros experimentais (linha preta) de RPE e seus respectivos simulados com duas componentes (em vermelho) medidos em vesículas de DPPC marcadas com 16-PCSL. As setas apontam para as mudanças na forma de linha nos espectros medidos em $28,0^{\circ} \mathrm{C}$ e $30,1^{\circ} \mathrm{C}$. 


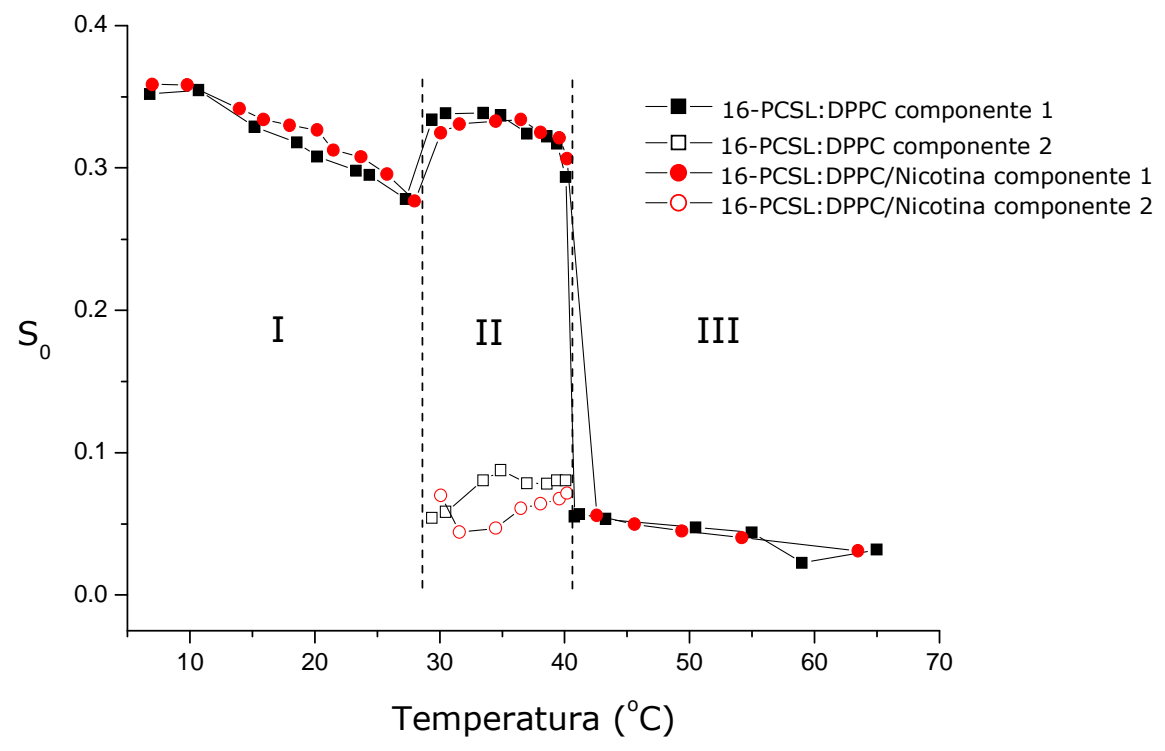

Figura 1.3.7 Dependência do parâmetro de ordem $S_{0}$ com a temperatura obtido a partir dos ajustes espectrais das amostras 16-PCSL/DPPC (quadrados) e 16-PCSL/DPPC/nicotina (círculos). As barras verticais mostram possíveis transições de fases.

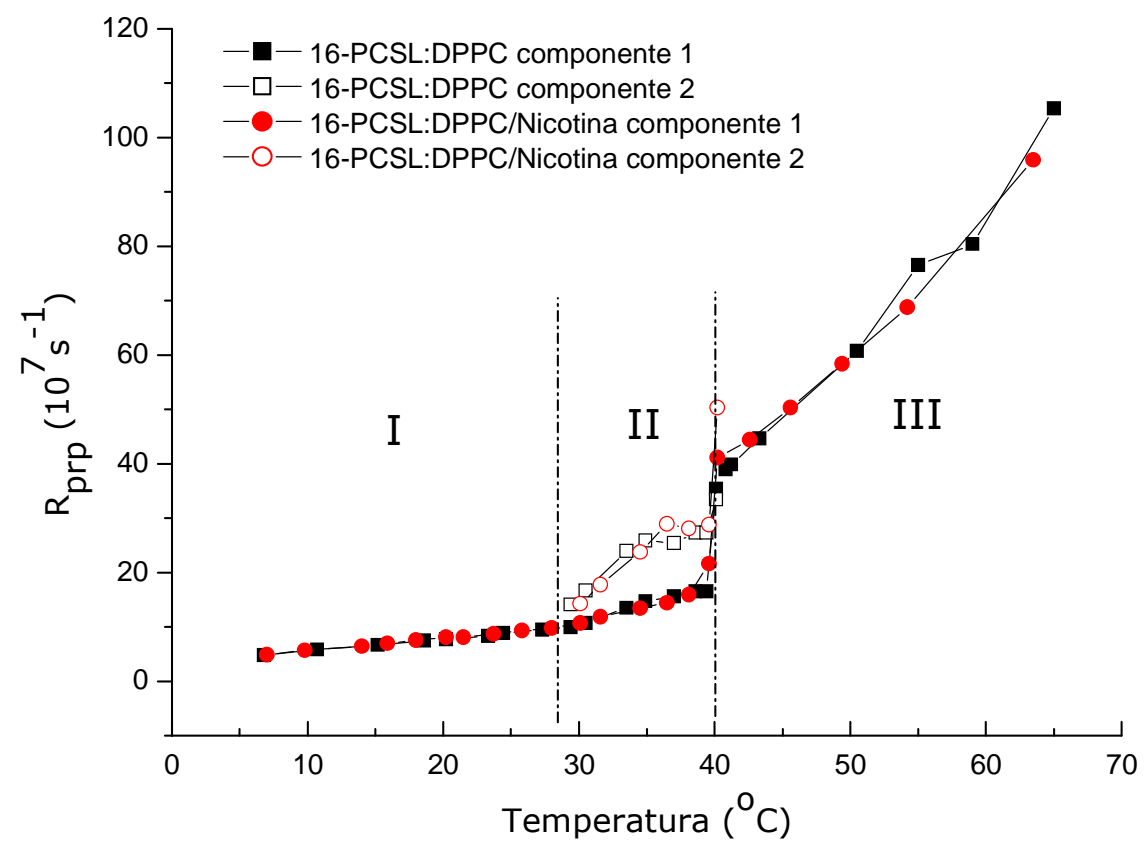

Figura 1.3.8 Dependência da taxa de difusão rotacional $R_{\text {prp }}$ com a temperatura obtida a partir dos ajustes espectrais das amostras 16-PCSL/DPPC (quadrados) e 16-PCSL/DPPC/nicotina (círculos). As barras verticais mostram possíveis transições de fases. 


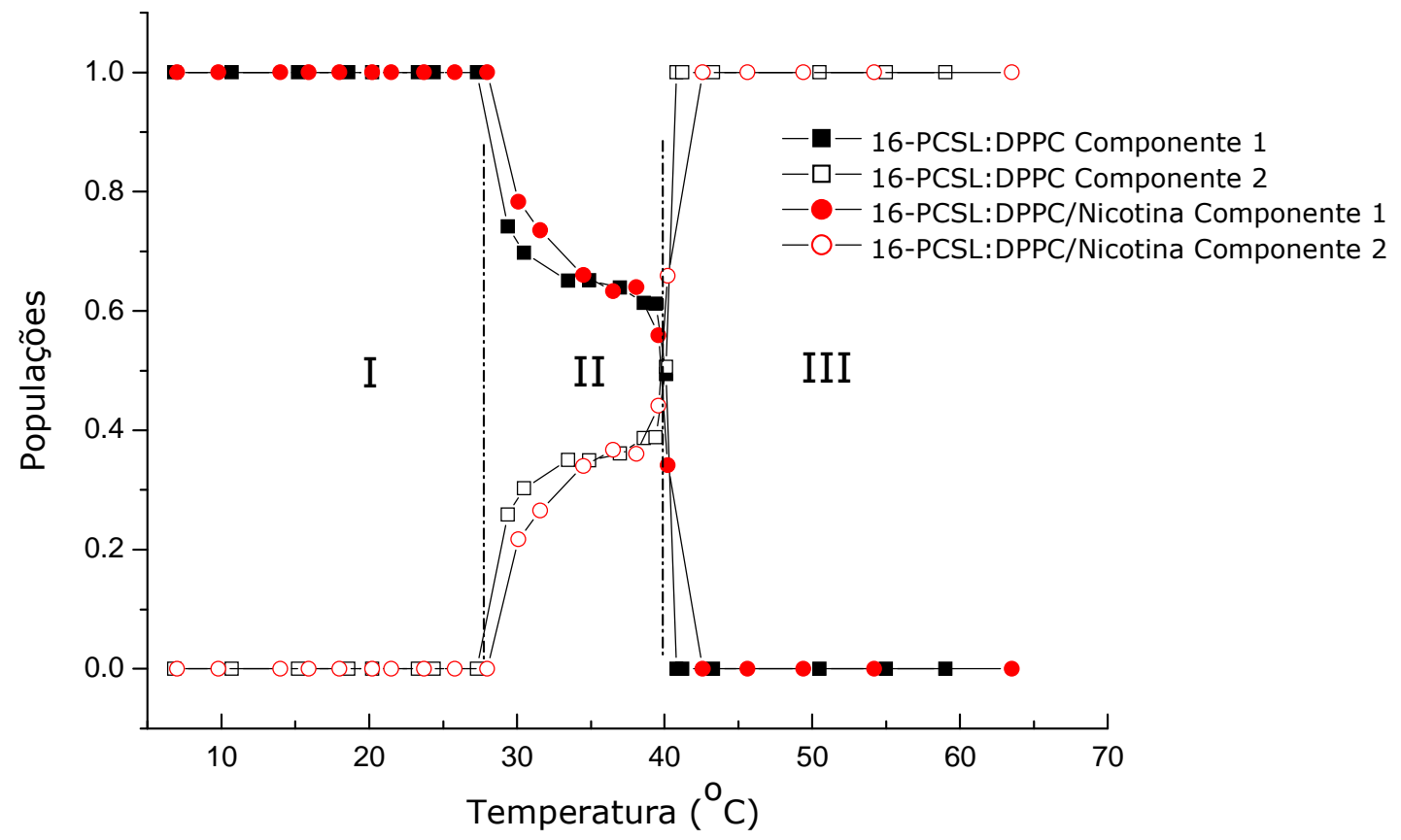

Figura 1.3.9 Dependência da população de marcadores com a temperatura obtida a partir dos ajustes espectrais das amostras 16-PCSL/DPPC (quadrados) e 16-PCSL/DPPC/nicotina (círculos). As barras verticais mostram possíveis transições de fases.

Um resultado interessante que surge dos espectros do marcador $16-\mathrm{PCSL}$ das amostras estudadas diz respeito à existência de duas componentes espectrais no intervalo de temperatura $30-40^{\circ} \mathrm{C}$ independentemente da presença de nicotina. Nessas temperaturas, o sistema de membrana está na chamada fase gel rippled $\left(\mathrm{P}_{\beta^{\prime}}\right)$ que seria estruturalmente heterogênea. Segundo os espectros nas figuras acima, a fase lipídica no intervalo de $30-40{ }^{\circ} \mathrm{C}$ é constituída por uma mistura de regiões mais ordenadas e menos fluidas, que provavelmente se assemelham à fase gel $L_{\beta^{\prime}}$ (região I na Figura 1.3.7), com regiões apresentando propriedades mais similares à fase $L_{\alpha}$ (região III). Essa heterogeneidade da fase $P_{\beta^{\prime}}$ em membranas do fosfolipídio PC foi reportada anteriormente ${ }^{(32-33)}$ e, mais recentemente, investigada por Riske e colaboradores, ${ }^{(34)}$ que discutem o papel 
da pré-transição como início do processo de melting das cadeias observado na transição principal de fosfolipídios.

Em relação às alterações decorrentes da adição de nicotina, pouco se percebe do comportamento geral em função da temperatura dos parâmetros $\mathrm{S}_{0} \mathrm{e}$ $\mathrm{R}_{\text {prp }}$ (Figuras 1.3 .7 e 1.3.8). No entanto, no intervalo de temperaturas em que há coexistência de duas componentes, um tratamento mais detalhado pode ser feito com base no modelo tradicional de van't Hoff para processos químicos envolvendo dois estados termodinâmicos. Este modelo baseia-se na seguinte equação, $\ln \mathrm{K}=-\frac{\Delta \mathrm{H}}{\mathrm{RT}}+\frac{\Delta \mathrm{S}}{\mathrm{R}}$, onde $\mathrm{K}$ representa a constante de equilíbrio do sistema; $\mathrm{H}$, a entalpia e $\mathrm{S}$, a entropia. $\mathrm{R}$ é a constante universal dos gases e T a temperatura absoluta.

Assim, assumindo um processo em que moléculas de fosfolipídio podem estar em uma fase mais ordenada do tipo gel (componente 1 dos espectros de RPE) ou outra mais fluida (componente 2) e que estabelecem um equilíbrio componente $1 \leftrightarrow$ componente 2 , podemos calcular uma constante de equilíbrio $\mathrm{K}$ a partir das populações de cada componente (Figura 1.3.9) como: $\mathrm{K}=$ (componente 2)/(componente 1), onde os parêntese indicam concentração (população). Com os valores de $\mathrm{K}$ determinados tanto na ausência quanto na presença de nicotina, construímos gráficos de van't Hoff que mostram a dependência do In K (logaritmo natural de K) com o inverso da temperatura (Figura 1.3.10). 


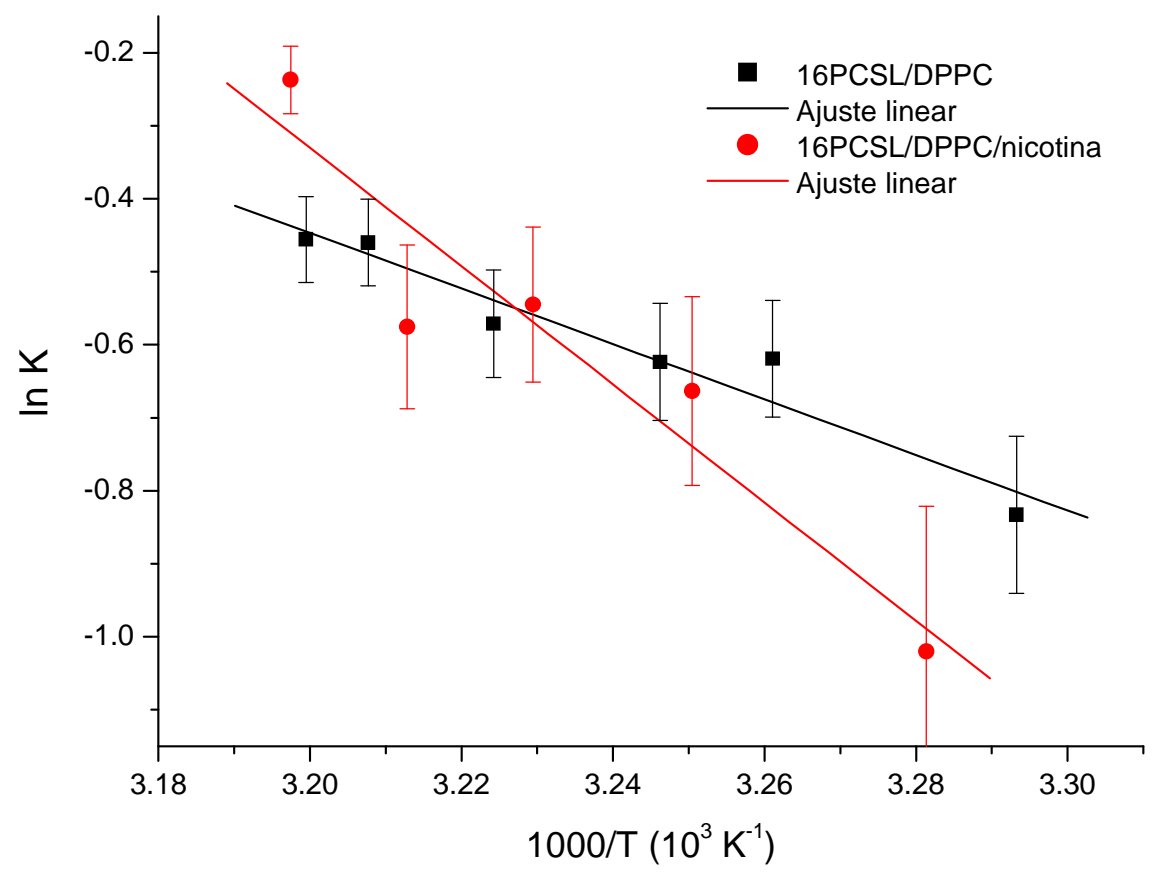

Figura 1.3.10 Gráficos de van’t Hoff obtidos a partir das populações referentes às duas componentes espectrais das amostras 16-PCSL/DPPC (preto) e 16-PCSL/DPPC/nicotina (vermelho) e mostradas na Figura 1.3.9 (intervalo de temperatura entre $30-40{ }^{\circ} \mathrm{C}$ ).

Os gráficos de van't Hoff para as amostras sem e com nicotina apresentaram comportamento linear dentro do intervalo de temperatura onde coexistem duas componentes nos espectros de RPE (Figura 1.3.10). Do coeficiente angular desses gráficos, podemos calcular os valores da variação de entalpia de transferência de um fosfolipídio da região associada à componente 2 (fluid-like) em relação à região da componente 1 (gel-like): $\Delta \mathrm{H}=\mathrm{H}_{2}-\mathrm{H}_{1}$. Obtivemos, desta maneira, $\Delta \mathrm{H}_{\mathrm{sem}}=+7,5 \mathrm{kcal} / \mathrm{mol}$ e $\Delta \mathrm{H}_{\mathrm{com}}=+16,0 \mathrm{kcal} / \mathrm{mol}$ para as amostras sem e com nicotina, respectivamente. Os valores de $\Delta \mathrm{H}$ determinados são positivos, indicando que o processo de transferência de uma molécula de fosfolipídio da fase gel-like para fluida é entalpicamente desfavorável. Além disso, o valor de $\Delta \mathrm{H}$ na presença de nicotina é aproximadamente o dobro daquele determinado na sua ausência. 
Do coeficiente linear dos gráficos na Figura 1.3.10, podemos determinar o valor da variação de entropia, na ausência e na presença de nicotina, para o mesmo processo descrito acima. Encontramos $\Delta \mathrm{S}_{\mathrm{sem}}=+23,2 \mathrm{cal} / \mathrm{mol} \mathrm{K} \mathrm{e} \Delta \mathrm{S}_{\mathrm{com}}=$ $+50,7 \mathrm{cal} / \mathrm{mol} \mathrm{K}$, onde $\Delta \mathrm{S}=\mathrm{S}_{2}-\mathrm{S}_{1}$. Em ambos os casos, a variação de entropia é positiva, o que indica que o efeito de desordenamento das cadeias promovido pelo aumento de temperatura deva ser o driving force do processo em questão. Em relação à adição de nicotina, o valor de $\Delta \mathrm{S}$ mais do que dobra na presença do ligante, ou seja, a nicotina favorece, portanto, a desestruturação da parte hidrofóbica do modelo de membrana, facilitando a transição da região gel-like (componente 1 nos espectros de RPE) para a região mais fluida (componente 2).

\subsubsection{Vesículas do fosfolipídio POPC com e sem nicotina monitoradas com marcadores 5-PCSL e 16-PCSL em pHs ácido ( 6) e básico ( 10)}

Para investigarmos a dependência do efeito da nicotina em relação às propriedades do modelo de membrana, realizamos medidas de RPE em um sistema contendo o fosfolipídio POPC, caracterizado por cadeias hidrofóbicas distintas (uma com 16 e outra com 18 carbonos) e com uma insaturação (ácido oléico). Este fosfolipídio encontra-se na fase fluida para todo o intervalo de temperatura em que foram realizados os experimentos de RPE. Apresentamos, ainda, dados de RPE obtidos ao usarmos uma solução resultante da lavagem de um filtro de cigarro comum, após sua queima, como descrito no capítulo 1.2. 0 
objetivo foi averiguarmos se os efeitos causados neste caso eram similares àqueles observados para uma solução de nicotina.

Além disso, levando em conta o fato de que a nicotina possui grupos químicos protonáveis e deve, portanto, ter cargas diferentes em diferentes valores de $\mathrm{pH}$, realizamos as medidas de RPE para dois valores de $\mathrm{pH}$, sendo um ácido $(\sim 6)$, em que a nicotina encontra-se monoprotonada, e outro básico $(\sim 10)$, no qual a nicotina encontra-se na forma não-ionizada. ${ }^{(29)}$

\section{5-PCSL}

As Figuras 1.3.11, 1.3.12 e 1.3.13 exibem alguns espectros experimentais de RPE e seus respectivos ajustes calculados com o programa NLSL das amostras 5-PCSL/POPC medidos no intervalo de temperatura de $6,6{ }^{\circ} \mathrm{C}$ até $59,2{ }^{\circ} \mathrm{C}$, 5$\mathrm{PCSL} / \mathrm{POPC} /$ nicotina entre $5,6^{\circ} \mathrm{C}$ e $67,2^{\circ} \mathrm{C}$ e 5 -PCSL/POPC/filtro entre $5,8^{\circ} \mathrm{C}$ e $65,0^{\circ} \mathrm{C}$. 


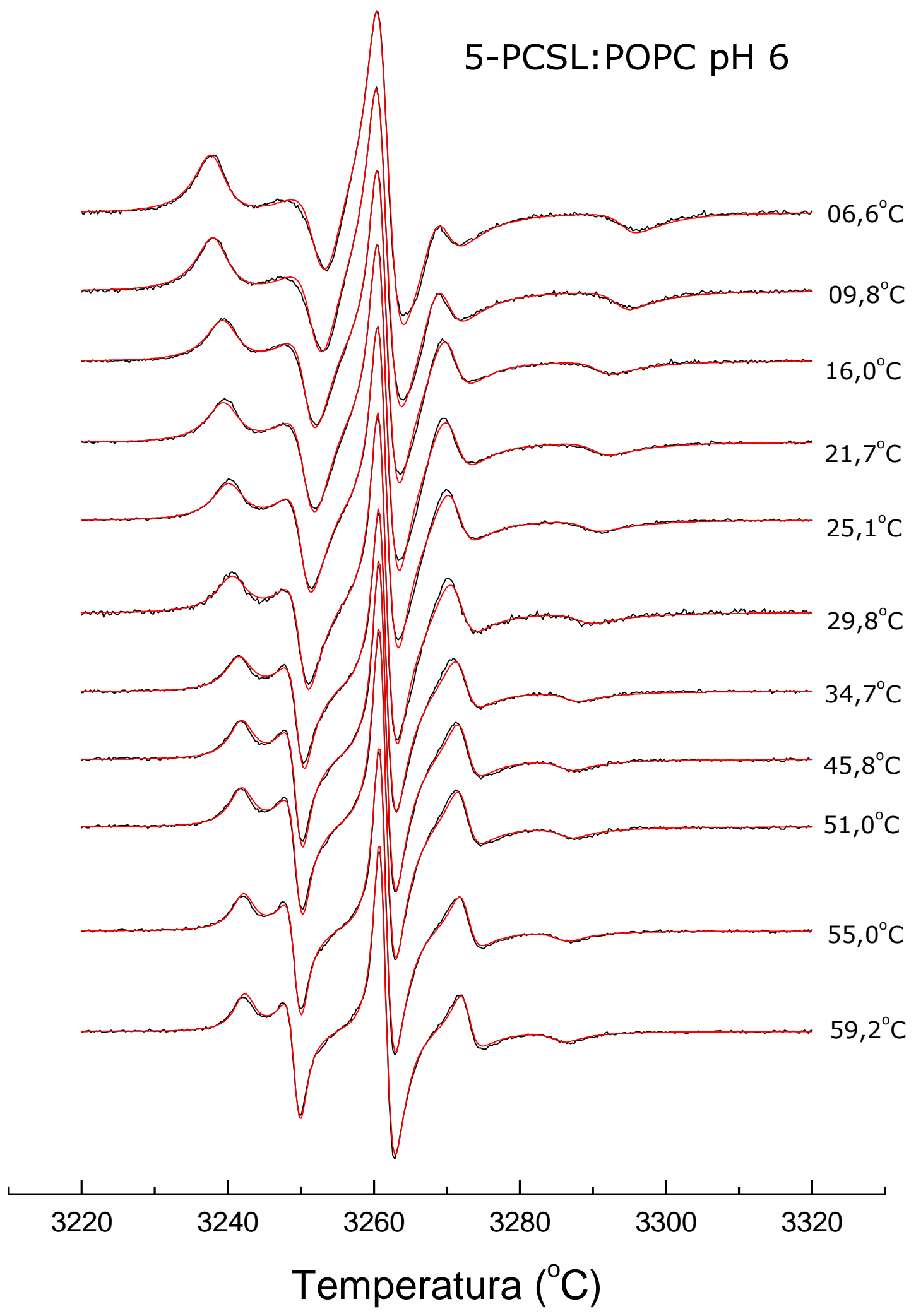

Figura 1.3.11 Espectros experimentais (linha preta) de RPE e seus respectivos espectros simulados (em vermelho) através do programa NLSL medidos em vesículas de POPC ( $\mathrm{pH} \sim 6)$ marcadas com 5-PCSL. 


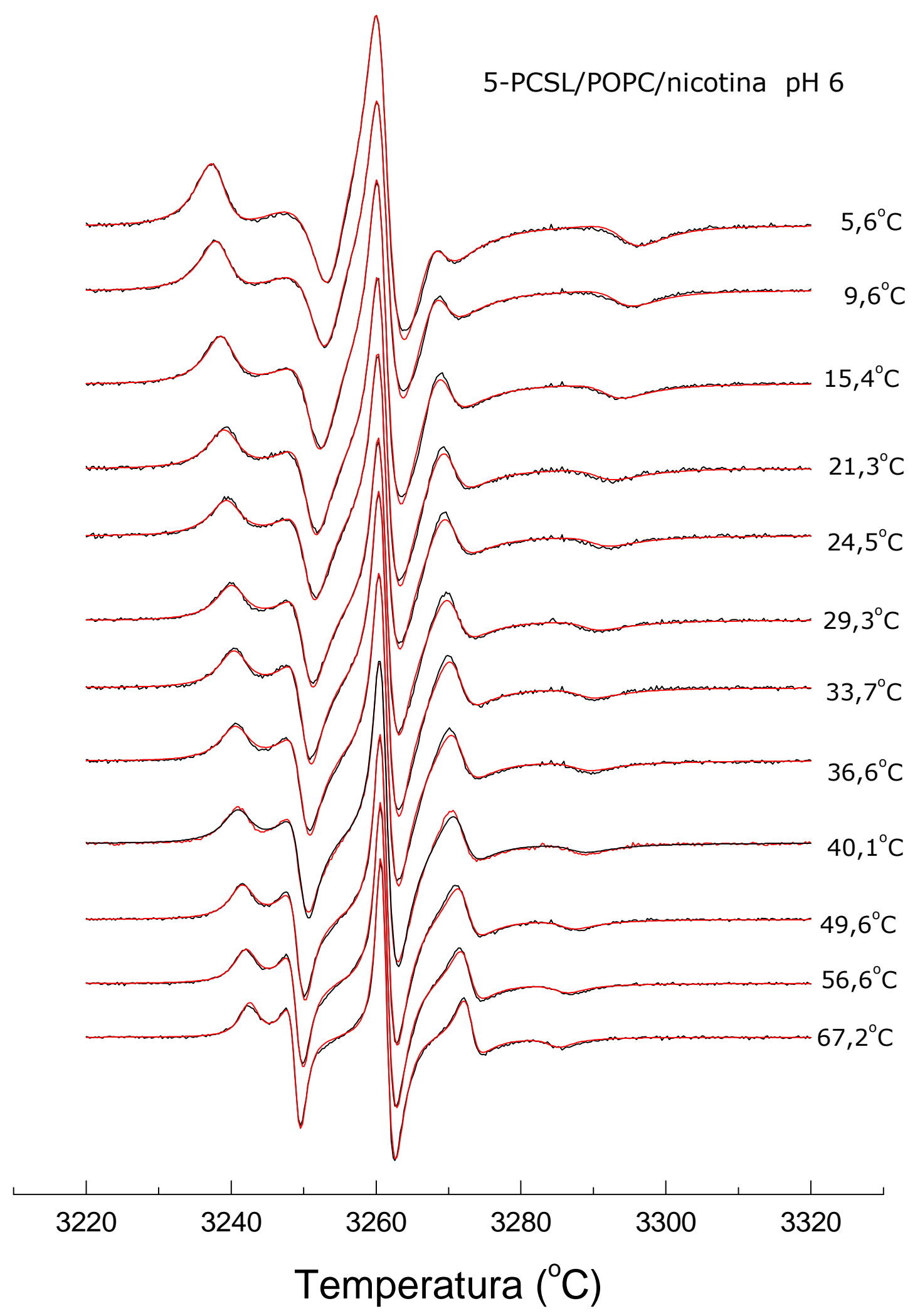

Figura 1.3.12 Espectros experimentais (linha preta) de RPE e seus respectivos simulados com uma componente (em vermelho) através do programa NLSL medidos em vesículas de POPC/nicotina ( $\mathrm{pH}$ (6) marcadas com 5-PCSL. 


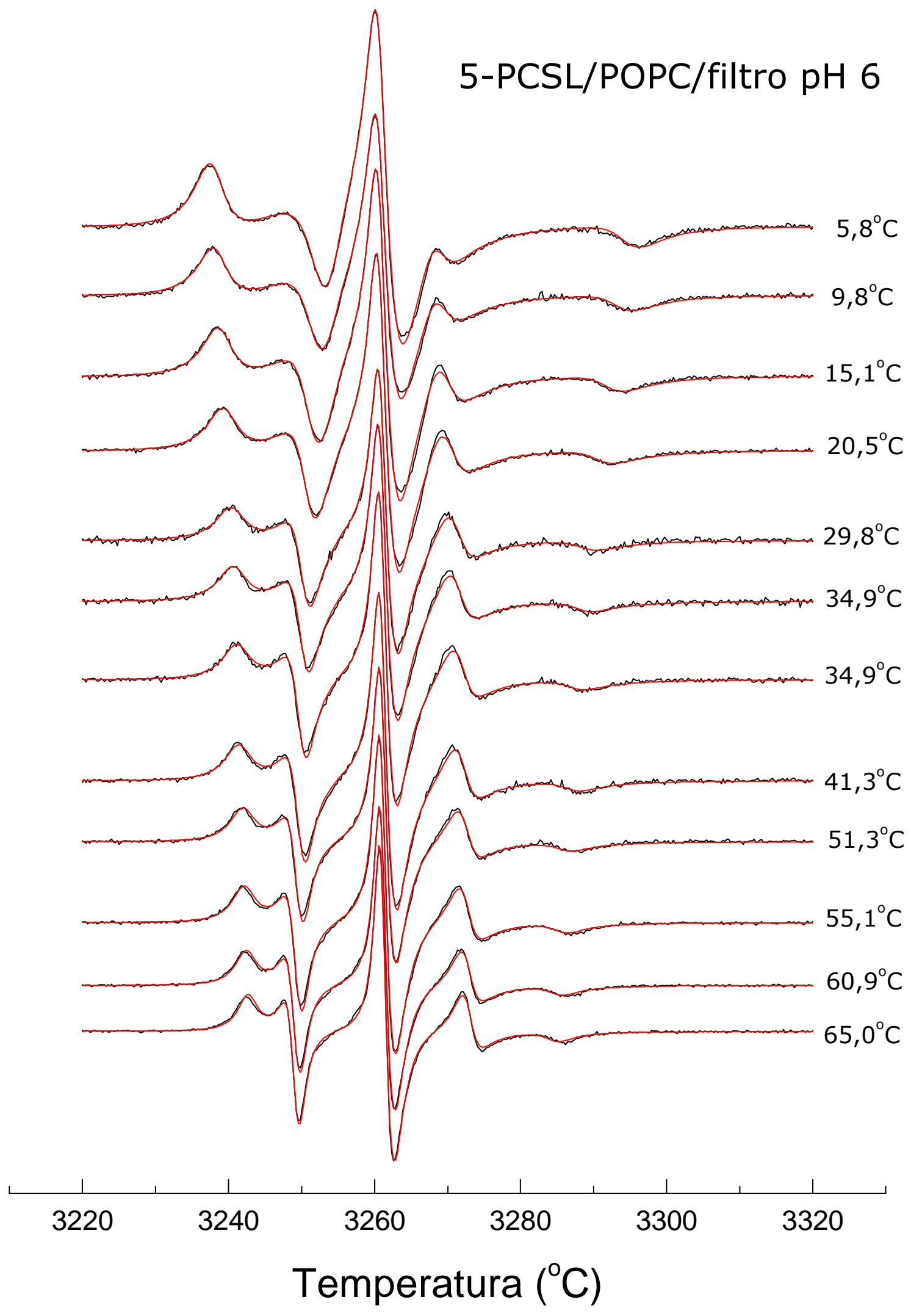

Figura 1.3.13 Espectros experimentais (linha preta) de RPE e seus respectivos simulados com uma componente (em vermelho) através do programa NLSL medidos em vesículas de POPC/filtro (pH 6) marcadas com 5-PCSL. 
Os espectros foram simulados satisfatoriamente com uma única componente em todo o intervalo de temperatura medido, o que é, provavelmente, reflexo da existência de uma única fase fluida do fosfolipídio POPC em todas as temperaturas acima de cerca de $-2{ }^{\circ} \mathrm{C} \cdot{ }^{(35)}$ Calculados de cada espectro através do programa de simulação, a Figura 1.3.14 exibe o parâmetro de ordem $\mathrm{S}_{0}$ em função da temperatura para as amostras 5-PCSL/POPC, 5PCSL/POPC/nicotina e 5-PCSL/POPC/filtro. Como esperado para o caso de POPC, o parâmetro de ordem $S_{0}$ diminui monotonicamente em função da temperatura, não se observando nenhuma mudança que possa ser atribuída a uma transição de fase. Os valores de ordenamento obtidos nas temperaturas entre 5 e $30{ }^{\circ} \mathrm{C}$ são sempre menores quando comparados com aqueles determinados para o mesmo marcador em vesículas de DPPC (Figura 1.3.3). Na presença de nicotina, há uma redução no ordenamento das cadeias hidrofóbicas dos fosfolipídios já perceptível mesmo com o marcador 5-PCSL, sugerindo que a nicotina interaja mais facilmente com fases mais fluidas. Percebe-se, ainda, que o efeito causado pela solução obtida a partir da lavagem de um filtro de cigarro comercial é similar àquele observado com a solução de nicotina pura, mostrando que o filtro continha realmente grande quantidade de nicotina. 


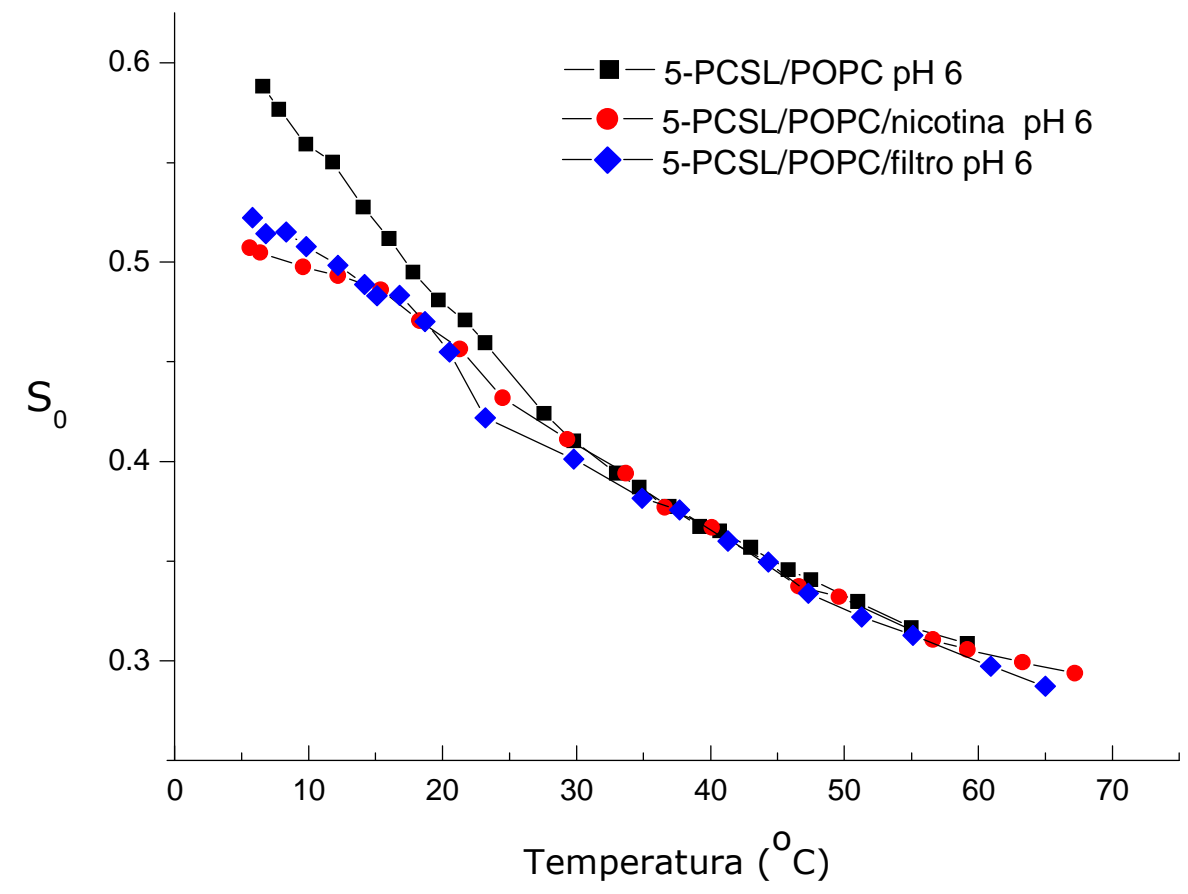

Figura 1.3.14 Dependência do parâmetro de ordem $\mathrm{S}_{0}$ com a temperatura obtida a partir dos ajustes espectrais das amostras 5-PCSL/POPC (quadrados), 5-PCSL/POPC/nicotina (círculos), 5PCSL/POPC/filtro (losangos).

Analogamente, a Figura 1.3.15 expõe a taxa de difusão rotacional $R_{\text {prp }}$ para as amostras acima citadas. Novamente, o parâmetro em questão apresenta comportamento que não indica mudanças associáveis com transição de fase dos fosfolipídios, aumentando monotonicamente com o aumento da temperatura. Aqui, o efeito de adição de nicotina foi o de promover uma pequena redução nos valores de $R_{\text {prp }}$ em todo o intervalo de temperatura, o que sugere menor fluidez da membrana na presença da nicotina. A solução oriunda da lavagem de filtro de cigarro comercial induz o mesmo tipo de redução de fluidez na membrana. Tomados conjuntamente com a diminuição de $\mathrm{S}_{0}$ para temperaturas abaixo de cerca de $30^{\circ} \mathrm{C}$, nossos dados indicam que a nicotina, ao interagir com vesículas de POCP em pH ácido, desordena o empacotamento das cadeias hidrofóbicas , 
que pode ser entendido como um aumento no valor médio do ângulo entre o eixo longo da cadeia acila e o vetor diretor da bicamada, e diminui a taxa de difusão do marcador em sua trajetória dentro do cone definido pelo mesmo ângulo citado acima.

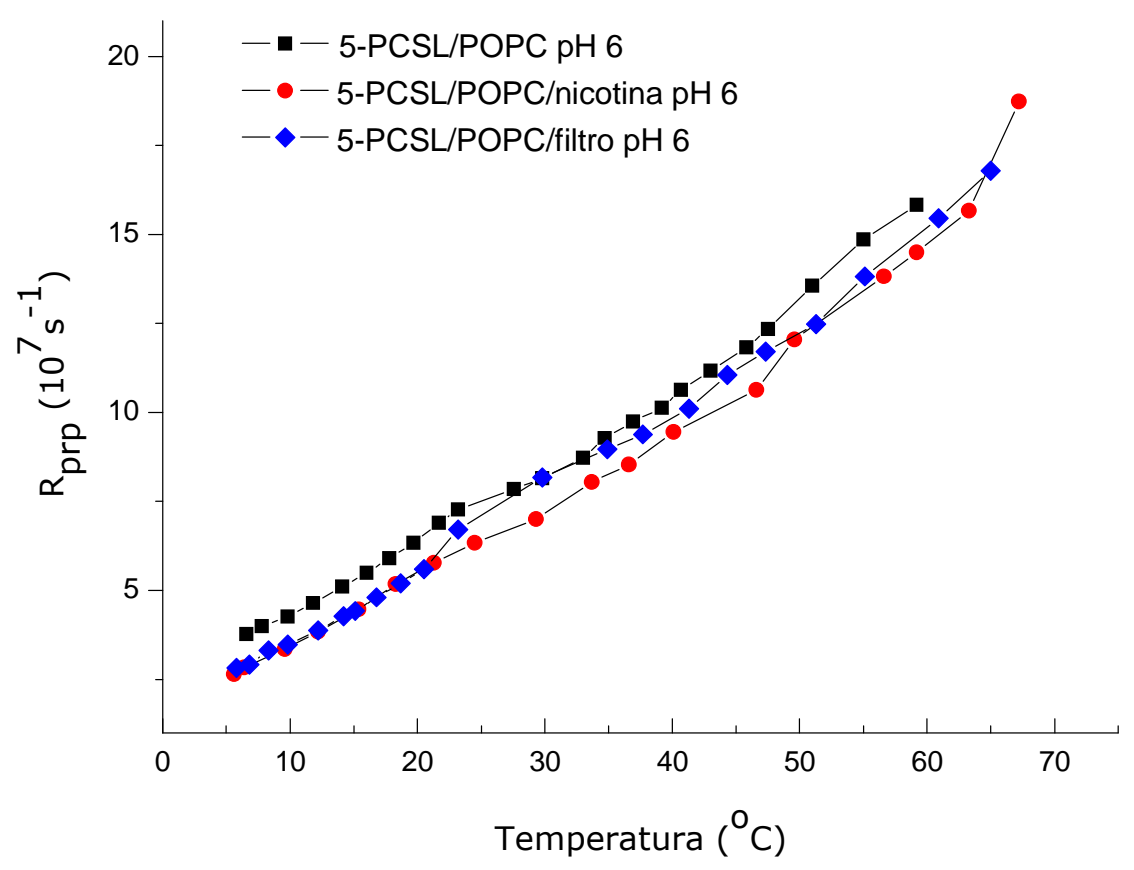

Figura 1.3.15 Dependência da taxa de difusão rotacional $R_{\text {prp }}$ com a temperatura obtida a partir dos ajustes espectrais das amostras 5-PCSL/POPC (quadrados), 5-PCSL/POPC/nicotina (círculos) e 5PCSL/POPC/filtro (losangos).

Do mesmo modo como descrito acima, expomos os espectros experimentais e calculados das mesmas amostras tomados com base no 5-PCSL marcador agora medido em pH básico ( $\mathrm{pH}$ 10). Estes são mostrados nas Figuras 1.3.16 e 1.3.17. O parâmetro de ordem $\mathrm{S}_{0}$ e a taxa de difusão rotacional $\mathrm{R}_{\mathrm{prp}}$ são colocados nas Figuras 1.3.18 e 1.3.19, respectivamente. 

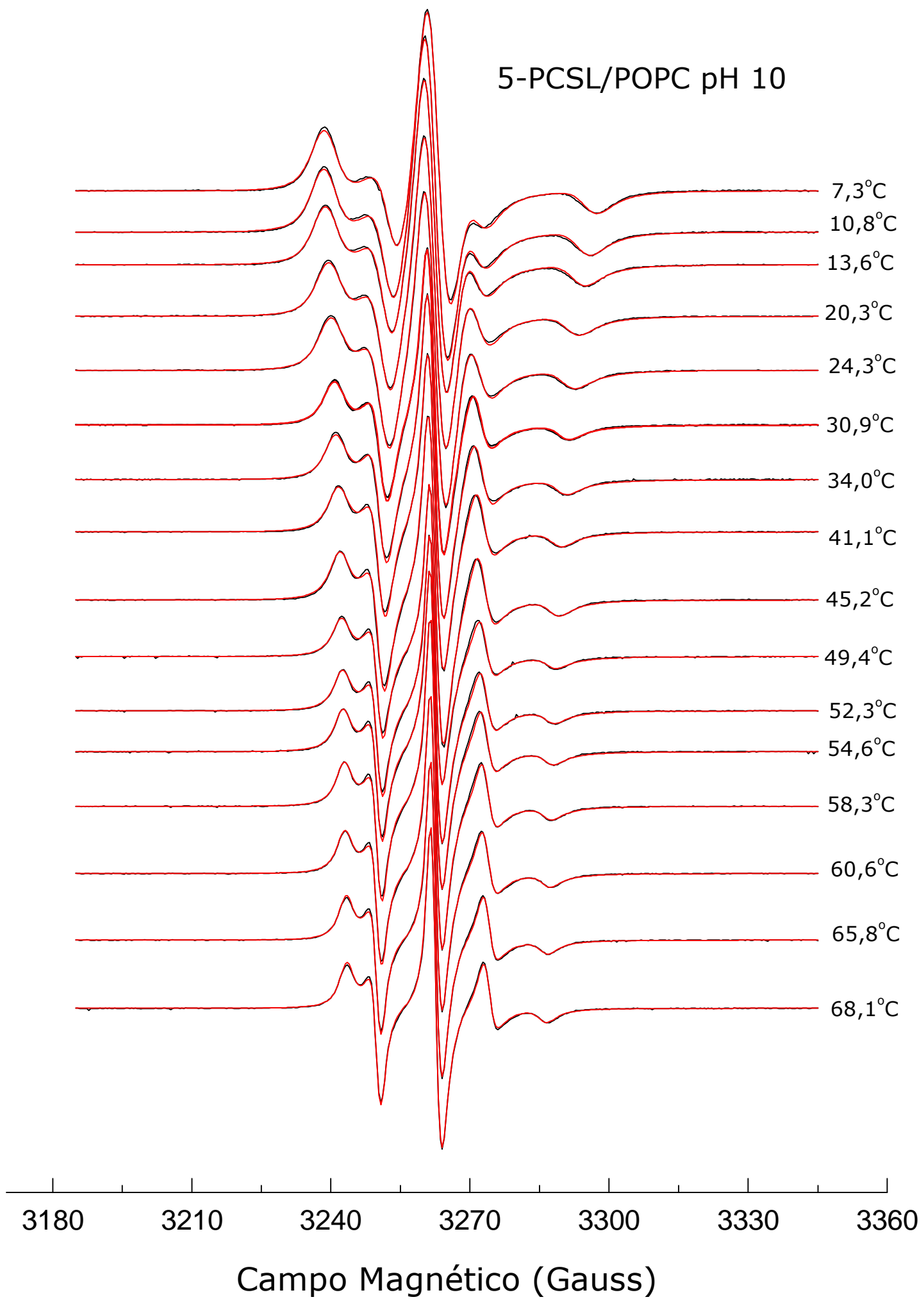

Figura 1.3.16 Espectros experimentais (linha preta) de RPE e seus respectivos simulados com uma componente (em vermelho) através do programa NLSL medidos em vesículas de POPC (pH 10) marcadas com 5-PCSL. 


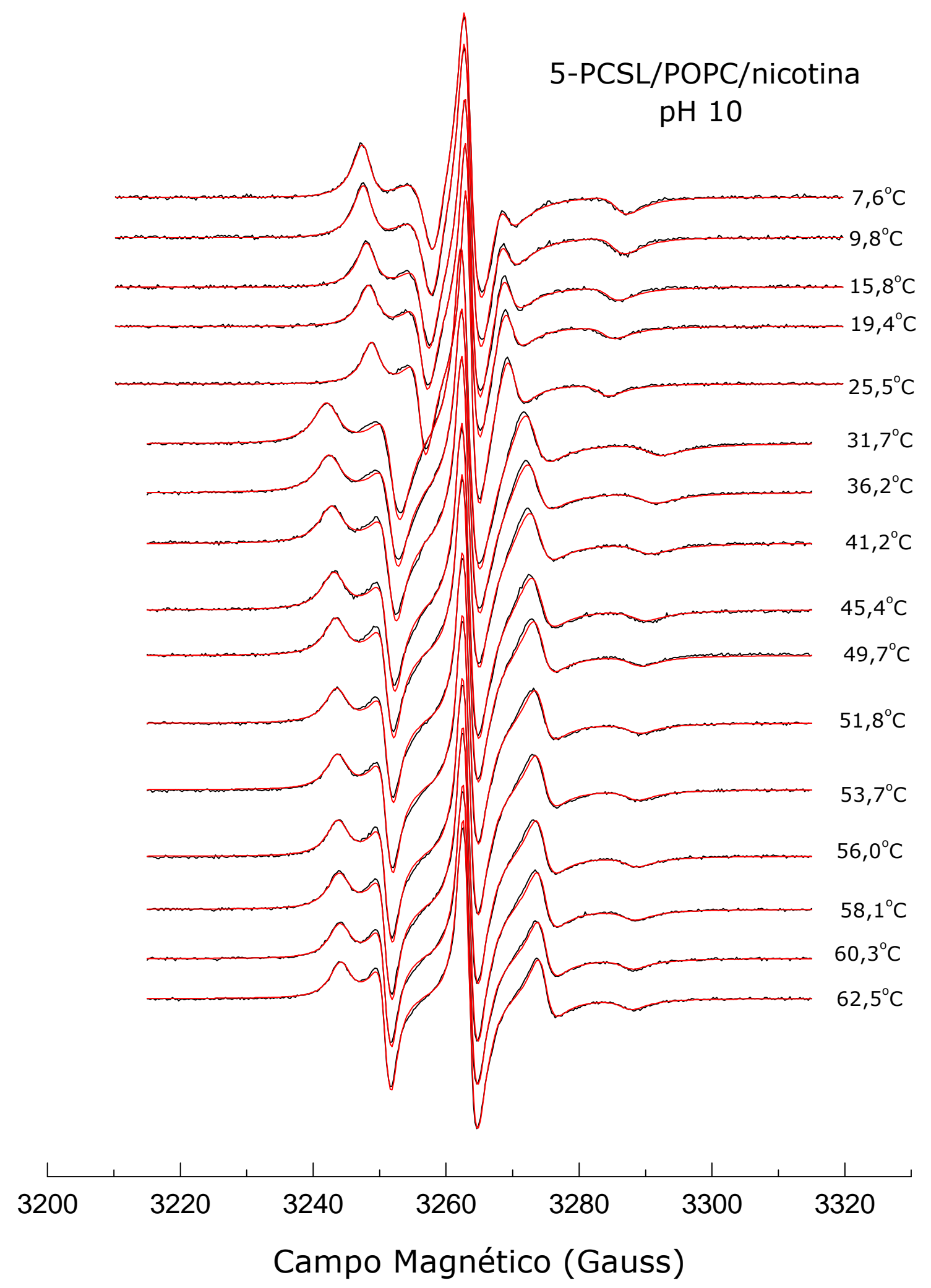

Figura 1.3.17 Espectros experimentais (linha preta) de RPE e seus respectivos simulados com uma componente (em vermelho) através do programa NLSL medidos em vesículas de POPC/nicotina (pH 10) marcadas com 5PCSL. 


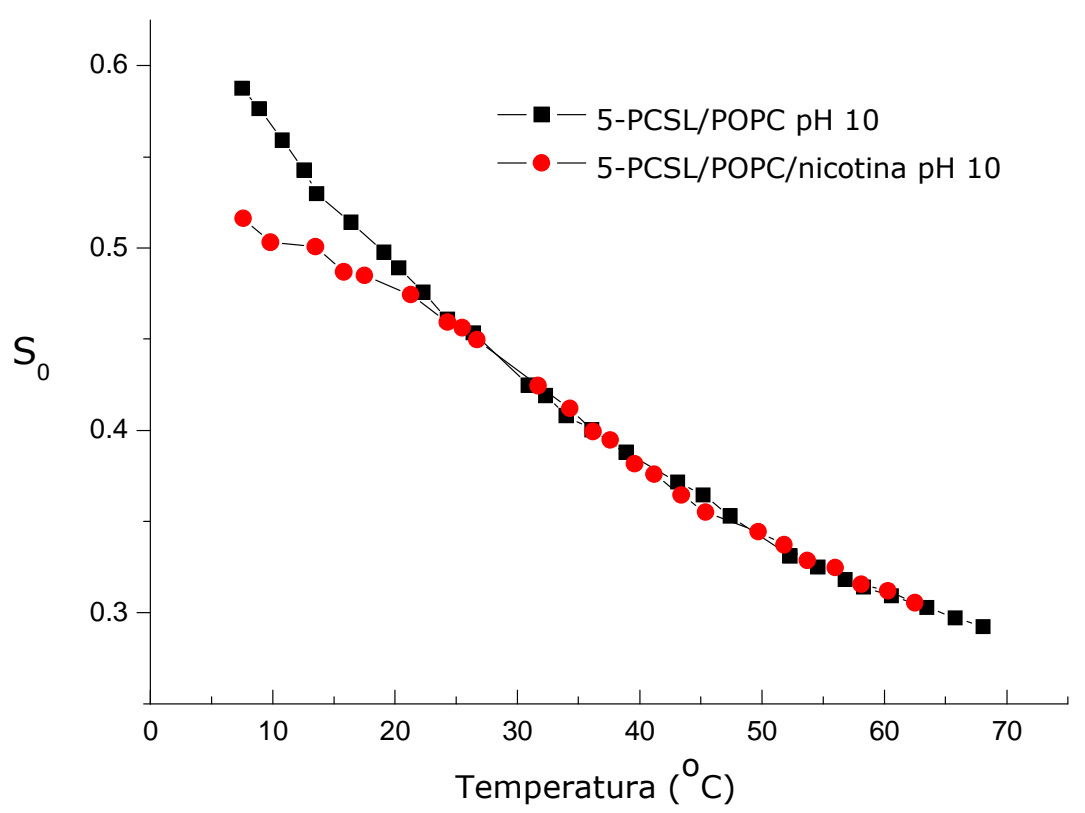

Figura 1.3.18 Dependência do parâmetro de ordem $\mathrm{S}_{0}$ com a temperatura obtida a partir dos ajustes espectrais das amostras 5-PCSL/POPC (quadrados) e 5-PCSL/POPC/nicotina (círculos) em pH 10.

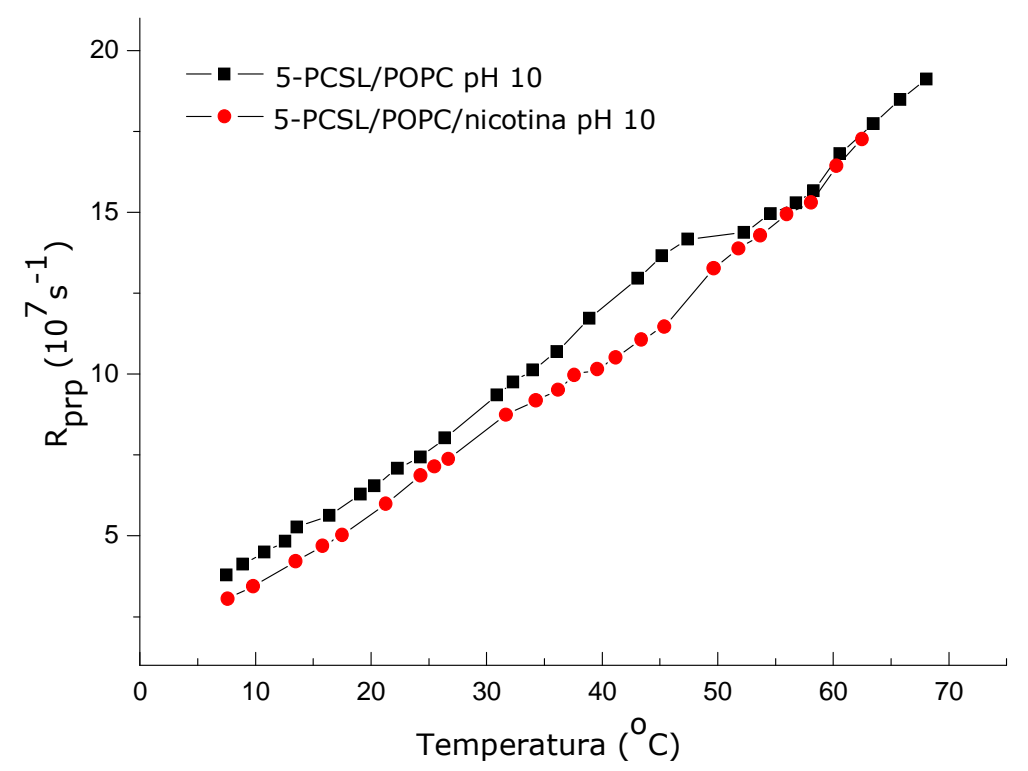

Figura 1.3.19 Dependência da taxa de difusão rotacional $R_{\text {prp }}$ com a temperatura obtida a partir dos ajustes espectrais das amostras 5-PCSL/POPC (quadrados) e 5-PCSL/POPC/nicotina (círculos) em pH 10. 
As alterações promovidas pela adição de nicotina a vesículas de POPC em pH básico e monitoradas na região próxima à cabeça polar pelo marcador 5-PCSL são bastante similares àquelas observadas em $\mathrm{pH}$ ácido (Figuras 1.3.14 e 1.3.15): diminuição do parâmetro de ordem $S_{0}$ para temperaturas inferiores a cerca de $30{ }^{\circ} \mathrm{C}$ e pequena diminuição da taxa de difusão rotacional em todo o intervalo de temperatura medido. Podemos concluir, então, que da perspectiva do marcador 5-PCSL, a variação no pH da amostra, que leva a uma mudança na carga líquida da nicotina que passa de monoprotonada $(\mathrm{pH}$ 6) para não ionizada (pH 10), não afeta a estrutura dinâmica da vesícula após adição da nicotina. Nada podemos afirmar a respeito da afinidade da nicotina pelas vesículas nos dois valores de $\mathrm{pH}$, pois não é possível determinarmos constante de ligação a partir dos espectros de RPE obtidos para as amostras descritas. Se há um aumento (ou diminuição) na constante de associação oriundo da variação do pH, isto não é refletido na estrutura sentida pelo marcador na posição 5 da cadeia hidrofóbica do fosfolipídio ao compararmos as amostras com nicotina em $\mathrm{pH}$ ácido e básico.

\section{6-PCSL}

As figuras seguintes mostram os espectros experimentais e os respectivos ajustes para as amostras 16-PCSL/POPC (Figura 1.3.20) e 16PCSL/POPC/nicotina (Figura 1.3.21) medidas em pH ácido ( 6). 


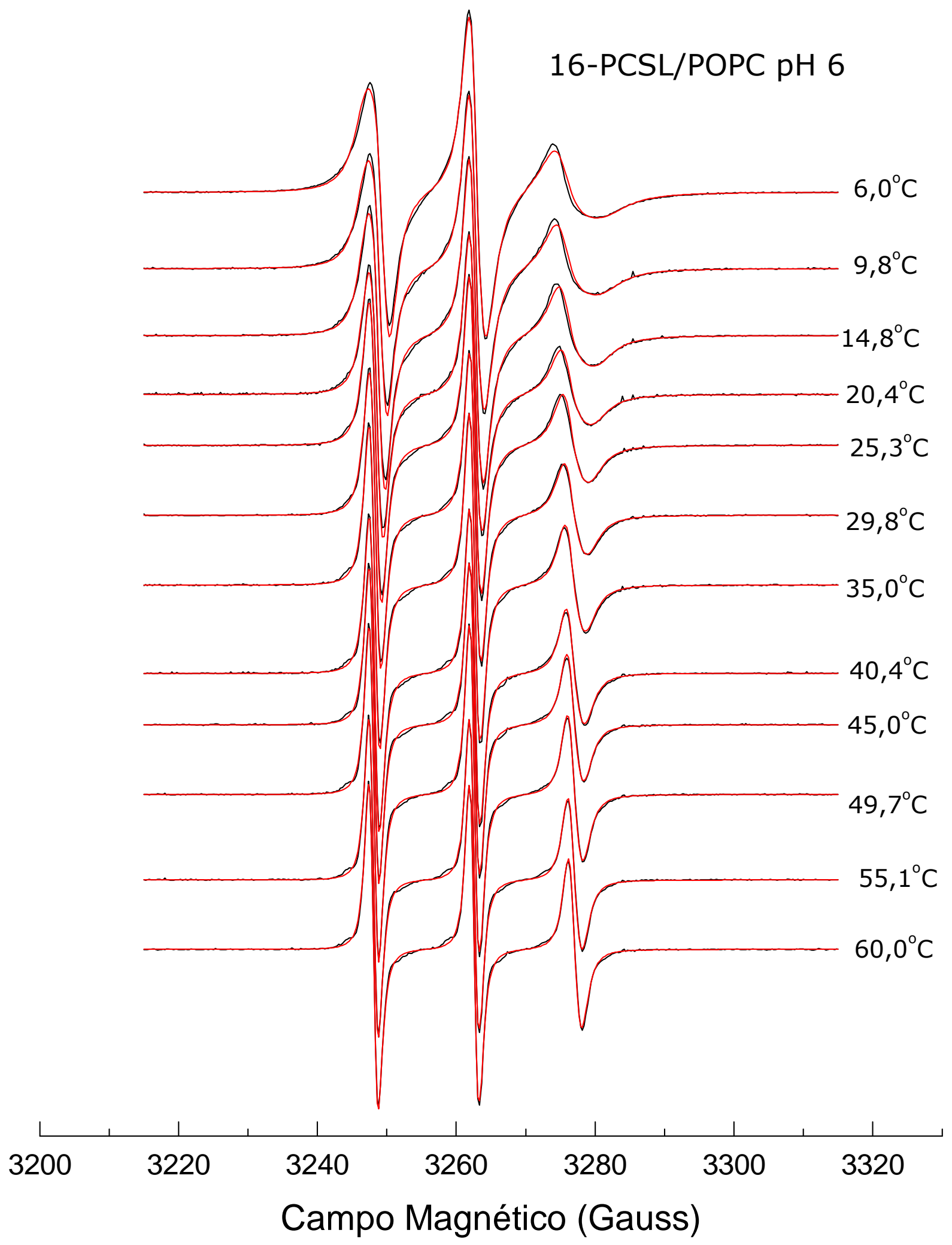

Figura 1.3.20 Espectros experimentais (linha preta) de RPE e seus respectivos simulados (em vermelho) através do programa NLSL medidos em vesículas de POPC em pH $\sim 6$ marcadas com 16-PCSL 


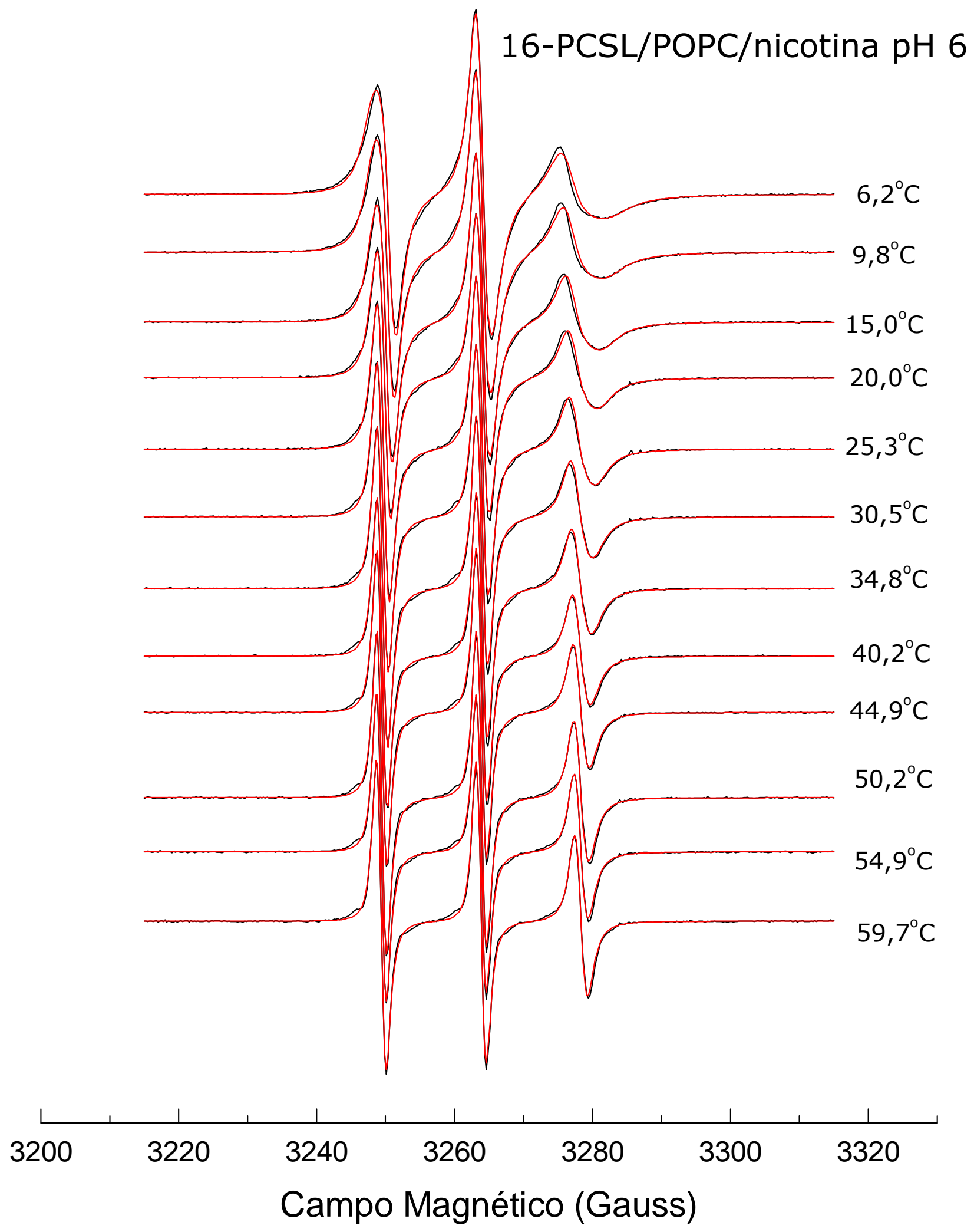

Figura 1.3.21 Espectros experimentais (linha preta) de RPE e seus respectivos simulados com uma componentes (em vermelho) através do programa NLSL medidos em vesículas de POPC/nicotina (pH 6) marcadas com 16-PCSL. 
Nas simulações dos espectros apresentados nas Figuras 1.3.20 e 1.3.21 apenas uma componente foi necessária em todo o intervalo de temperatura, o que difere daquilo que havia sido observado no caso de vesículas de 16PCSL/DPPC e que ilustra mais uma vez o fato de termos vesículas compostas por um fosfolipídio com comportamento termotrópico simplificado e que está, nas temperaturas utilizadas, sempre na fase fluida. Das simulações espectrais, obtivemos mais uma vez a dependência com a temperatura do parâmetro de ordem $\mathrm{S}_{0}$ (Figura 1.3.22) e da taxa de difusão rotacional $\mathrm{R}_{\mathrm{prp}}$ (Figura 1.3.23). Nessas figuras, vemos que, como é característico para a região do final da cadeia carbônica do fosfolipídio (centro da bicamada lipídica), os valores de $\mathrm{S}_{0}$ são substancialmente menores e os de $R_{\text {prp }}$ consideravelmente maiores do aqueles obtidos próximo à cabeça polar (monitorada pelo marcador 5-PCSL - Figuras 1.3.18 e 1.3.19), mostrando que o centro da bicamada experimenta dinâmica muito mais rápida e pouca estruturação dos fosfolipídios. 


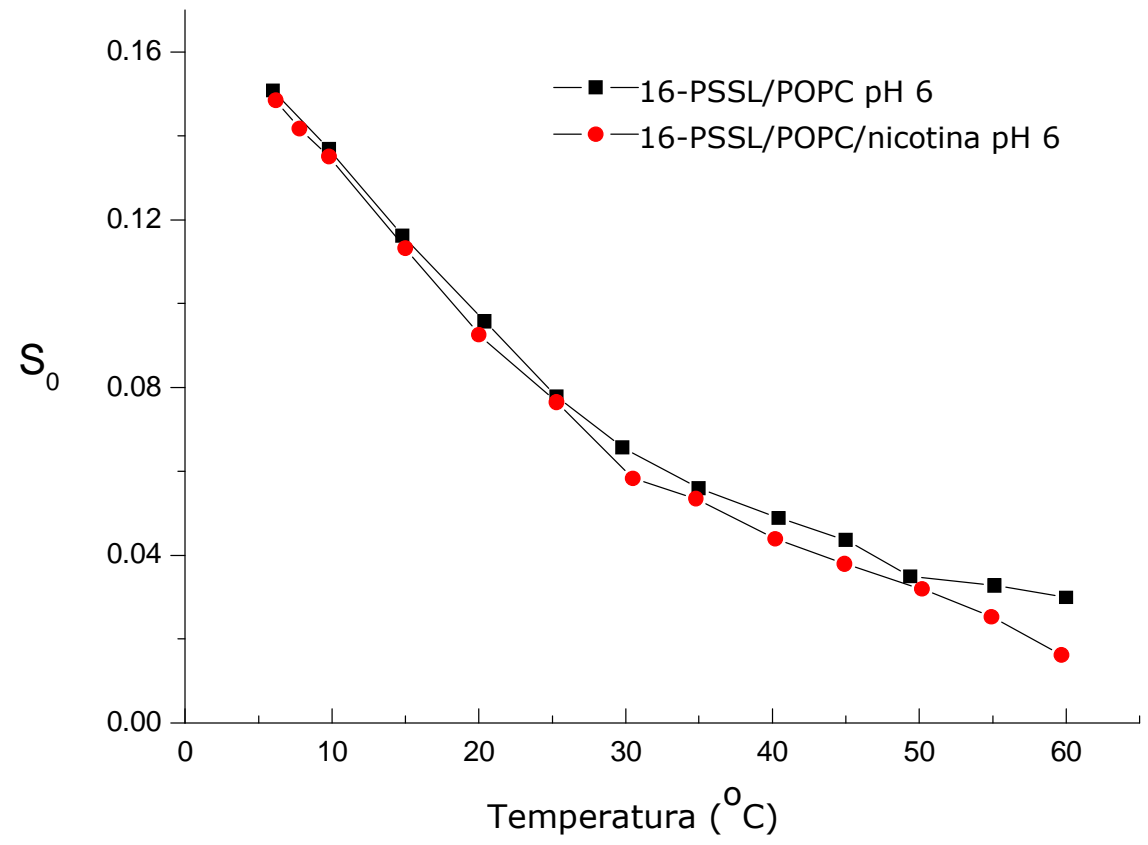

Figura 1.3.22 Dependência do parâmetro de ordem $S_{0}$ com a temperatura obtida a partir dos ajustes espectrais das amostras 16-PCSL/POPC (quadrados) e 16-PCSL/POPC/nicotina (círculos).

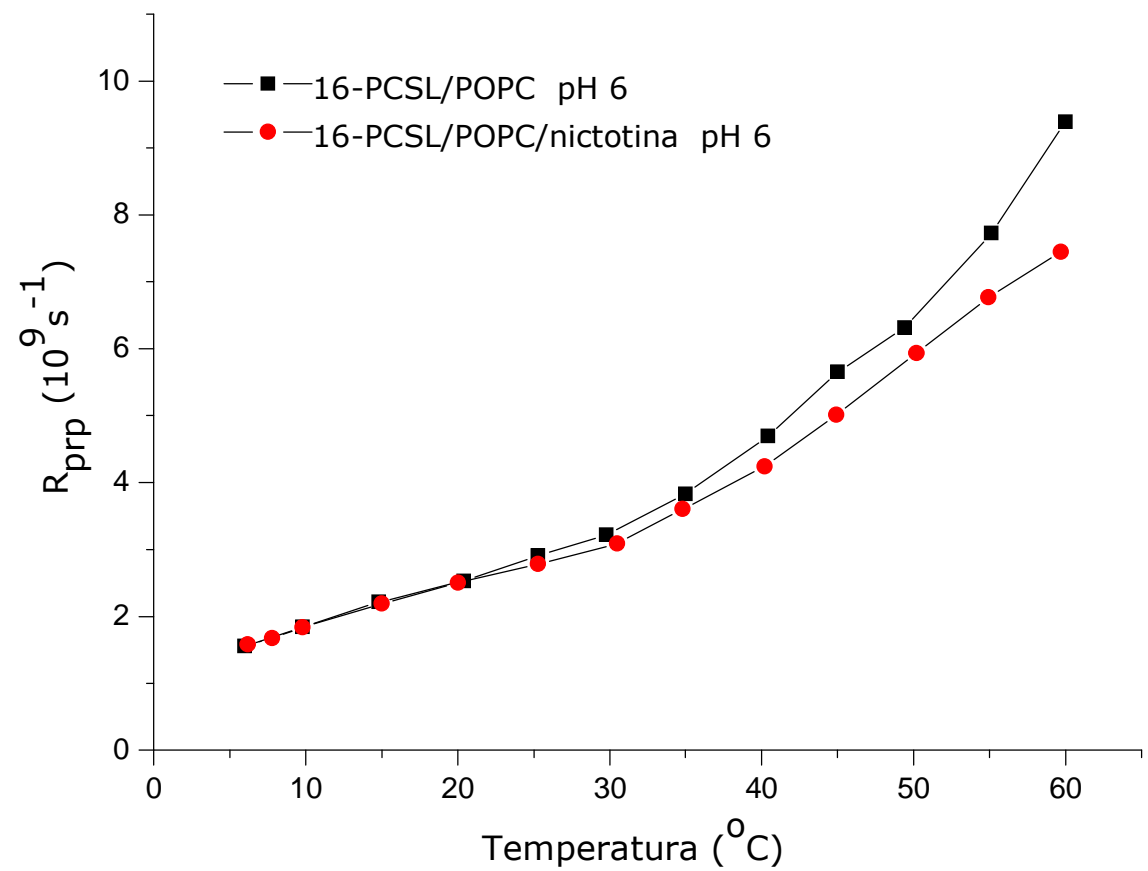

Figura 1.3.23 Dependência da taxa de difusão rotacional $\mathrm{R}_{\mathrm{prp}}$ com a temperatura obtida a partir dos ajustes espectrais das amostras 16-PCSL/POPC (quadrados) e 16-PCSL/POPC/nicotina (círculos). 
Ainda dos dados apresentados nas Figuras 1.3.22 e 1.3.23, vemos que a adição de nicotina às vesículas de DPPC em pH ácido não induz mudanças detectáveis nos espectros do marcador 16-PCSL, a menos de uma leve diminuição da taxa de difusão rotacional para temperaturas acima de $30{ }^{\circ} \mathrm{C}$. Provavelmente, a alta mobilidade e o baixo ordenamento sentido pelo marcador 16-PCSL na fase fluida do POPC é pouco influenciada pela presença de nicotina. É interessante notar que, essa maior mobilidade do marcador 16-PCSL, que nos ajudou a distinguir duas componentes espectrais no caso de vesículas de DPPC em temperaturas correspondentes a uma fase do tipo gel, agora, no caso de marcador em uma fase fluida, nos leve à pouca sensibilidade evidenciada nas Figuras 1.3.22 e 1.3.23. Isto é, a maior resolução dos espectros do marcador 16PCSL é útil nos casos em que temos alguma organização do microambiente em torno do marcador, como na fase gel de fosfolipídios, mas leva a uma insensibilidade quando em situações de muito alta mobilidade e baixa ordem. Tudo isto colocado conjuntamente nos leva a inferir que a nicotina tem efeito desestabilizador sobre a fase fluida das vesículas de POPC restrito à região inicial das cadeias hidrofóbicas dos fosfolipídios.

Assim como feito para o marcador 5-PCSL, conduzimos experimentos nas amostras de 16-PCSL/POPC e 16-PCSL/POPC/nicotina em pH básico ( 10). Os espectros experimentais com os ajustes são mostrados nas Figuras 1.3.24 (16PCSL/POPC) e 1.3.25 (16-PCSL/POPC/nicotina). Já os parâmetros calculados a partir das simulações são mostrados nas Figuras 1.3.26 $\left(\mathrm{S}_{0}\right)$ e $1.3 .27\left(\mathrm{R}_{\mathrm{prp}}\right)$. Neste caso, um pequeno aumento no ordenamento das cadeias é observado até cerca de $35{ }^{\circ} \mathrm{C}$. Acima desta temperatura, os valores de $\mathrm{S}_{0}$ oscilam em torno de zero, indicando que os ajustes perderam sensibilidade para os coeficientes do potencial restaurador, o que é comum em situações de modelos de membrana 
com ordenamento muito baixo. Mesmo para as temperaturas acima de $35{ }^{\circ} \mathrm{C}$, a diferença obtida após adição de nicotina é de apenas cerca de 0,02 em $\mathrm{S}_{0}$. Assim, em pH 10, os efeitos da nicotina em relação ao parâmetro de ordem das cadeias na posição $\mathrm{n}=16$ são, assim como em pH ácido, discretos. Em relação à difusão do marcador 16-PCSL, o padrão observado em pH básico segue aquele previamente determinado em pH ácido (Figura 1.3.23), com leve decréscimo da mobilidade do marcador na presença de nicotina. 


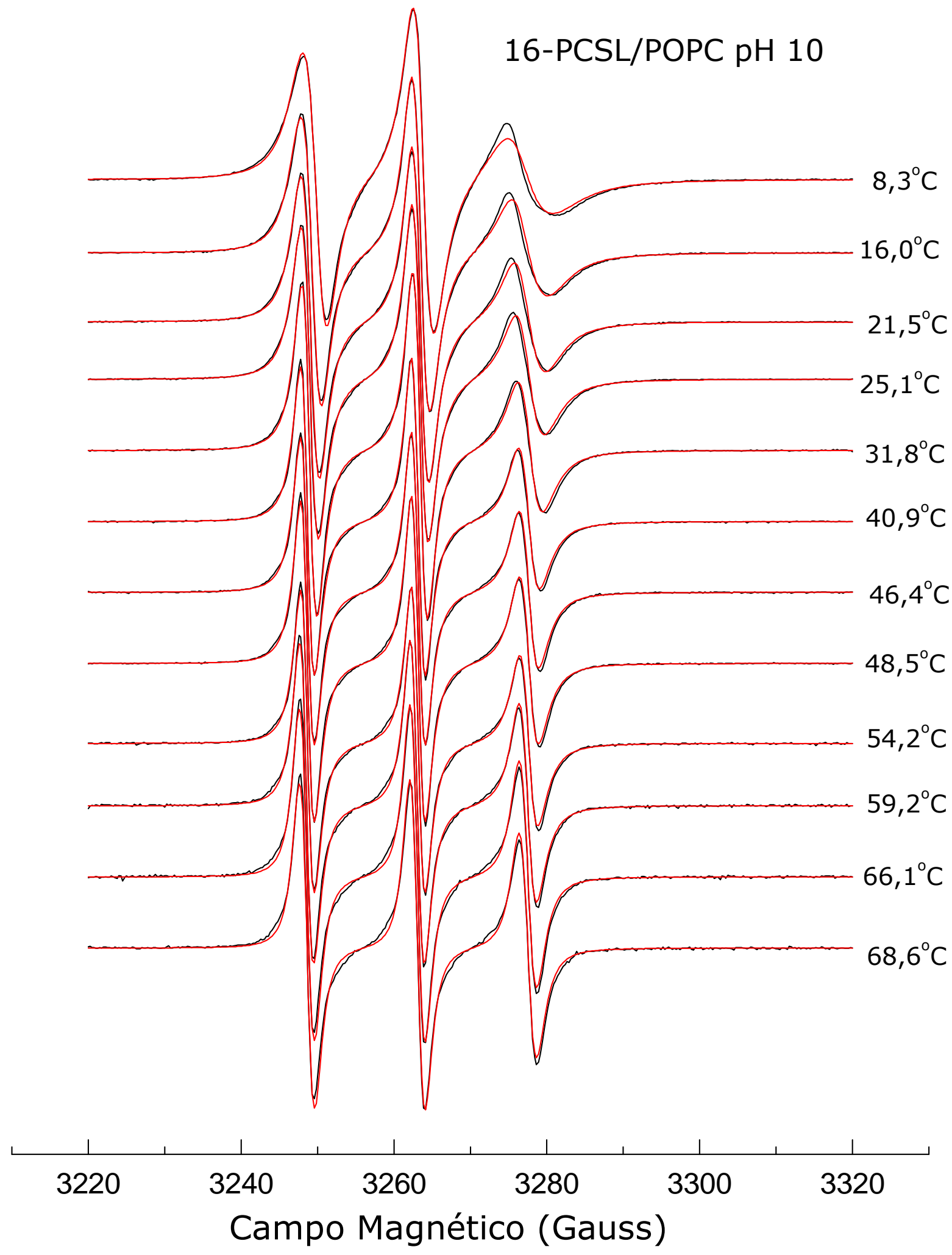

Figura 1.3.24 Espectros experimentais (linha preta) de RPE e seus respectivos simulados (em vermelho) através do programa NLSL medidos em vesículas de POPC em pH 10 marcadas com 16-PCSL. 


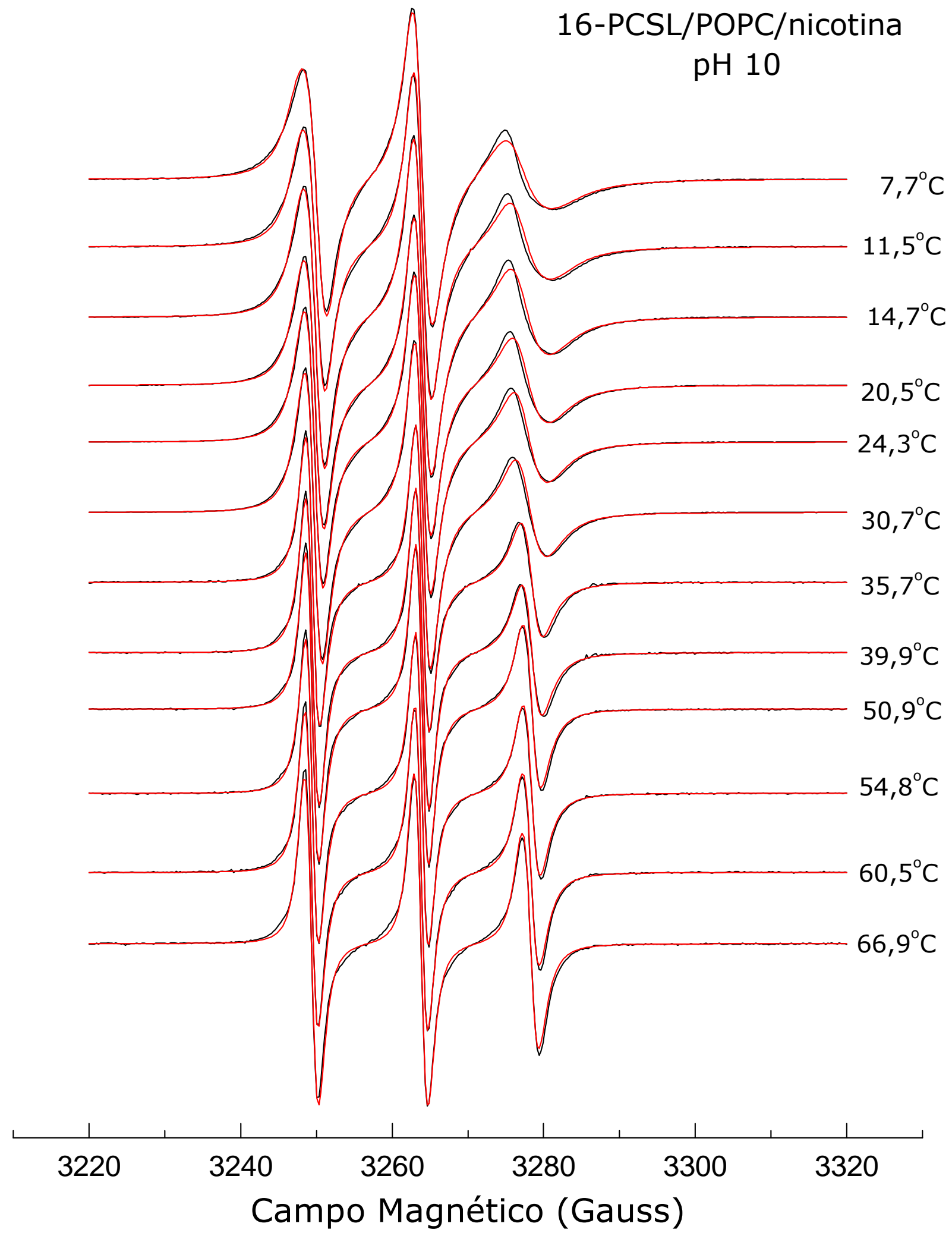

Figura 1.3.25 Espectros experimentais (linha preta) de RPE e suas respectivas simulações (em vermelho) através do programa NLSL medidos em vesículas de POPC/nicotina em pH 10 marcadas com 16-PCSL. 


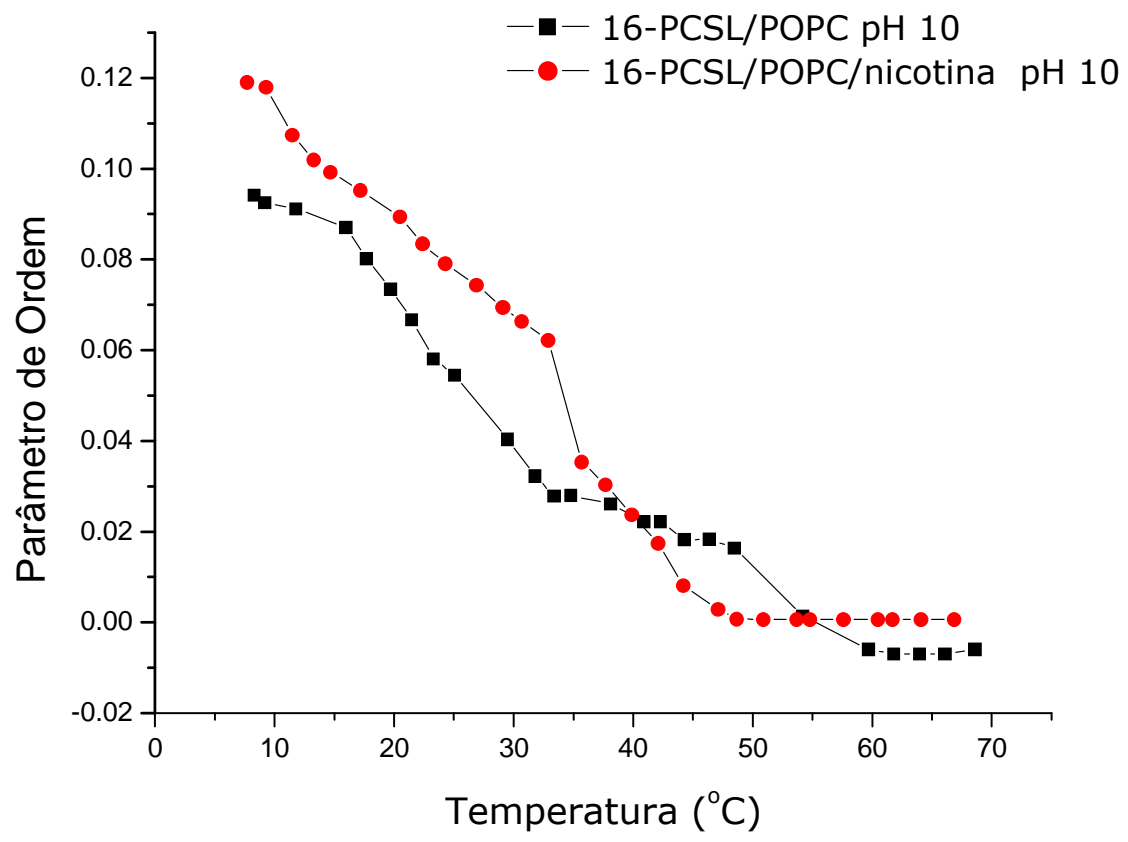

Figura 1.3.26 Dependência do parâmetro de ordem $S_{0}$ com a temperatura obtida a partir dos ajustes espectrais das amostras 16-PCSL/POPC (quadrados) e 16-PCSL/POPC/nicotina (círculos), pH 10.

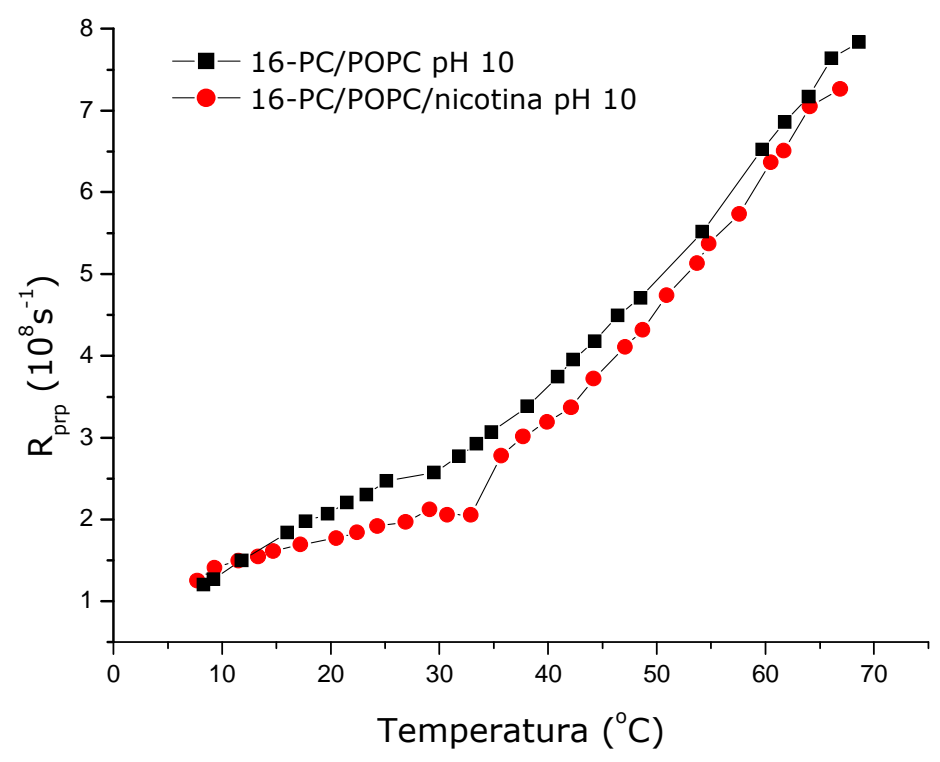

Figura 1.3.27 Dependência da taxa de difusão rotacional $R_{\text {prp }}$ com a temperatura obtida a partir dos ajustes espectrais das amostras 16-PCSL/POPC (quadrados) e 16-PCSL/POPC/nicotina (círculos), $\mathrm{pH} \sim 10$. 


\subsubsection{Discussão geral dos resultados}

O presente estudo mostra o efeito da interação da nicotina com dois dos principais fosfolipídios que compõem os chamados surfatantes pulmonares (DPPC e POPC) com base na variação de temperatura e $\mathrm{pH}$.

A nicotina é uma molécula que apresenta dois grupos protonáveis: os dois nitrogênios presentes em sua estrutura, cujos valores dos $\mathrm{pK}_{a}$ 's são 3,04 e7,84(29), ou seja, a molécula pode existir em três estados de ionização dependendo do pH da solução. A dissociação dessa molécula é descrita, portanto, como:

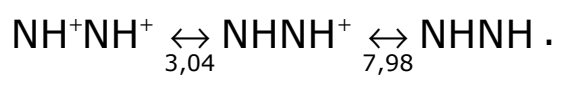

Como exemplo, em $\mathrm{pH} \mathrm{6,0} \mathrm{a} \mathrm{nicotina} \mathrm{está} \mathrm{predominantemente} \mathrm{na} \mathrm{forma}$ monoprotonada $\mathrm{NHNH}^{+}$, ao passo que em $\mathrm{pH}$ 10,0, sua forma predominante é não ionizada. As possíveis interações que podem ocorrer entre a nicotina e vesículas de fosfolipídios dependem do $\mathrm{pH}$ da solução e dos estados de protonação da molécula. Interação eletrostática, adsorção da molécula na região da cabeça polar ou penetração da mesma na matriz lipídica são exemplos dos tipos de interações que podem ocorrer.

Os dois fosfolipídios utilizados neste trabalho, DPPC e POPC, são zwiteriônicos, ou seja, com carga total líquida nula. Assim, se tais fosfolipídios são dispersos em uma solução levemente ácida $(\mathrm{pH} 6)$ na presença de nicotina na forma monoprotonada, é esperado que haja uma maior interação desta molécula com a região das cabeças polares (adsorção) destes fosfolipídios. Já em pH básico $(\sim 10)$ e com a nicotina na forma não protonada, interações 
eletrostáticas deixam de ter contribuição principal e esta molécula pode apresentar uma maior capacidade de penetração nas membranas.

Com base no exposto acima, buscamos entender o efeito da presença da nicotina sobre a estrutura dinâmica de sistemas modelo de membranas constituídos pelos fosfolipídios DPPC e POPC. Este estudo concentrou-se na investigação das mudanças no ordenamento e dinâmica das cadeias acila em regiões próximas à cabeça polar dos lipídios (5-PCSL) e no centro da bicamada (16-PCSL). Nossos resultados basearam-se no comportamento termotrópico do parâmetro de ordem $S_{0}$ e da taxa de difusão rotacional $R_{\text {prp }}$ obtidos através do uso intensivo de simulações espectrais.

Para o marcador 5-PCSL em vesículas de DPPC ( $\mathrm{pH}$ ácido), verificamos pouca ou nenhuma alteração significativa dos parâmetros oriundos das simulações após adição de nicotina (Figuras 1.3 .3 e 1.3.4). Por outro lado, no caso de vesículas constituídas pelo fosfolipídio POPC, com comportamento termotrópico simplificado (sempre em uma fase fluida dentro do intervalo de temperaturas deste trabalho), observamos, em ambos os pHs investigados, que a região próxima às cabeças polares mostrou um decréscimo em termos tanto de ordenamento (Figuras 1.3.14 e 1.3.18) quanto de mobilidade (Figuras 1.3 .15 e 1.3.19) para temperaturas inferiores a cerca de $30{ }^{\circ} \mathrm{C}$. O valor extremamente elevado do marcador 5-PCSL em DPPC nessa faixa de temperaturas (algo em torno de 0,9$)$ provavelmente é o responsável pela incapacidade em detectarmos mudanças. A fase fluida das vesículas de POPC deve facilitar a interação da nicotina com este modelo de membrana. Cabe salientar que nossos dados de RPE não nos permitem inferir magnitudes da referida interação e, portanto, não podemos correlacionar, em princípio, magnitude dos efeitos observados com maior ou menor afinidade da nicotina por um dado modelo de membrana. 
Os resultados para o marcador 16-PCSL mostraram mudanças bastante interessantes no caso das vesículas de DPPC na região que chamamos de fase gel (entre cerca de 30 e $40{ }^{\circ} \mathrm{C}$ ). Neste intervalo de temperaturas, espectros de RPE contendo duas componentes foram observados tanto na ausência quanto na presença de nicotina (Figuras 1.3 .5 e 1.3.6). Aqui, as simulações espectrais deram contribuição única pois tornaram possível a determinação direta das populações associadas com cada componente no espectro e, a partir delas, fomos capazes de calcular parâmetros termodinâmicos como a variação de entalpia $(\Delta \mathrm{H})$ e de entropia $(\Delta \mathrm{S})$ através de um gráfico de van't Hoff (Figura 1.3.10) para os casos de vesículas sem e com nicotina adicionada. Os valores de $\Delta \mathrm{H}$ e de $\Delta \mathrm{S}$ obtidos foram ambos positivos, mostrando que a troca entre os dois microambientes experimentados pelo marcador 16-PCSL, indo do ambiente mais ordenado (gel-like) para aquele mais fluido, é um processo governado por entropia. Além disso, vimos que a presença de nicotina, apesar de não causar efeitos diretamente perceptíveis nos espectros de RPE, leva a aumento de $\Delta \mathrm{H}$ e de $\Delta \mathrm{S}$, facilitando o processo de transição para a região fluid-like.

Estudos anteriores mostram que o efeito de redução da tensão superficial desempenhada pelo complexo surfatante é atribuída, principalmente, à presença do fosfolipídio DPPC. ${ }^{(40)}$ Isto significa que qualquer alteração na estrutura lipídica deste fosfolipídio pode afetar indiretamente a função principal do surfatante levando a uma disfunção do sistema surfatante provocando o aparecimento de doenças respiratórias. ${ }^{(38)}$

O mesmo tipo de comportamento não foi observado quando o marcador de spin 16-PCSL foi incorporado a vesículas de POPC. A existência de uma fase fluida em todo o intervalo de temperatura leva a uma insensibilidade dos espectros desse marcador a mudanças que possam acontecer na estrutura da 
bicamada. Assim, não observamos alterações significativas neste caso em nenhum dos pHs (Figuras 1.3.22, 1.3.23, 1.3.26 e 1.3.27). Acreditamos que este é um caso em que interações devam acontecer, mas simplesmente não conseguimos detectá-las.

Nossos resultados apontam para uma desestabilização da estrutura do modelo de membrana, principalmente na região próxima às cabeças polares, após a adição de nicotina em estado monoprotonado, ou seja, pH ácido. Vale lembrar que as mudanças observadas nos espectros do marcador 16-PCSL em vesículas de DPPC não necessariamente mostram que a nicotina penetra na membrana até o final das cadeias carbônicas. Muitas vezes, esse tipo de mudanças espectral é vista apenas no espectro do marcador 16-PSCL, pois este apresenta maior resolução (linhas estreitas) e que facilitam a visualização de alterações no espectro.

Doenças respiratórias, como enfisema, são caracterizadas pela perda da elasticidade normal do pulmão, elasticidade que ajuda a manter as vias aéreas abertas (http://www.healthscout.com/ency/68/149/main.html). Estudos anteriores mostraram que a ruptura da parede alveolar pode acontecer por causa de uma diminuição da tensão superficial do surfatante alveolar. ${ }^{(39)}$ A nicotina parece ter um efeito desestabilizador (diminuição de estruturação, dano estrutural) dos modelos por nós estudados, o que poderia ser estendido para se entender o efeito sobre o surfatante pulmonar e uma possível relação com doenças respiratórias.

Existem poucos estudos que tratam da interação da nicotina com membranas modelo. Nos trabalhos encontrados, a nicotina exibe uma rápida penetração através da epiderme ${ }^{(41)}$ em membranas de mucosas ${ }^{(29)}$ naturais, principalmente em pH básico. O comportamento do parâmetro $\mathrm{S}_{0}$ (Figura 1.3.26) 
e $R_{\text {prp }}$ apontam nesta direção. Estudos realizados em cultura de células tipo II de ratos, tratadas com fumaça de cigarro, mostram inibição da secreção estimulada de fosfatidilcolina. ${ }^{(10)}$ O comportamento dos parâmetros calculadas do ajuste espectral de POPC tratado com lavagem de filtro de cigarro apresenta o mesmo comportamento que aqueles tratados com nicotina, a inibição da secreção de fosfatidilcolina pode estar relacionada com a interação direta da nicotina com este fosfolipídio nas células do alvéolo pulmonar.

O estudo aqui apresentado não é, obviamente, suficiente para caracterizarmos completamente o sistema fosfolipídio-nicotina, mas aponta no sentido em que a nicotina interage com a região da cabeça polar em solução ácida e tem ação penetrante em meio básico tendo como consequênica uma desestruturação da matriz lipídica. Isto pode estar relacionado com muitas doenças respiratórias em fumantes. Experimentos complementares serão necessários a fim de termos um conjunto de dados suficiente para uma melhor caracterização do sistema em pHs complementares. O fosfolipídio POPG é também um componente importante na composição de surfatantes naturais e desempenha um papel importante na adsorção da proteína surfatante SP-B na matriz surfatante, ${ }^{(4)}$ que por sua vez tem atividade funcional relacionada ao ordenamento da bicamada lipídica. Ademais, como não existem trabalhos em sistemas modelo que relacionam a interação da nicotina com o complexo lipídeo, também estamos encaminhando experimentos no sentido de verificarmos e caracterizarmos as relações interagentes da nicotina e lavagem de filtro de cigarro com sistemas modelos do complexo DPPC/POPC/POPG nas proporções naturais encontradas, em pHs ácido $(\sim 6)$ básico $(\sim 10)$ com variação de temperatura. 


\section{Nanopartículas superparamagnéticas de óxido de ferro como marcadores celulares}

\subsection{Fundamentos Teóricos}

No presente capítulo, apresentamos os fundamentos teóricos para compreender o uso de suspensões coloidais à base de nanopartículas superparamagnéticas de óxido de ferro (NSOF) ${ }^{(42)}$ conhecida como ferrofluido, para marcação de células-tronco. O estudo está direcionado à análise quantitativa mediante a técnica de Ressonância Ferromagnética (RFM) da concentração de NSOF após marcação das células tronco CD133+(Figura 2.1.1).

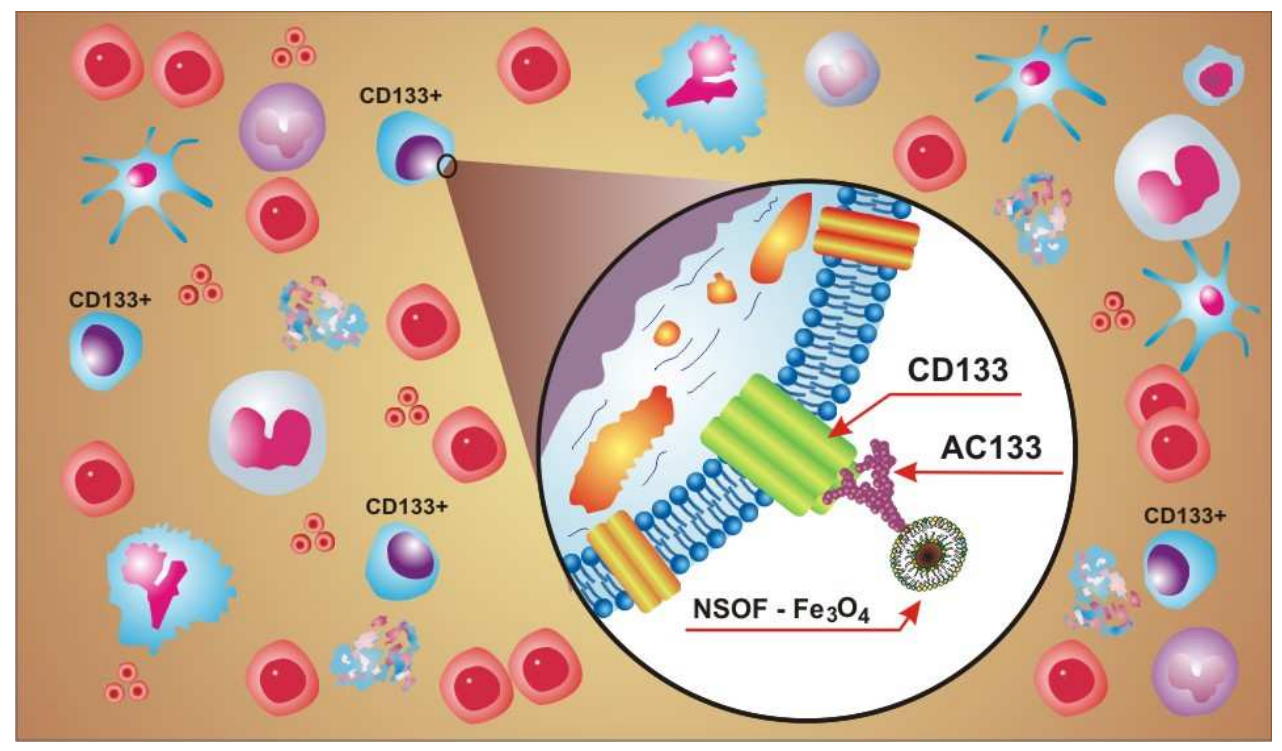

Figura 2.1.1 Esquema representativo da marcação de moléculas situadas na superfície de célula tronco $\mathrm{CD}_{133^{+}}$pelo anticorpo monoclononal anti-CD133 acoplado às nanopartículas superparamagnéticas de óxido de ferro (NSOF). 


\subsubsection{Introdução}

As chamadas nanopartículas ocupam a região de transição entre as moléculas e estruturas macroscópicas. Estes materiais têm sido recentemente empregados em muitas áreas do conhecimento tais como ciências dos materiais, física, química e biologia. ${ }^{(43)}$ Nanopartículas magnéticas são partículas notáveis por apresentarem o fenômeno de superparamagnetismo, ${ }^{(44)}$ fenômeno que surge como conseqüência do tamanho finito e efeito de superfície que dominam o comportamento magnético das mesmas. ${ }^{(45)}$ Partículas de materiais ferromagnéticos com dimensões críticas menores que 100 nm apresentam monodomínios magnéticos. ${ }^{(46)}$ Isto confere a estas partículas comportamentos idênticos aos átomos paramagnéticos, porém com momentos magnéticos extremamente grandes. ${ }^{(44)}$

Por causa de seu comportamento superparamagnético à temperatura ambiente, e condições particulares de estabilidade em água a pH neutro e salinidade fisiológica (ferrofluido biocompativel), as nanopartículas têm sido usadas como ferramentas tanto em diagnóstico quanto em terapias médicas. ${ }^{(47)}$

Em aplicações in vivo, as partículas magnéticas devem ser protegidas por matérias biocompatíveis a fim de prevenir formação de agregados, biodegradação e mudanças na estrutura original aos sistemas biológicos ${ }^{(48)}$ Partículas de óxidos de ferro tais como magnetita $\left(\mathrm{Fe}_{3} \mathrm{O}_{4}\right)$ ou sua forma oxidada maghemita $\left(\gamma-\mathrm{Fe}_{2} \mathrm{O}_{3}\right)$ são as mais empregadas. Fatores como biocompatibilidade 
e toxicidade fazem destes compostos importantes agentes em aplicações biomédicas.

In vitro, as restrições são menos rigorosas, principalmente quanto ao tamanho. No entanto, o maior desafio no uso de tais materiais está no método de preparação, principalmente no que diz respeito ao tamanho e consequentemente às propriedades magnéticas. ${ }^{(49)}$ Tais características são importantes, pois irão quantificar e qualificar o uso das partículas segundo sua estrutura tanto na indústria como na medicina.

Testes de toxicidade e alterações morfológicas, alterações citométricas, análise citogenética, cinética de eliminação e biodistribuição da suspensão coloidal no organismo têm sido estudados mediante técnicas espectroscópicas como a de Ressonância Magnética Nuclear (RMN), Ressonância Paramagnética Eletrônica (RPE), Fluorescência de Raios X, Microscopia de Luz, ${ }^{(50)}$ dentre outras.

Os chamados fármacos magnéticos constituem uma classe de fármacos usada no diagnóstico clínico através da técnica de imagem por ressonância magnética (IRM). Partícula nanomagnética é uma classe dos chamados agentes de contraste usada em Ressonância Magnética Nuclear (RMN). O uso de tais partículas tem como finalidade: ${ }^{(51)}$ (1) realçar o contraste da imagem entre o tecido doente e o tecido sadio e (2) indicar o estado da função orgânica ou da corrente sanguínea. Muitos materiais têm surgido com potencial para agente contrastante por IRM, podendo apresentar tanto características paramagnéticas quanto superparamagnéticas. ${ }^{(52)}$

Em se tratando de aplicabilidade, o uso de partículas nanoestruturadas apresenta-se como uma área em expansão. ${ }^{(53)}$ Em ciências biomédicas, tais partículas estão sendo utilizadas na marcação e isolamento de células com a finalidade de identificar e remover células tumorais, de separar seletivamente as 
chamadas células tronco, ${ }^{(54)}$ além de atuar na seleção de células apoptóticas geneticamente transformadas ou de organelas celulares. O uso de nanopartículas em vez de micropartículas magnéticas permite que se tenha um sistema de suspensão estável em relação à sedimentação na ausência de um campo magnético ${ }^{(55)}$

As células-tronco são extremamente raras nos tecidos em que ocorrem. A sua freqüência varia de $0,01 \%$ a $0,0001 \% .{ }^{(56)} \mathrm{A}$ identidade de células tão raras no meio de outras mais abundantes somente pode ser determinada com a utilização de recursos técnicos apropriados. A identificação das células-tronco é possível utilizando-se marcadores de superfície que, em conjunto, refletem as características biológicas e funcionais das células de forma geral e permitem, por outro lado, a individualização de um determinado tipo celular. ${ }^{(42)}$

Entre os diversos tipos de identificação e quantificação de células-tronco, tem-se usado nanopartículas superparamagnéticas de óxido de ferro (NSOF). ${ }^{(57)}$ Estas são acopladas a um anticorpo específico para assim evidenciar a expressão dos marcadores antígenos das células-tronco em estudo de identificação através da imagem molecular ${ }^{(58-61)}$ e por quantificação por Ressonância Ferromagnética. ${ }^{(56,57)}$

A Ressonância Ferromagnética (RFM) de nanopartículas é um experimento análogo ao de RPE exceto pelo fato que os spins eletrônicos interagem na rede ferromagnética (ou ferrimagnética) constituída de nanopartículas de monodominios magnéticos. Assim, o momento magnético total de cada nanopartícula precessiona em torno da direção do campo estático total, o qual é a soma do campo estático externo e as contribuições internas, tais como o campo anisotrópico da nanopartícula. ${ }^{(62)}$ Esta técnica é bastante adequada para o estudo e a detecção de nanopartículas ferromagnéticas ${ }^{(63,64)}$ As partículas, grãos 
de material magnético nano-estruturados representados por estruturas cristalinas de óxido de ferro descritas pela fórmula geral $\mathrm{Fe}^{3+}{ }_{2} \mathrm{O}_{3} \mathrm{M}^{2+} \mathrm{O}$, onde $\mathrm{M}^{2+}$ é um íon de um metal divalente tal como o ferro, manganês, níquel, cobalto ou magnésio, são dispersas em um fluido (fluído magnético). Para a síntese dos agentes de contraste, pequenos cristais de magnetita $\mathrm{Fe}^{3+}{ }_{2} \mathrm{O}_{3} \mathrm{Fe}^{2+} \mathrm{O}$ são predominantemente usados. ${ }^{(65)}$

\subsubsection{Ferrofluidos}

Ferrofluido é uma suspensão coloidal de pequenas partículas magnéticas dispersas em um líquido suporte. ${ }^{(66)}$ Uma das principais características de um ferrofluido é sua estabilidade. Um ferrofluido tem que ser estável frente a forças gravitacionais, gradientes de campo magnético e aglomeração de partículas causada por interação dipolar ou interação tipo van der Waals. As condições necessárias para sua estabilidade determinam o intervalo de tamanho das partículas constituintes. Elas devem ser suficientemente pequenas para que a agitação térmica e o movimento browniano possam se contrapor à aglomeração promovida por gradientes de campo. ${ }^{(67)}$ A ordem de magnitude aceitável para tamanhos das partículas pode ser obtida através da energia térmica $\left(k_{B} T\right)$, gravitacional $(\Delta \rho \mathrm{Vg})$ e magnética $\left(\mu_{0} \mathrm{M}_{\mathrm{p}} \mathrm{HV}\right)$, onde $\mathrm{k}_{\mathrm{B}}$ é a constante de Boltzman, T é a temperatura absoluta em Kelvins, $\Delta \rho$ é a diferença em densidade entre a partícula e o líquido que a contém, V é o volume das partículas, g é a aceleração da gravidade, I é a altura do líquido no campo gravitacional, $\mu_{0}$ é a permeabilidade do vácuo, $M_{p}$ é a magnetização da partícula e H é o campo 
magnético. Assumindo uma partícula típica de magnetita $\mathrm{Fe}_{3} \mathrm{O}_{4}$ de diâmetro d em um recipiente com altura de 0,05 $\mathrm{m}$ suspensa em um fluido com densidade relativa $\Delta \rho=4300 \mathrm{~kg} / \mathrm{m}^{3}$ a uma temperatura de $300 \mathrm{~K}$, calcula-se que o seu diâmetro é tal que, ${ }^{(66)}$

$$
\frac{\mathrm{k}_{\mathrm{B}} \mathrm{T}}{\Delta \rho \mathrm{Vgl}} \geq 1
$$

ou seja, d $\leq 15 \mathrm{~nm}$. Já o trabalho para mover uma partícula (p.ex. magnetita) com uma magnetização $M_{p}$ em um fluido de uma região onde o campo magnético tem um valor $\mathrm{H}$ para outra onde o campo nulo é tal que:

$$
\frac{k_{B} T}{\mu_{0} M_{p} H V} \geq 1
$$

Para uma magnetização de $4,46 \times 10^{5} \mathrm{~A} / \mathrm{m}$ (5600 Gauss) e um campo máximo de $8 \times 10^{4} \mathrm{~A} / \mathrm{m}(\sim 0,1$ Tesla), temos que $\mathrm{d} \leq 8 \mathrm{~nm}$. Isto mostra que a estabilidade em gradiente de campo parece ser o maior fator limitante para os tamanhos das partículas, pois exige que os mesmos sejam menores que $10 \mathrm{~nm} .^{(67)}$

Estes critérios para a estabilidade assumem que as partículas permaneçam pequenas para que não se aglomerem. Em tais condições, as partículas são como pequenos dipolos e as interações dipolares tendem a aglomerá-las. Assim, a distâncias muito curtas as forças de van der Waals entre as partículas são atrativas. A energia térmica necessária para opor-se à aglomeração de origem dipolar tem a mesma ordem de magnitude daquelas que se opõem à sedimentação. ${ }^{(68)}$ Porém, a aglomeração de origem van der Waals é irreversível, pois a energia necessária para separar duas partículas uma vez aglomeradas é muito grande. Isolar as partículas com uma camada de polímero surfatante (interação estérica) ou carregando-as eletricamente (repulsão Coulombiana) são 
as soluções encontradas para prevenir que as partículas fiquem muito próximas uma das outras. ${ }^{(68,69)}$

Os ferrofluidos do tipo surfactados são compostos por cadeias de polímeros (sais de ácidos graxos) com uma das terminação polar tipo carboxila, hidroxila ou amina, que pode adsorvê-lo na superfície da partícula magnética, e a outra com afinidade pelo líquido suporte. ${ }^{(70)} \mathrm{Em}$ ferrofluidos surfactados à base de ferritas magnéticas, o ácido dodecanóico é o agente estabilizante usado com o grupo carboxila ligado fortemente a superfícies da nanopartícula e a cadeia alifática (octano) voltada para o solvente. Em surfactados em meio aquoso, a extremidade da molécula do surfatante voltada para o solvente deve apresentar um grupo polar (carboxila, amino, hidroxila) participando de um equilíbrio tipo ácido-base, ionizando-se positiva ou negativamente numa faixa ampla de valores de $\mathrm{pH}$. Quando isto ocorre, a estabilidade do ferrofluido será determinada simultaneamente por repulsão estérica e eletrostática. Quando o grupo polar ioniza em $\mathrm{pH}$ próximo ao $\mathrm{pH}$ neutro e salinidade em torno de 0,9\% (condições fisiológicas), o ferrofluido pode ser considerado biocompatível e, portanto, adequado para uma grande variedade de aplicações biomédicas. Nos ferrofluidos iônicos as partículas são carregadas. Deste modo, íons que possuem uma grande densidade de carga positiva ou negativa mantêm-se afastados uns dos outros por repulsão eletrostática em meio aquoso. ${ }^{(71)}$

Algumas aplicações para os ferrofluidos surgem de seu caráter líquido e magnético. Estas características têm a vantagem do material ser deformável e assim adotar uma forma desejada, pode ser mantido em um lugar ou movê-lo por meio de gradientes de campo. ${ }^{(66)}$ Sendo composto de pequenas partículas em uma variedade de solventes, o material pode ser incorporado em vários tipos de substâncias ou material. Algumas dessas aplicações já foram industrializadas, 
tais como lubrificação com transferência de calor, impressão, acelerômetro, absorvedores de choques mecânico, etc ${ }^{(66)}$ Atualmente há um grande espectro de aplicações de ferrofluidos no campo da medicina e ciências biomédicas. ${ }^{(72,73)}$ Uma das aplicações mais comuns tem sido seu emprego como agente de contraste em imagem médica por meio de RMN. Neste caso, não só há uma melhora no sinal como também no contraste entre os tecidos. ${ }^{(74-76)}$ O transporte de moléculas ativas vem sendo também explorado através da marcação de células com partículas magnéticas, o que torna possível localizá-las e quantificá-las. ${ }^{(50)}$

A possibilidade de marcar células com agentes específicos que carregam uma partícula magnética fixando-a em um alvo é uma estratégia que pode ser explorada tanto no tratamento de tumores com conseqüente "queima" por meio de aquecimento local usando um campo magnético externo, mas também com o objetivo de reconhecimento. Nesta metodologia é preciso recobrir o material com agentes específicos. Nos últimos anos os anticorpos monoclonais têm sido bastante investigados e são os melhores candidatos para o recobrimento do material magnético. Obviamente, várias questões estão envolvidas neste procedimento como eficiência do processo de cobertura da nanopartícula magnética, estabilidade da ligação anticorpo-superfície da nanopartícula prérecoberta até o nível de comprometimento da estereoquímica do sítio ativo. Neste sentido, o uso de diversas técnicas de caracterização de nanoestruturas magnética recoberta com biomoléculas se faz necessário para o sucesso da metodologia. 


\subsubsection{Células tronco CD133 ${ }^{+}$}

Células-tronco são células capazes de multiplicar-se e diferenciar-se nos mais variados tecidos do corpo humano (sangue, ossos, nervos, músculos, etc.). Sua utilização para fins terapêuticos pode representar talvez a única esperança para o tratamento de inúmeras doenças.

As células-tronco existem em vários tecidos humanos, no cordão umbilical e em células embrionárias na fase de blastócito. Entre estas células-tronco temos as $\mathrm{CD}_{133^{+}}$.

A marcação de sistemas biológicos, sobretudo das chamadas célulastronco, com moléculas específicas vem se desenvolvendo com bastante sucesso nos últimos tempos. Isto se deve ao desenvolvimento do primeiro antígeno CD133 para ligação do anticorpo monoclonal AC133.

O antígeno CD133 é uma glicoproteína integral de membrana de $97 \mathrm{KDa}$, que pertence a uma família molecular de proteínas 5TM com cinco domínios transmembrana. ${ }^{(78)}$ Esta estrutura glicoprotéica (5-TM) caracteriza-se pela presença de um $\mathrm{N}$-terminal extracelular, dois loops curtos intracelulares, dois loops largos extracelulares e um C-terminal extracelular (Figura 2.1.2) ${ }^{(79,80)}$ Esta glicoproteína (5-TM) foi descrita como homologa a prominin (5-TM) de murinos (PROML 1) e filogeneticamente conservada em Drosophila, Caenorhabditis elegans e mamíferos, ${ }^{(79,81)}$ estando especialmente associada com prolongamentos de membrana plasmática e com desenvolvimento epitelial em mamíferos. ${ }^{(81,82)}$ 
CD133 pode ser um antígeno expresso em uma variedade de tecidos incluindo rim, pâncreas, placenta e fígado fetal, ${ }^{(87)}$ músculo esquelético e tecido neural humano, ${ }^{(83)}$ sugerindo importantes aplicações clínicas, com destaque para a utilização das células-tronco progenitoras $\left(\mathrm{AC}_{133^{+}}\right)$na engenharia tecidual, onde se revelariam alguns aspectos fundamentais concernentes à capacidade de auto-renovação das células-tronco somáticas entre outras aplicações. ${ }^{(84)}$

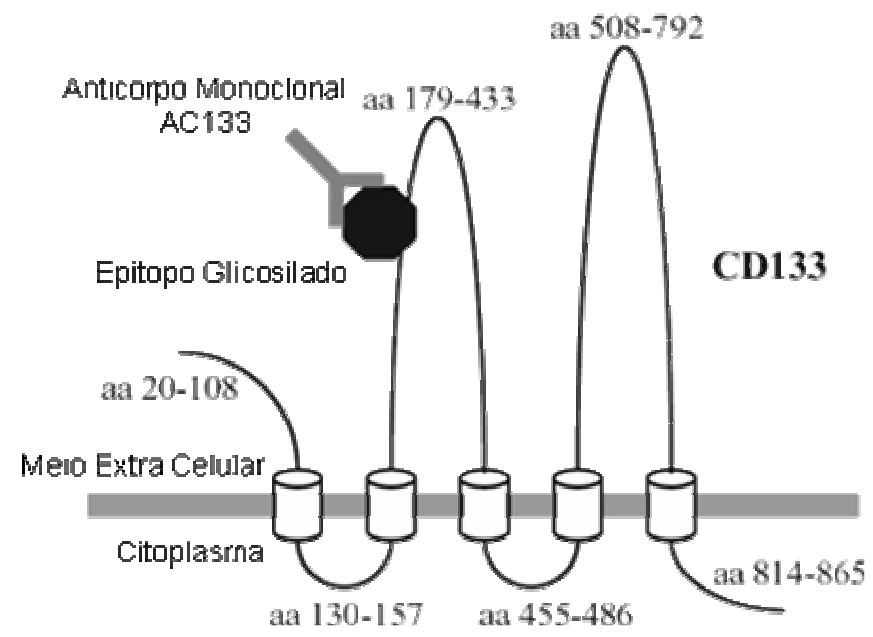

Figura 2.1.2 Diagrama da topologia predita da cadeia polipeptídica de CD133 bem como o anticorpo monoclonal AC133 ligado ao epitopo glicosilado na região extra celular. Os cilindros no diagrama representam regiões transmembranos ${ }^{(80)}$

As células $\mathrm{CD} 133^{+}$estão presentes na medula óssea, no sangue de cordão umbilical e no sangue periférico humano, sendo que frações $A C 133^{+}$da medula óssea mostraram-se eficientes modelos de xenotransplantes, possuindo precursores de granulócitos/macrófagos e de células dentríticas $\left(\mathrm{CD} 34^{+}\right)^{(85)}$

Células-tronco $\mathrm{CD}_{133^{+}}$, além de possuirem plasticidade hematopoética, ${ }^{\left({ }^{86}\right)}$ podem ser utilizadas em aplicações clínicas, sendo uma alternativa na utilização de células $\mathrm{CD}_{3} 4^{+}$, mais comumente utilizadas nos protocolos de transplantes. ${ }^{(87)}$ O isolamento, cultivo e expansão in vitro dessas células $\left(\mathrm{AC} 133^{+}\right)$ocorrem de maneira similar às células $\mathrm{CD} 34^{+},{ }^{(88)}$ além de grande parte delas co-expressarem 
o antígeno CD34, que é encontrado principalmente em células hematopoéticas e no endotélio vascular. ${ }^{(89)}$

Em humanos, o anticorpo monoclonal AC133 pode se ligar em diferentes epitopos, mas originalmente foi demonstrado que reage com antígeno de superfície celular expresso em células-tronco humanas e em vários progenitores celulares, incluindo aqueles derivados do sistema hematopoético. ${ }^{(85,88)}$ A expressão deste marcador também ocorre em outras células primitivas, tais como hemangioblatos e retinoblastoma. ${ }^{(90,85)}$

A expressão de células $\mathrm{AC} 133$ positivas $\left(\mathrm{AC} 133^{+}\right)$ocorre durante toda a ontogênese hematopoética humana, embora a proporção de sub-populações celulares seja diferente em todo o desenvolvimento humano. ${ }^{(91)}$

POWER et al. ${ }^{\left({ }^{92}\right)}$ relacionou doenças de artérias coronárias com a redução de frações de três diferentes subtipos de células $\mathrm{CD}_{133^{+}}$circulantes:

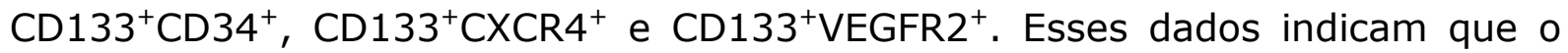
significado funcional de frações celulares $\mathrm{AC} 133$ positivas $\left(\mathrm{AC} 133^{+}\right)$transcendem o tecido hematopoético previamente sugerido. ${ }^{(83,85)}$

A expressão do antígeno CD133 também ocorre em progenitores neurais $(93,94)$ bem como, em cânceres originados desses sistemas ${ }^{(95)}$ tais como, tumores neuroectodermais. Destaca-se ainda que efetuou o isolamento de células-tronco neurais $\mathrm{AC}_{133^{+}}$, bem como a reconstituição cerebral de camundongos neonatos imunodeficientes (modelo de lesão neuronal). ${ }^{(93)}$ 


\subsubsection{Ressonância Ferromagnética}

Uma experiência de Ressonância Paramagnética Eletrônica (RPE) de partículas ferromagnéticas é denominada na literatura como Ressonância Ferromagnética (RFM) ou, mais precisamente, Ressonância Superparamagnética (RSP). Em amostras ferromagnéticas com estruturas de monodomínio, as partículas carregam momento magnético gigante e, sob efeito da agitação térmica, o sistema pode ser descrito como superparamagnético. Sistemas ferromagnéticos que estão no regime superparamagnético podem ser caracterizados como um sistema paramagnético com super spin eletrônico efetivo $S=1 / 2$, ou seja, um sistema de dois níveis.

A descrição fenomenológica da ressonância ferromagnética pode ser feita com base na dinâmica do vetor magnetização $\mathbf{M}$ em um campo magnético externo $\mathbf{H}$, cujo movimento de precessão é descrito por $^{(96)}$

$$
\frac{d}{d t} \vec{M}=\gamma\left(\vec{M} \times \vec{H}_{e f}\right)
$$

onde $\gamma$ é a razão giromagnética e $\mathbf{H}_{\text {ef }}$ é um vetor que inclui os campos estático (efetivo) e de microondas, bem como campos efetivos associados a torques internos sobre o sistema de spins ( $v$. abaixo).

Em sistemas ferromagnéticos, os spins vizinhos estão acoplados por meio da interação de intercâmbio (exchange). ${ }^{(97)}$ Assim, as excitações do sistema de spins correspondem a precessões coletivas em torno da posição de equilíbrio. A excitação de menor energia é o modo uniforme, no qual os spins precessionam 
em torno de $H$ mantendo-se paralelos uns aos outros, ou seja com a mesma fase, como ilustrado na Figura 2.1.3(a). Neste caso, a interação entre os spins não contribui para a freqüência de precessão, que é dada pela mesma expressão da Eq. (2.1.3). Devido à interação entre os spins, o sistema tem também modos coletivos nos quais a fase da precessão varia no espaço, chamados ondas de spin. A Figura 2.1.3(b) ilustra uma onda de spin, na qual a diferença de fase do primeiro ao último spin é $2 \pi$, correspondendo a um comprimento de onda. 0 modo uniforme é, na realidade, uma onda de spin com comprimento de onda infinito. À medida que o comprimento de onda diminui, aumenta o ângulo entre spins vizinhos e, por conseguinte, aumenta a contribuição da energia de intercâmbio para a energia da excitação.

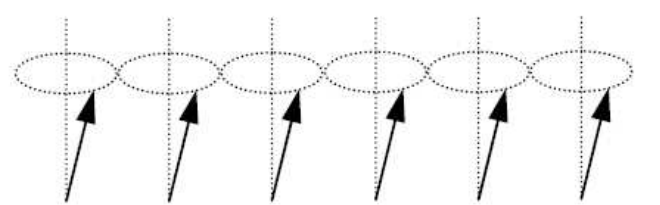

(a)

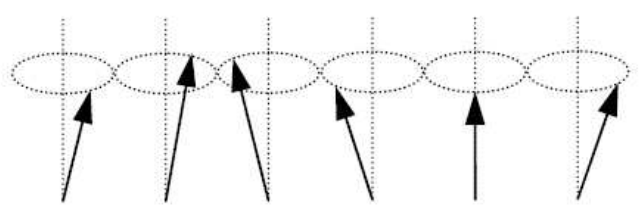

(b)

Figura 2.1.3 Desenho esquemático mostrando (a) o modo uniforme e (b) de onda de spin em sistema ferromagnético. ${ }^{(98))}$

Como em RPE, a idéia básica de um experimento de ressonância ferromagnética consiste em se aplicar um campo de microondas numa amostra situada num campo magnético estático $H_{0}$, e observar as linhas de absorção ressonante. O campo magnético da radiação de microondas é aplicado perpendicularmente ao campo estático, de modo que ele tende a perturbar os spins e desviá-los da posição de equilíbrio. Quando a freqüência da radiação está próxima da freqüência do modo uniforme, o campo de microondas produz o movimento de precessão dos spins e a amostra absorve energia da radiação. 
O campo magnético efetivo sentido pela nanopartícula magnética (monodomínio magnético com momentos magnéticos gigantes) é dado pela derivada primeira da densidade de energia livre da partícula com relação a projeção do vetor magnetização na direção correspondente ao estado de equilíbrio, ou seja, ${ }^{(99)}$

$$
H_{e f}=-\left.\frac{\partial \varepsilon}{\partial M}\right|_{e q} .
$$

A densidade de energia nesta equação tem contribuições de diferentes origens. A primeira delas é a interação Zeeman tradicional em ressonâncias magnéticas. Outra contribuição está relacionada a uma das características marcantes de materiais magnéticos que é o efeito de desmagnetização. Ele resulta dos campos criados pelos dipolos magnéticos não compensados nas superfícies da amostra. Por fim, existe ainda uma contribuição referente às interações entre o campo elétrico cristalino e os momentos magnéticos atômicos que tendem a dirigir a magnetização local para certas direções de grande simetria do cristal. Estas interações podem ser representadas por uma energia magnetocristalina, também chamada de energia de anisotropia. A origem microscópica da anisotropia reside no fato de que os spins dos elétrons interagem com os momentos orbitais, através da interação L.S, e as cargas eletrônicas dos orbitais sofrem a ação do campo elétrico cristalino. Sendo assim, o campo efetivo sentido pelos spins contém contribuições tanto dos campos externos aplicados à amostra, quanto dos campos efetivos que representam torques internos sobre os spins.

Portanto, na equação (2.1.2), a densidade de energia é dada por ${ }^{(99)}$

$$
\varepsilon=-\vec{M} \cdot \vec{H}_{0}+\varepsilon_{a}\left(K_{u}\right)+\frac{1}{2} \mu_{0} \vec{M} \cdot \vec{\eta} \cdot \vec{M} .
$$


O primeiro termo de (2.1.5) é a energia Zeeman com relação ao campo estático aplicado $H_{0}$, o segundo é a energia magnética anisotrópica considerando que a partícula possui simetria uniaxial e o último termo é a energia devido ao efeito de desmagnetização, onde $\eta$ é o tensor de desmagnetização da amostra, ${ }^{(100)}$ considerando que a partícula tem forma elipsoidal. Estes dois últimos são dependentes da orientação e provocam, portanto, a dependência angular do espectro de RFM.

A resposta do sistema de spins à aplicação do campo de microondas é representada através de uma susceptibilidade complexa, cuja componente imaginária $\left(\chi^{\prime \prime}\right)$ é a responsável pela potência média absorvida pela amostra, originando o espectro de RFM. O desenvolvimento teórico que evidencia este fato é análogo àquele utilizado no caso da RPE e encontra-se descrito em uma série de textos clássicos. ${ }^{(101,102)}$

\subsubsection{Características Físico-Químicas dos Óxidos de Ferro:}

\section{Magnetita e Maghemita}

A composição química de óxido de ferro (ferrites) tem a fórmula geral(103)

$$
\mathrm{Fe}_{2}^{3+} \mathrm{O}_{3} \mathrm{M}^{2+} \mathrm{O}
$$

onde $\mathrm{M}^{2+}$ é um íon metálico divalente tal como o ferro, manganês, níquel, cobalto ou magnésio. A fórmula acima representa a magnetita quando o íon do metal $\left(\mathrm{M}^{2+}\right)$ é o ferro ferroso $\left(\mathrm{Fe}^{2+}\right)$, ou seja;

$$
\mathrm{Fe}_{2}^{3+} \mathrm{O}_{3} \mathrm{Fe}^{2+} \mathrm{O} \rightarrow \mathrm{Fe}_{3} \mathrm{O}_{4}
$$


A magnetita possui estrutura de espinélio invertido, com metade dos os íons $\mathrm{Fe}^{3+}$ distribuídos nos sítios tetraédricos (sítio $[\mathrm{A}]$ ) e o dos íons $\left(\mathrm{Fe}^{2+}\right.$ ) ocupando os sítios octaédricos (sítio $\{\mathrm{B}\}$ ) do cristal com parâmetro de rede $\mathrm{a}_{\mathrm{o}}=$ $8,394 \AA$. Na temperatura ambiente há um salto eletrônico entre os sítios $\{B\}$ $\left(\mathrm{Fe}^{2+}, 3 \mathrm{~d}^{6}\right)$ para o sítio $[\mathrm{A}]\left(\mathrm{Fe}^{3+}, 3 \mathrm{~d}^{5}\right)$ com intervalo de tempo da ordem de $10^{-9}$ s. Este processo envolve baixa energia de ativação $\left(10^{-2} \mathrm{eV}\right)$ e alta condutividade elétrica $(1,34 \times 10 \Omega)$. A escala de tempo envolvida neste processo permite tratar o ferro formalmente como $\mathrm{Fe}^{2,5+}$, ou seja, igual número de íons férricos e ferroso. Por outro lado, a magnetita torna-se isolante em temperaturas abaixo de $120 \mathrm{~K}$. (94)

Para a magnetita os dois sítios catiônicos, um tetraédrico (ocupado por $\mathrm{Fe}^{3+}$ ) e o outro octaédrico (ocupado por $\mathrm{Fe}^{2+}$ ) formam a base para a interpretação das duas sub-redes magnéticas. Na temperatura do ambiente, os spins dos sítios tetraédricos e octaédricos estão alinhados de formas antiparalelas, com o sítio octaédricos ocupado com o dobro de átomos do que o sítio tetraédrico, conseqüentemente há um momento magnético líquido de $4 \mu_{B}$ $\left(\mu_{\mathrm{B}}\right.$, magneton Bohr). Este tipo de arranjo de spin pode ser representado do seguinte modo:

$$
\left\lfloor F e^{3+\uparrow} \int F e^{3+} \downarrow F e^{2+} \downarrow\right\} O_{4}-5 \mu_{B}+5 \mu_{B}+4 \mu_{B}
$$

Por outro lado a maghemita $\left(\gamma-\mathrm{Fe}_{2} \mathrm{O}_{3}\right)$ não possui um caráter fortemente magnético pois este oxido não possui estrutura estequiométrica do tipo espinélio, pelo fato de não existir $\mathrm{Fe}^{3+}$ suficiente para preenchimento de todos os sítios tetraédricos sitio $[A]$ e octaédricos sítio $\{B\}$. A estequiometria ideal corresponde a $x=1 / 3$ na série substitucional magnetita-maghemita.

$$
\left\lfloor F e^{3+}\right\rfloor\left\{F e_{1-3 x}^{2+} F e_{1-2 x}^{3+} V_{x}\right\} O_{4}
$$


onde [ ] representando o sítio tetraédrico, \{\} sítio octaédrico e $V$ vacância catiônica. Sendo que $x$ varia no intervalo $0 \leq x \leq 1 / 3$. A célula unitária da maghemita totalmente oxidada tem 21,33 íons $\mathrm{Fe}^{3+}$ e 32 átomos de oxigênio. Uma vez que a estrutura da magnetita e da maghemita são idênticas e que a magnetita tem 2,67 átomos de ferro a mais que a maghemita, existem 2,67 vacâncias por unidade de célula. Isto tem como conseqüência uma contração da célula unitária cúbica, provavelmente devido ao menor raio iônico do $\mathrm{Fe}^{3+}$ (65 pm) comparado ao $\mathrm{Fe}^{2+}(74 \mathrm{pm})$, nos sítios octaédricos. Caos as vacâncias estejam ordenadamente localizadas no sítio octaédrico s, a maghemita apresenta simetria tetragonal ( $a_{0}=8,340 \AA$ ), por outro lado se ocorrem aleatoriamente, prevalece à simetria cúbica $\left(a_{\circ}=8,350 \AA\right) \cdot{ }^{(43)}$

A maghemita $\gamma-\mathrm{Fe}_{2} \mathrm{O}_{3}$ e a magnetita $\mathrm{Fe}_{3} \mathrm{O}_{4}$, apresentam estruturas cristalina semelhantes, onde os oxigênios conformam uma estrutura cúbica de empacotamento compacto, cсp. A maghemita não pode apresentar a variedade de $\mathrm{Fe}^{2+} / \mathrm{Fe}^{3+}$, uma vez que o Ferro só aparece com valência $3^{+}$. Na maghemita, a relação entre os sítios $[A]$ e $\{B\}$ é de $0,6: 1$ e as longitudes de ligação são 2,094 $\AA$ e $1,876 \AA$, respectivamente. Ambos os materiais $\gamma-\mathrm{Fe}_{2} \mathrm{O}_{3}$ e $\mathrm{Fe}_{3} \mathrm{O}_{4}$ são ferrimagnéticos, apresentando magnetizações de saturação à temperatura ambiente de $M_{s}=90-92 \mathrm{meu} / \mathrm{g}$ e $M_{s}=70-80 \mathrm{meu} / \mathrm{g}$, respectivamente.

O objetivo principal do presente estudo é a analise quantitativa da concentração de NSOF $\left(\mathrm{Fe}_{3} \mathrm{O}_{4}\right)$, mediante a técnica de ressonância ferromagnética, onde estas nanopartículas se encontram acopladas a um anticorpo monoclonal específico (AC133) evidenciando a expressão dos marcadores antigênicos (CD133) das células-tronco $C D 133^{+}$de sangue de cordão umbilical humano. Este estudo é auxiliado com as técnicas de citometria de fluxo 
e Microscopia Eletrônica de Transmissão (MET) realizadas nos laboratório de nanotecnologia do Instituto de Ensino e Pesquisa Albert Einstein. As duas últimas abordagens foram necessárias tendo em vista que a análise de citometria de fluxo teve a finalidade de determinar se as células CD133 selecionadas por cromatografia de afinidade realmente expressaram a glicoproteina transmembrana conhecida como CD133, bem como estabelecer a eficiência do procedimento seletivo. A análise mediante a Microscopia Eletrônica de Transmissão (MET) foi pertinente para observar a presença de anticorpos acoplados às NSOF expressos na membrana das células

\subsection{Materiais e Métodos}

No presente capítulo apresentamos os materiais e métodos utilizados na metodologia de quantificação da carga de ferro após a marcação das células tronco $\mathrm{CD}_{133^{+}}$. A quantificação foi realizada mediante a Ressonância Ferromagnética(RFM).

\subsubsection{Marcador magnético: Descrição da amostra}

A marcação das células $\mathrm{CD}_{133^{+}}$foi realizada em protocolo in vitro utilizando anticorpo monoclonal anti-CD133 acoplado às NSOF de magnetita (Miltenyi Biotec), como marcador celular. Estas nanopartículas estão na forma de 
uma suspensão coloidal conhecida como ferrofluido ou fluido magnético contendo $0,1 \%$ de gelatina e $0,05 \%$ de acido de sódio, numa concentração de $200 \mu \mathrm{g}$ de $\mathrm{Fe} / \mathrm{mL}$, que equivale a $\sim 3 \times 10^{11}$ partículas de NSOF em $2 \mu \mathrm{L}$. $\mathrm{O}$ ferrofluido se encontra em condições fisiológicas, ou seja, pH neutro e salinidade de 0,09\% de Nacl. ${ }^{(104-108)}$ A dispersão e distribuição de tamanho das nanopartículas, baseada em uma distribuição log-normal, ${ }^{(109)}$ indicam um diâmetro médio de $(9,0 \pm 0,3)$ $\mathrm{nm}$.

\subsubsection{CÉLULAS-TRONCO CD133 ${ }^{+}$}

\section{A) Separação e coleta das células do sangue do cordão umbilical}

As células do sangue do cordão umbilical foram obtidas no centro de obstetricia do Hospital Israelita Albert Einstein, São Paulo-Brasil, de voluntários $(n=5)$ sob consentimento escrito (CEP - IEPAE $n^{\circ}$. 105/02). A coleta foi feita com material esterilizado através de punctura da veia do cordão umbilical no momento do nascimento e após o cordão umbilical ser removido. As células mononucleares foram purificadas por centrifugação em sistema Ficoll-Paque ${ }^{T M}$ Plus (GE Helthcare), de acordo com o método previamente publicado. ${ }^{(110)} \mathrm{O}$ procedimento foi realizado no laboratório de nanotecnologia do Instituto Israelita de Ensino e Pesquisa Albert Einstein (IIEPAE). 


\section{B) Marcação magnética e isolamento das Células CD133+}

Após a separação das células mononucleares, a população de células $\mathrm{CD}_{133^{+}}$foi purificada usando-se NSOF (anti-CD133 mAb-coupled da empresa Miltenyi Biotec). Para cada $10^{8}$ células foi adicionado $100 \mu \mathrm{L}$ de reagente bloqueador FcR, para inibir receptores Fc não específico mediante ligação de anticorpos às células alvos. Depois, as células foram marcadas por $100 \mu \mathrm{L}$ de CD133 totalizando um volume final de $500 \mu \mathrm{L} / 10^{8}$ células. Estas foram incubadas por 30 minutos num intervalo de temperatura de $4-8{ }^{\circ} \mathrm{C}$, seguidas por lavagem e resuspensas em $500 \mu \mathrm{L}$ de tampão. Em seguida, as células magneticamente marcadas foram separadas em uma coluna colocada em um campo magnético com separador apropriado. Neste processo, as células $\mathrm{CD}_{133^{+}}$magneticamente marcadas ficam retidas na coluna. A coluna foi, então, removida do campo magnético e as células retidas foram coletadas.

\subsubsection{Metodologia de quantificação das NSOF}

Descreveremos a metodologia sugerida para a análise quantitativa de NSOF nas células tronco $\mathrm{CD}_{133^{+}}$através da técnica de RFM. A metodologia para a quantificação dos NSOF, após a sua administração, é a seguinte: 
a) Realizar uma prévia visualização qualitativa das células tronco $\mathrm{CD}_{133^{+}}$ para observar a localização das NSOF, assim como a conservação da morfologia da célula, validando assim a posterior análise da quantificação.

b) Identificar os picos de RFM das NSPOF, entre outros que eventualmente estejam presentes e que não correspondem aos NSOF administrados.

c) Construir a curva de calibração do ferrofluido utilizando diferentes concentrações conhecidas as quais são proporcionais às áreas abaixo da curva de absorção da ressonância das NSOF. Esta curva permite uma interpolação indireta no processo de quantificação. Para a construção desta curva, os parâmetros utilizados na aquisição dos dados por RFM, assim como o volume da amostra de todas as concentrações, utilizadas devem ser iguais.

d) Após garantir a presença das NSOF nas células, após identificação do pico de ressonância correspondente aos NSOF e tendo em conta a curva de calibração realizamos a quantificação das NSOF nas diferentes amostras.

Realizar as medidas de RFM das amostras em estudo, onde os parâmetros utilizados na aquisição dos dados por RFM (não necessariamente os mesmos parâmetros da curva de calibração) assim como o volume das amostras em estudo devem ser iguais.

Realizar uma medida de RFM de uma concentração conhecida onde a área de absorção desta, deve ser interpolada com a área da curva de calibração (correspondente à concentração conhecida) para obter um "fator" que vai multiplicar as áreas obtidas por RFM das amostras em estudo e assim encontrar as concentrações correspondentes (calibração indireta). 


\subsubsection{Detecção das células marcadas - Citometria de Fluxo}

Após a separação das células CD133 por cromatografia de afinidade, as células CD133 foram caracterizadas por citometria de fluxo usando anticorpo monoclonal comercial (Becton Dickinson, San Jose, CA and Miltenyi Biotec). Para monitorar a expressão de marcador de superfície foi usado o anticorpo CD34 (clone 581) FITC - Conjugado, CD45 (clone 2D1) PerCPCy-5.5-conjugado e CD133/2 (clone: AC141) APC-conjugado e o respectivo controle isotipo IgG1 FITC-conjugado, IgG1 PerCP Cy-5.5-conjugado e IgG1 APC-conjugado.

As células foram incubada à $4{ }^{\circ} \mathrm{C}$ no escuro por 30 minutos e, em seguida, forma lavadas e fixadas com $1 \%$ de paraformaldeído. Eventos celulares fluorescentes foram registrados no citômetro de fluxo FACSARIA (BD Bioscience) e filtrados usando-se o software FACSDIVA. A população de $C D 45^{+}$foi analisada para a expressão de CD34 e CD133. As medidas de citometria de fluxo foram realizadas no laboratório de nanotecnologia do IIEAPE.

\subsubsection{Visualização qualitativa das $\mathrm{CD}_{133^{+}}$: Microscopia Eletrônica de Transmissão}

Após a separação das células CD133, sua população foi fixada em $2,5 \%$ de glutaraldeído em $0,2 \mathrm{M}$ de tampão cacodilato por 2 horas à $4{ }^{\circ} \mathrm{C}$. Os 
procedimentos rotineiros para as medidas de MET incluem lavagem, fixação, contraste, desidratação e inclusão em resina até completa polimerização. Seções ultrafinas foram obtidas com a ajuda de um Porter Blum utramicrotomo. As seções ultrafinas foram colocadas em uma grade de cobre e fotografadas usando um microscópico eletrônico por transmissão, PHILIPS CM/100 (Eindhoven, Netherlands). O estudo por MET foi realizado no Laboratório de nanotecnologia do IIEPAE.

\subsubsection{Medidas de Ressonância Ferromagnética}

As medidas de RFM foram realizadas em um espectrômetro de RPE Bruker ELEXSYS E580 operando na freqüência de microondas de $9.5 \mathrm{GHz}$. Foi usada uma cavidade retangular $\mathrm{TE}_{102}$ e freqüência de modulação do campo estático de $100 \mathrm{kHz}$. A potência de microondas e amplitude de modulação foram ajustadas em cada experimento para que obtivéssemos a melhor relação sinal-ruído sem distorção e/ou saturação do espectro. As medidas com variação de temperatura foram realizadas no mesmo equipamento com controle de temperatura feito através de um sistema Oxford ITC503 que permite variação da temperatura da amostra desde $4 \mathrm{~K}$ até temperatura ambiente. 


\subsection{Resultados e Discussão}

Neste capítulo, apresentamos os resultados relativos ao uso de nanopartículas de óxido de ferro para marcação das células tronco. Começamos com a caracterização magnética do marcador celular, para em seguida apresentar os resultados obtidos do processo de quantificação das NSOF após marcação das células tronco.

\subsubsection{Caracterização Magnética do marcador celular}

A caracterização das NSOF que apresentam diferentes propriedades físicoquímicas é fundamental para sua posterior aplicação médica. As propriedades físicas de um conjunto de monodomínios magnéticos em uma matriz diamagnética dependem tanto dos parâmetros que caracterizam o composto magnético, quanto da morfologia das nanopartículas. Estes sistemas de NSOF vem sendo estudados por diferentes métodos experimentais com o objetivo principal de explorar as propriedades desses materiais e assim aumentar seu potencial de aplicabilidade.

Nesta parte de nosso trabalho, caracterizamos uma suspensão coloidal de $\mathrm{NSOF}^{\left({ }^{(7)}\right.}$ através da técnica de RFM, este material é usado como marcador celular. Os experimentos de RFM são realizados da mesma maneira que 
experimentos tradicionais de RPE, exceto pelo fato de as amostras conterem monodomínios da ordem de alguns nanômetros. As medidas foram feitas com variação da temperatura para que ganhássemos informação acerca das propriedades superparamagnéticas da amostra e da dependência com a temperatura de parâmetros como a largura de linha pico-a-pico, fator g e número de spins.

O espectro de RFM do ferrofluido à temperatura ambiente está mostrado na Figura 2.3.1 e, como é típico para este tipo de sistema, apresenta uma linha larga centrada em torno de g 2. Uma análise da forma da linha pode ser empregada para calcularmos a constante de anisotropia magnetocristalina $K_{1}$ através de um método proposto por Griscom ${ }^{(11)}$ para o caso de monodomínios esféricos. No espectro de RFM (derivada da absorção), identificamos os campos de máxima $\left(H_{\max }\right)$ e mínima $\left(H_{\min }\right)$ intensidade do sinal e de máxima inclinação $\left(H_{\mathrm{ms}}\right)$ centrados, respectivamente, nos seguintes valores de $\mathrm{g}$ efetivo: $g_{[100]}=(2,22 \pm 0,01) ; \quad g_{[110]}=(1,98 \pm 0,02)$ e $g_{[111]}=(1,89 \pm 0,01)$. A separação em campo entre $H_{\max }$ e $H_{\min }$ é proporcional à anisotropia em campo $H_{\mathrm{a}}$. O valor de $\mathrm{K}_{1}$ foi determinado a partir de $H_{\mathrm{a}}$ (Figura 2.3.1) e das relações: $H_{a}=2 K_{1} / M_{s}$ e $H_{s}=$ $(4 \pi / 3) M_{s}$ (erg G $\mathrm{cm}^{-3}$ ), onde $H_{s}$ é o campo de saturação para um NSOF e vale cerca de 2 kG no caso do material ser magnetita ${ }^{(111)}$ Assim, o valor obtido para $K_{1}$ foi $(1,2 \pm 0,2) \times 10^{5}$ erg $\mathrm{cm}^{-3}$. 


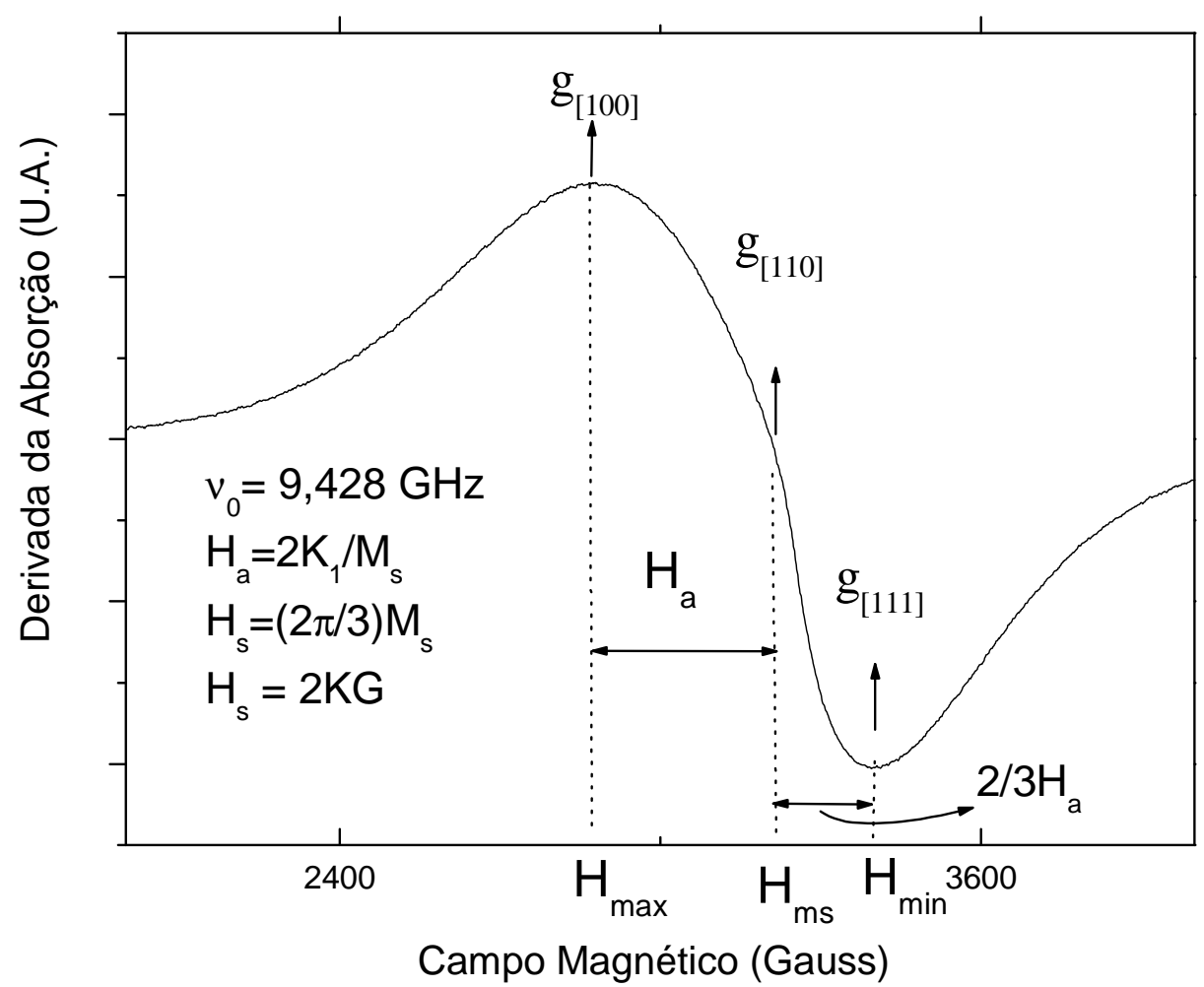

Figura 2.3.1 Espectro de RFM de NSOF medido em 9,428 GHz e à temperatura ambiente. As relações usadas para calcularmos $K_{1}$ estão mostradas no detalhe e os significados de $H_{\mathrm{a}}, H_{\mathrm{s}}, H_{\max }, H_{\min }$ e $H_{\mathrm{ms}}$ estão colocados no texto.

Os espectros de RFM em função da temperatura desde $4 \mathrm{~K}$ até temperatura ambiente estão mostrados na Figura 2.3.2. Os espectros apresentaram forma de linha assimétrica, sem alterações na sua intensidade pico-a-pico à medida que a temperatura foi elevada.

No entanto, em espectros de RFM, incluindo-se aqueles apresentados na Figura 2.3.2, tem-se observado a dependência com a temperatura do campo de ressonância e da largura de linha do espectro.(121) O campo de ressonância tem como base o campo magnético estático do espectrômetro, mas inclui também contribuições do campo de anisotropia magnética e do campo de desmagnetização Em um sistema macroscopicamente isotrópico, as partículas magnéticas estão orientadas ao acaso, assim os espectros de ressonâncias são mais estreitos. O campo magnético do espectrômetro tende alinhar os momentos 
magnéticos, porém, as flutuações térmicas restabelecem a desorientação e como resultado há um estreitamento no espectro de ressonância.

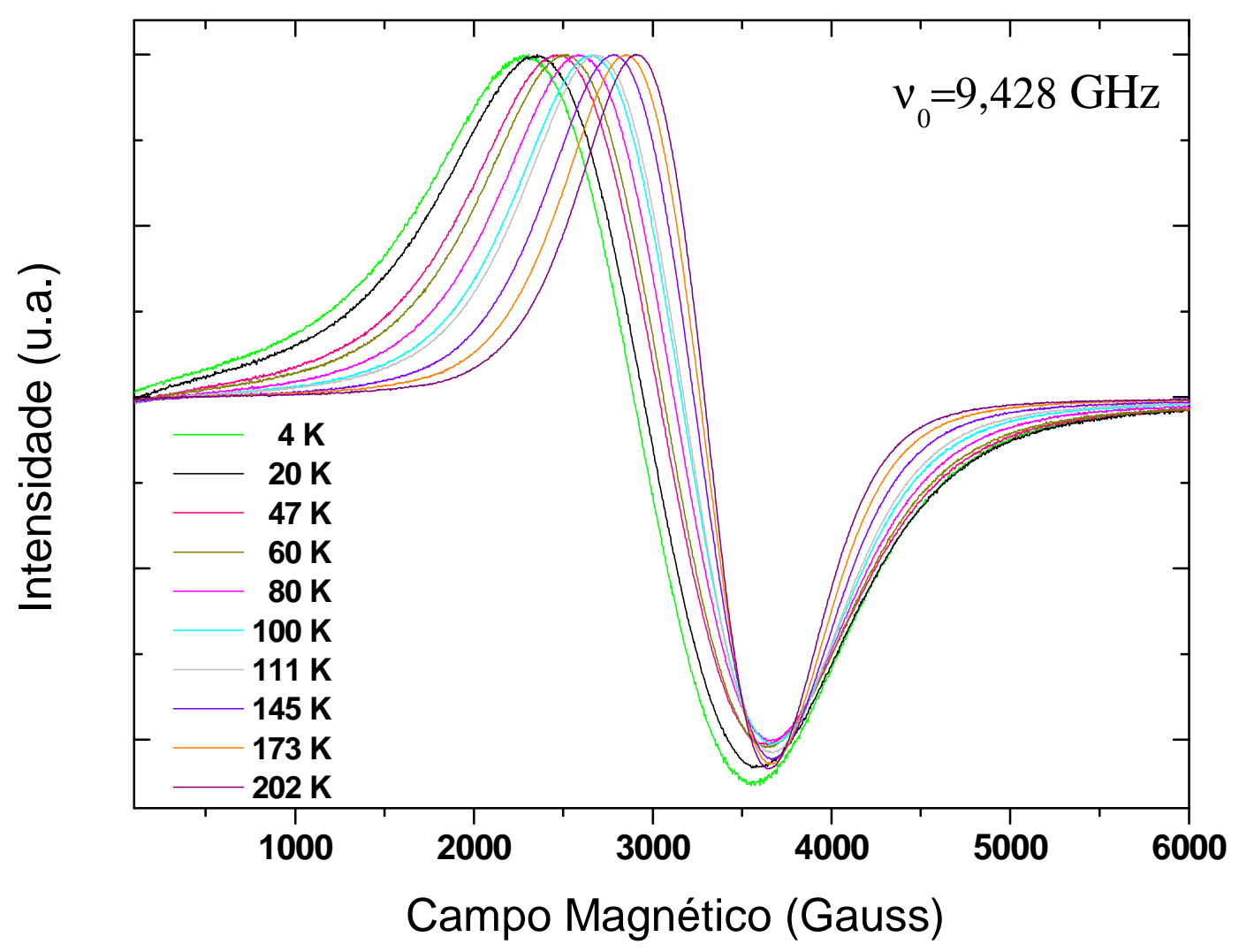

Figura 2.3.2. Dependência com a temperatura dos espectros de RFM medidos no intervalo de 4-300K.

Este comportamento pode ser entendido se adicionarmos um termo dissipativo na equação (2.3.1) que rege a dinâmica dos momentos magnéticos tendo já que há uma largura de linha finita. Na aproximação de baixo amortecimento, válido para sistemas paramagnéticos diluídos, todas as equações resultam em uma forma de linha Lorentziana. Considerando o caso de forte amortecimento (ferromagnético ou ressonância superparamagnética em baixa temperatura) as condições de ressonância são consideravelmente alteradas e a expressão para a forma de linha depende da forma do termo de amortecimento. Foi mostrado que o modo de ação da temperatura sobre os espectros de RFM em 
temperaturas baixas é melhor descrito pela equação fenomenológica de LandauLifschitz: ${ }^{(99,113,114)}$

$$
\frac{d}{d t} \vec{M}=\gamma(\vec{M} \times \vec{H})-\frac{\lambda}{|\vec{M}|^{2}}[\vec{M} \times(\vec{M} \times \vec{H})]
$$

$\lambda>0$ é o chamado fator de amortecimento. Se o campo magnético aplicado é suficiente para saturar a magnetização, a equação (2.3.1) leva à forma de linha de absorção normalizada:

$$
L L\left(H, H_{0}, \Delta_{H}\right)=\frac{\left(\Delta_{H} \cdot H_{0}^{2}\right)\left(\left(H_{0}^{2}+\Delta_{H}^{2}\right) \cdot H^{2}+H_{0}^{4}\right]}{\pi \cdot\left[H_{0}^{2} \cdot\left(H-H_{0}\right)^{2}+\left(\Delta_{H} \cdot H\right)^{2}\right]\left[H_{0}^{2} \cdot\left(H+H_{0}\right)^{2}+\left(\Delta_{H} \cdot H\right)^{2}\right]},
$$

onde o parâmetro largura de linha é dado por $\Delta_{H}=\lambda H_{0} /|\gamma \mathbf{M}|$. Contrastando com as formas de linhas Lorentziana ou Gaussiana, a equação acima é caracterizada por um campo de ressonância aparente dependente da largura de linha dado por $(99,113)$

$$
H_{r}=\frac{H_{0}^{2}}{H_{0}^{2}+\Delta_{H}^{2}} \sqrt{2 H_{0} \cdot \sqrt{\left(H_{0}^{2}+\Delta_{H}^{2}\right)}-H_{0}^{2}-\Delta_{H}^{2}}
$$

Isto mostra que o campo de ressonância diminui quando a largura de linha aumenta. Ou seja, a diminuição da temperatura leva a um alargamento de linha e deslocamento do campo de ressonância para valores menores, o que explica o comportamento observado em nossos espectros (Figura 2.3.2), o que indica que o comportamento das nanopartículas de óxido de ferro na amostra de interesse deve ser superparamagnético(115,116)

Para verificarmos a correlação entre posição da ressonância e largura de linha descrita pela equação (2.3.3), mostramos na Figura 2.3.3, a variação do campo de ressonância $\left(\delta H_{\text {ressonância }}=\left[H_{\text {ressonância }}\right]_{300 \mathrm{~K}}-\left[H_{\text {ressonância }}\right]_{\mathrm{T}}\right)$ em função da largura de linha pico-a-pico $\left(\Delta H_{\mathrm{PP}}=H_{\max }-H_{\min }\right)$ dos espectros de RFM nas várias 
temperaturas medidas. No inserto da Figura 2.3.3, mostramos a variação com a temperatura discutida acima para os parâmetros campo de ressonância e largura de linha.

Em geral, para um sistema de partículas superparamagnéticas apresentando uma distribuição estatística de formas e tamanhos, há uma relação simples entre o expoente $\mathrm{n}$ de $\delta H_{\text {ressonância }} \sim\left(\Delta H_{\mathrm{PP}}\right)^{\mathrm{n}}$ com a organização estrutural das partículas: ${ }^{(117)} \mathrm{n}=2$ para orientação parcial e $\mathrm{n}=3$ para partículas orientadas aleatoriamente na amostra. Do comportamento linear mostrado na Figura 2.3.3 e do ajuste linear feito, obtemos um valor de $n=3,1$, o que indica que o comportamento as nanopartículas de magnetita estão isoladas, aleatoriamente orientadas e são superparamagnéticas. 


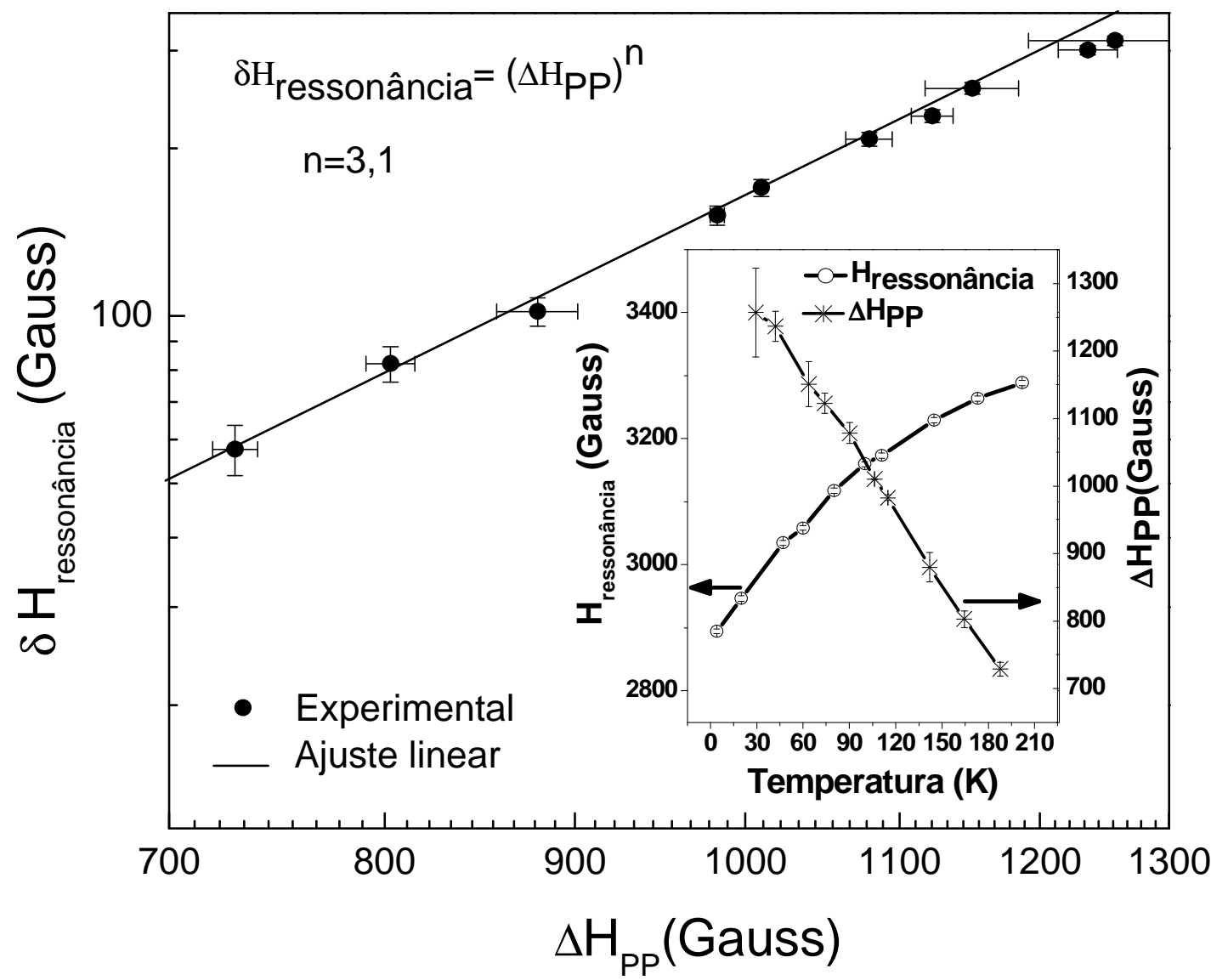

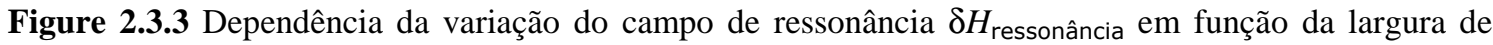
linha pico-a-pico $\Delta H_{\mathrm{PP}}$. No inserto, a variação explícita com a temperatura de $H_{\text {ressonância }}$ e $\Delta H_{\mathrm{PP}}$.

Portanto, a análise dos espectros de RFM dentro do intervalo de temperatura 4-300 K confirma o estado superparamagnético das nanopartículas de magnetita e mostra a forte dependência com a temperatura dos parâmetros $\Delta H_{\mathrm{PP}}$ e fator $\mathrm{g}$. 


\subsubsection{Detecção das Células Marcadas: Citometria de Fluxo}

Nas amostras estudadas, 98\% das células CD45 expressadas, caracterizam suas fontes hematopoiética. Após a seleção de CD45, a expressão de CD34 (progenitor marcado) foi analisada, as quais mostraram que $82 \%$ de todas as células $\mathrm{CD} 133^{+}$também expressaram CD34 (Figura 3.3.4A) indicando seu fenótipo progenitor. A especificidade do teste foi considerada adequada de acordo com um resultado negativo encontrado no controle isotipo mostrado na (Figura 3.3.4B) Por fim, observamos que a eficiência da seleção de CD133 determinada pela análise de citometria de fluxo foi de $83,3 \%$.

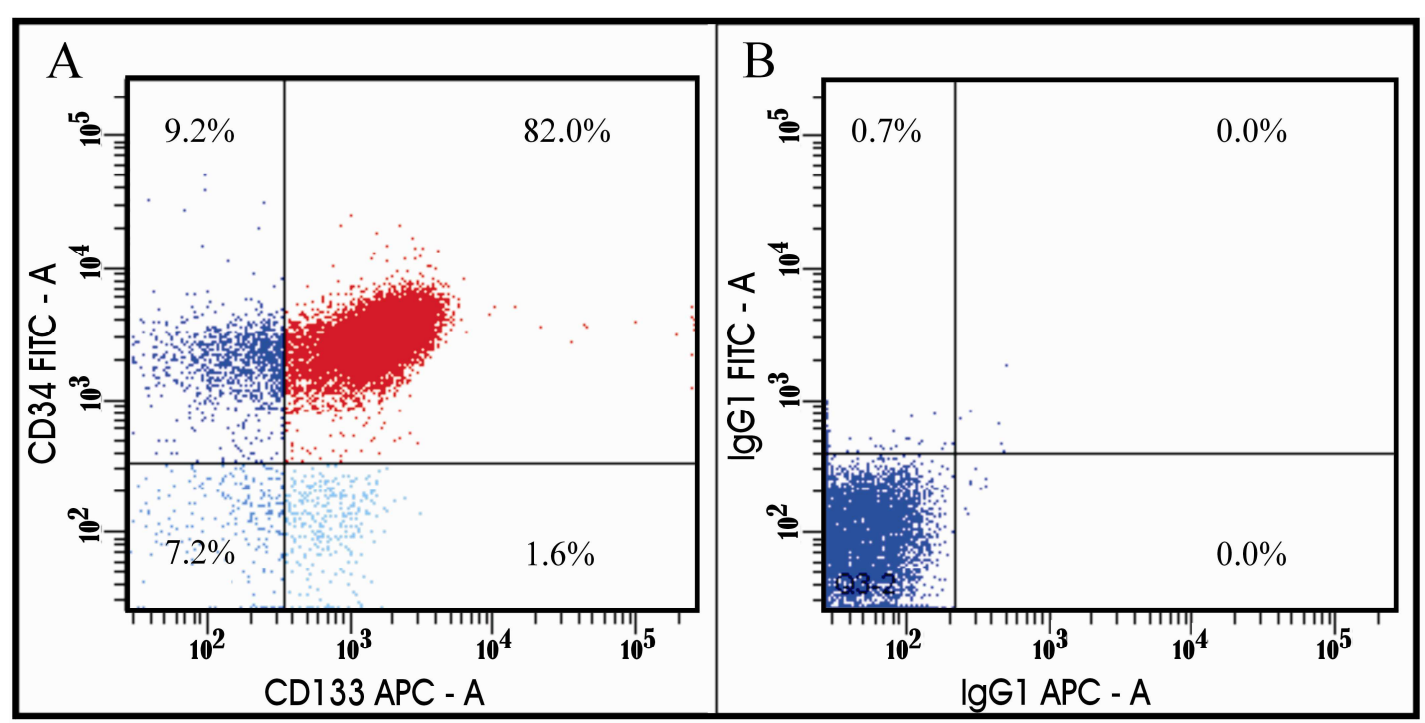

Figura 2.3.4 (A) O gráfico de citometria de fluxo mostra que CD133 ${ }^{+} / \mathrm{CD} 34^{+}(82 \%)$, CD133-/CD34 ${ }^{+}$ $(1,6 \%)$ and $\mathrm{CD}^{+} 4^{+} \mathrm{CD} 133^{-}(9,2 \%)$ (B) Gráfico do controle isotipo mostra que não há coloração específica. 


\subsubsection{Visualização Qualitativa das Células Marcadas: MET}

O destaque da densidade eletrônica granular nas superfícies das células mostram a presença de anticorpos monoclonal ligados aos NSOF expressados na membrana celular das células-tronco $\mathrm{CD} 133^{+}$como mostra as Figuras 2.3.5A, B e E. Este mesmo tipo de padrão não ocorre no grupo de células controle mostrados na Figura 2.3.5G, isto porque estas células não expressam o antígeno CD133 (Células-tronco CD133).

As células-tronco $\mathrm{CD}_{133^{+}}$são caracterizadas por uma morfologia com um núcleo ativo que ocupa quase toda a célula como mostra a Figura 2.3.5A e B. Analisando a Figura 2.3.5C, observamos a presença dos NSOF no citoplasma celular. Estas nanopartículas ligadas aos anticorpos expressados na membrana celular foram incorporadas no interior da célula por processos de endocitose mais precisamente por processo de pinocitose. Estas podem ser visualizadas na micrografia eletrônica através da densidade eletrônica da partícula mostrada na Figura 2.3.5C. 

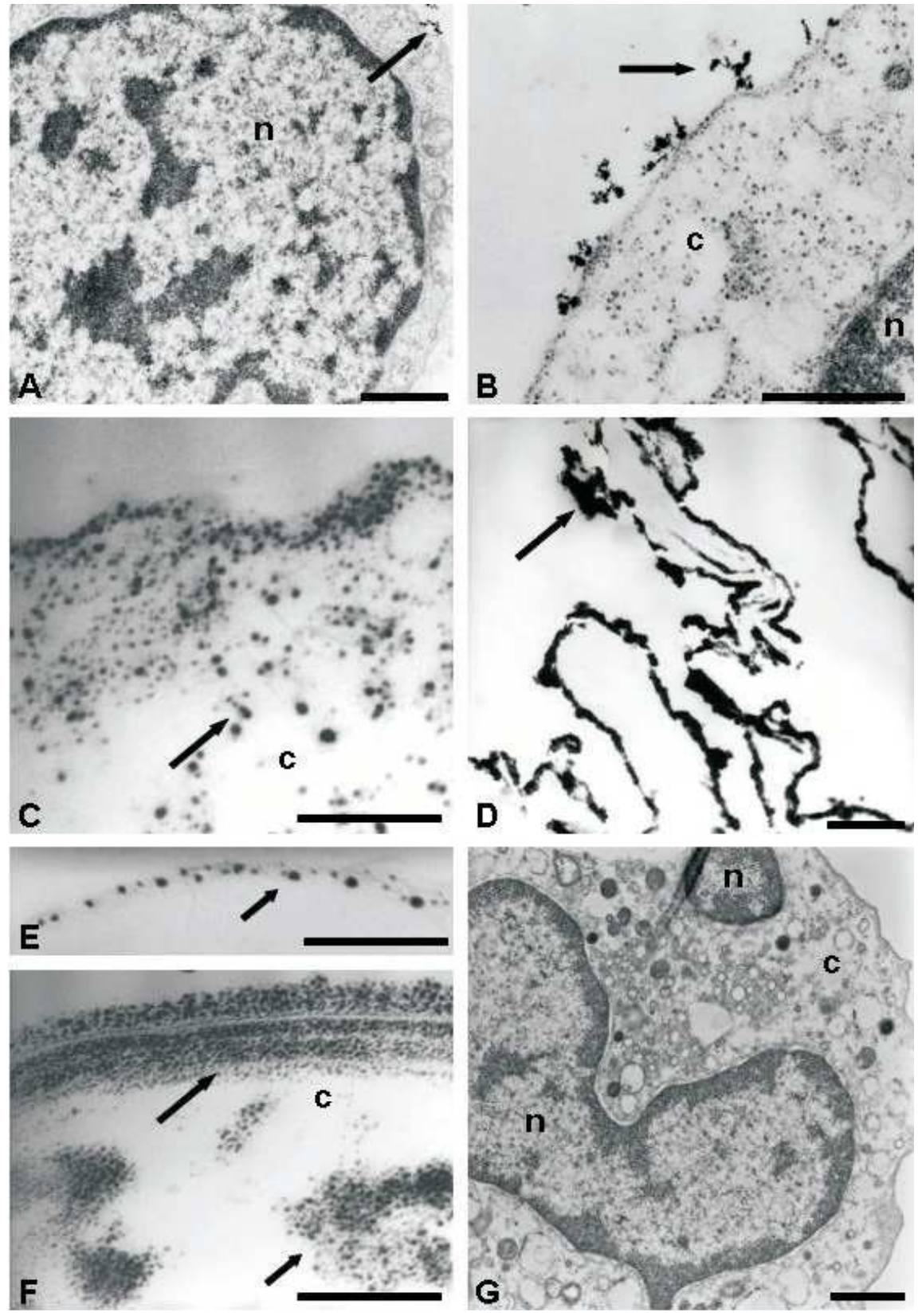

Figura 2.3.5 A-F MET das células-tronco CD133'; G, MET de células-tronco CD133- (controle); n,

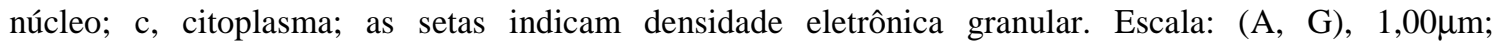
(B,C,E,F) $0,25 \mu \mathrm{m}$; D, $0,50 \mu \mathrm{m}$.

Experimentos prévios evidenciaram uma densidade eletrônica marcantemente forte na periferia do conteúdo celular sendo que a morfologia da célula $\mathrm{CD}_{133^{+}}$não foi conservada como mostra a Figura 2.3.5D. Isto ocorre provavelmente devido a má fixação do material por meio de $2,5 \%$ de 
glutaraldeído em 0,2M de tampão "cacodylate". A MET revela um excesso de densidade eletrônica de nanopartículas tanto na membrana celular como no citoplasma mostrados nas Figuras 2.3.5C e F

\subsubsection{Construção da curva de calibração}

De acordo à metodologia de quantificação é necessária a construção de uma curva de calibração. A linha característica no espectro de RFM do $\mathrm{Fe}^{+3}$ contido no ferrofluido à base de magnetita se encontra aproximadamente em $g=2,1$. A concentração de spins na amostra é calculada indiretamente através da área sob a curva de absorção de RFM no intervalo do campo magnético onde acontece a ressonância. Para determinar a constante de proporcionalidade entre a concentração do ferro e a intensidade de RFM foi montada a curva de calibração mostrada na Figura 2.3.6.

A curva de calibração foi montada usando diferentes concentrações do marcador celular desde 0,04 $\mu \mathrm{M}$ até $3,58 \mathrm{mM}$ em um volume de $2 \mu \mathrm{L}$. O espectro típico de RFM do Marcador celular é mostrado em detalhe da Figura 2.3.1. A forma de linha de absorção é típica de um espectro de monodomínios ferromagnéticos discutidos anteriormente. ${ }^{(111,118,114)}$ 


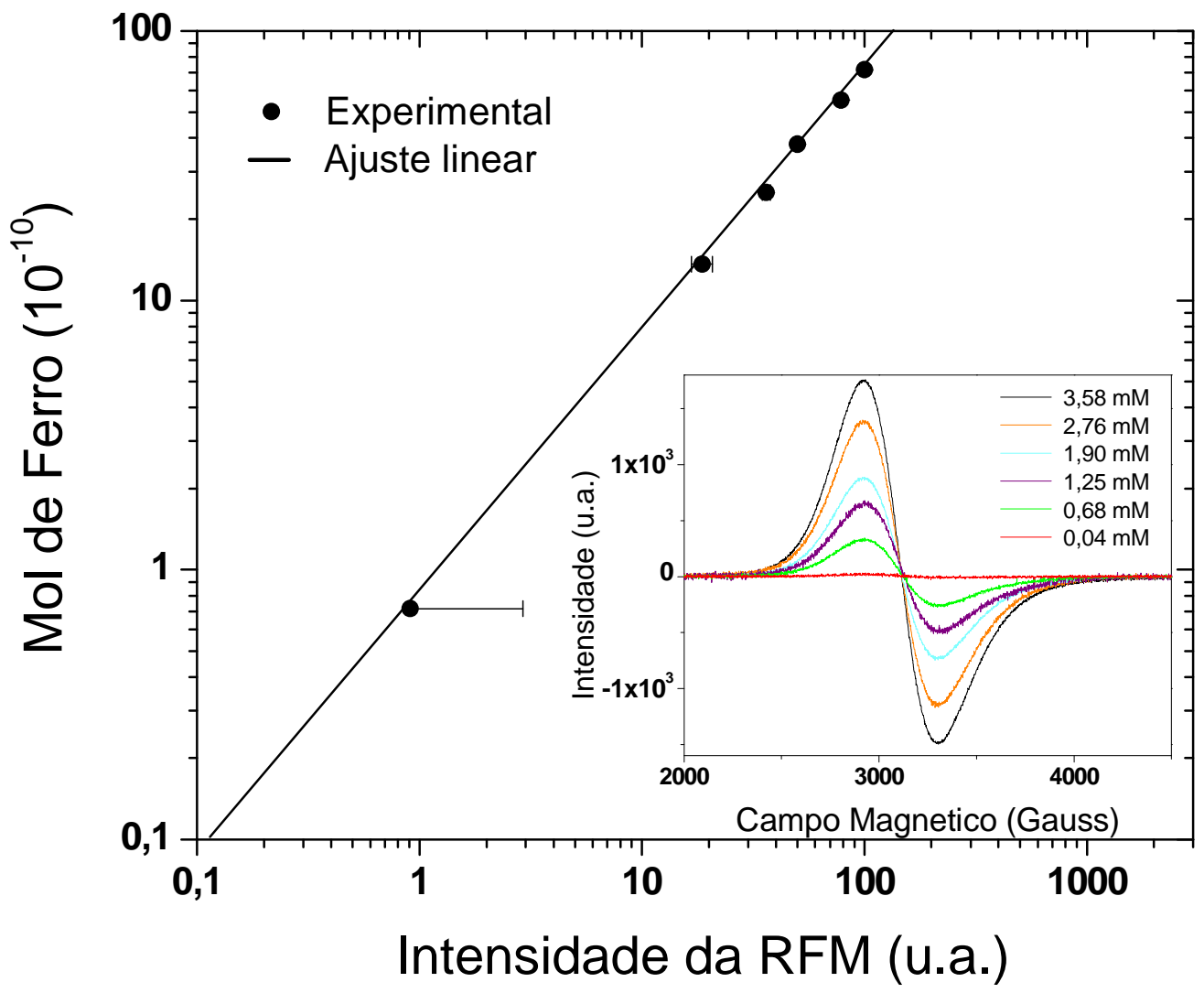

Figure 2.3.6 Curva de calibração de FMR da concentração de NSOF relacionada como a área da curva de absorção de ressonância em $\mathrm{g}=2,1$. No detalhe são apresentados os espectros típicos de FMR em diferentes concentrações da magnetita contida no marcador celular.

\subsubsection{Quantificação por FMR das células marcadas por NSOF}

Para evidenciar a expressão do marcador antigênico CD133 pela célula em estudo, realizou-se primeiramente o espectro de RFM somente dos grânulos magnéticos (Figura 2.3.7), ou seja, do anticorpo monoclonal anti-CD133 acoplado a microesferas magnéticas compostas por NSOF (Miltenyi Biotec) observando-se a ressonância em $\mathrm{g}=2,1$, a qual provém dos spins do $\mathrm{Fe}^{3+}$ que 
interagem entre si, porém, apresentando um comportamento superparamagnético $^{(74,120)}$ que caracteriza a presença de aglomerados. Este sinal consiste de uma forte absorção, cuja grande largura é atribuída à forte interação entre os íons de Ferro (cluster de íons $\mathrm{Fe}^{3+}$ aglomerados por uma forte interação de troca).

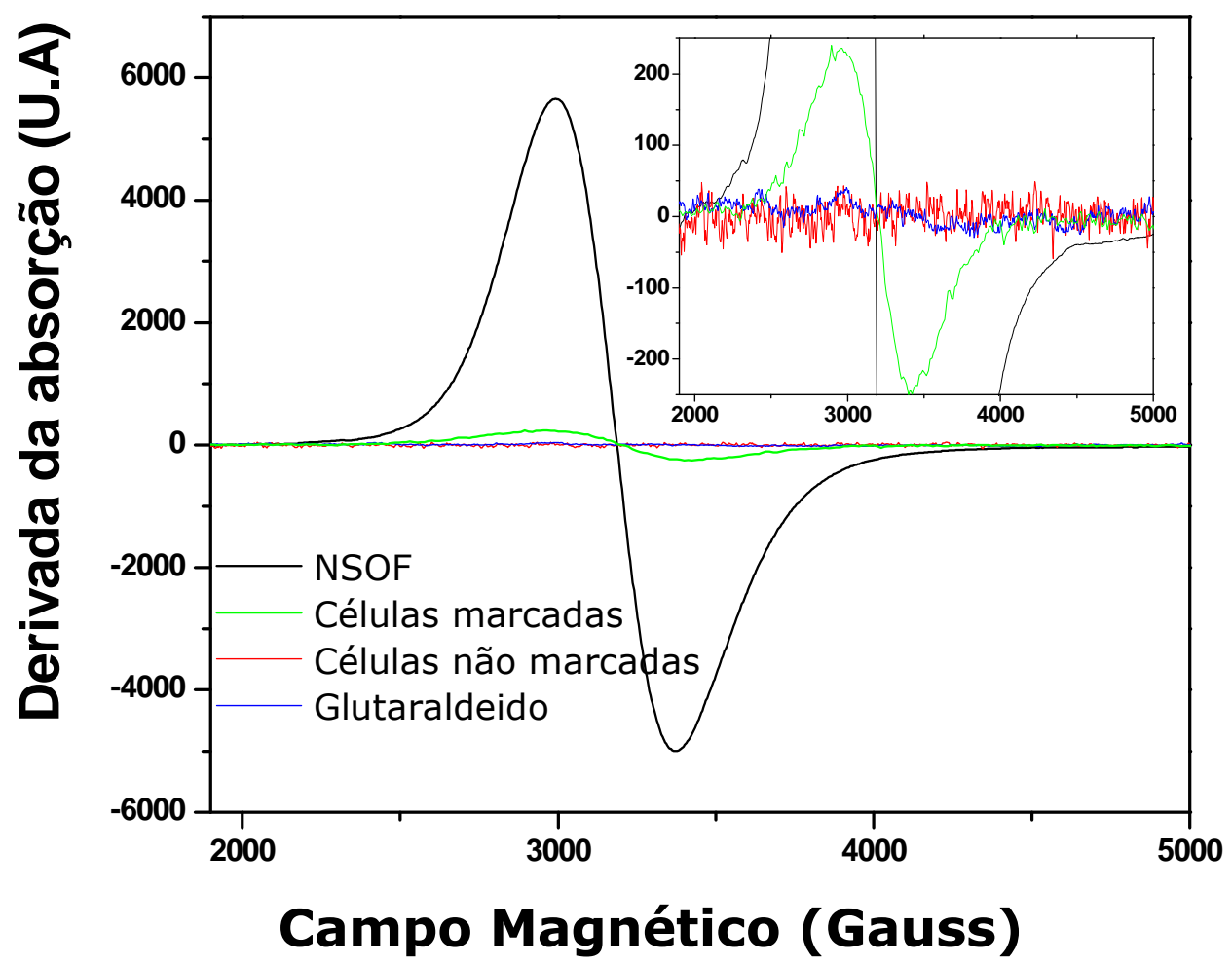

Figura 2.3.7 Espectros de RFM, mostrando a curva de absorção de ressonância do marcador das células, células não marcadas, células marcadas e glutaraldeído. No detalhe realçam-se os espectros com intensidade baixa.

Em seguida, foi obtido o espectro de RFM das células não marcadas $\left(\mathrm{CD} 133^{\circ}\right)$ que serviram como controle, observando que o espectro não apresenta nenhuma linha de ressonância. 
Posteriormente foi obtido o espectro de FMR das células marcadas $\left(\mathrm{CD} 133^{+}\right)$(correspondente a $0,64 \times 10^{5}$ células marcadas contidas num volume $2 \mu \mathrm{l})$ observando se uma linha de ressonância em $\mathrm{g}=2,1$ mostrando assim a presença das NSOF ligadas às células, sendo que estas se encontravam imersas em fixador de glutaraldeído $2,5 \%$.

Para garantir que as nanopartículas não estavam presentes no fixador, este foi retirado por meio de centrifugação (1200 rpm por $10 \mathrm{~min}$ ) das células marcadas aspirando-o sobrenadante cuidadosamente. Foi obtido o espectro de FMR do fixador extraído onde este mostrou a ausência FMR no glutaraldeído, evidenciando assim a ausência de SPION fixador como é observada na detalhe da Figura 2.3.7. Este resultado foi já evidenciado pelo estudo do MET onde observamos que o anticorpo acoplado às nanopartículas se encontra ligado às células CD133+.

A quantificação do número médio de partículas de ferro por célula foi determinada a partir da área sob a curva de absorção de ressonância dos espectros de RFM das células marcadas (Figura 2.3.7), através da interpolação com a curva de calibração mostrada na Figura 2.3.6 encontrando que se tem $1.7 \times 10^{-13} \mathrm{~mol}$ de ferro $(9,5 \mathrm{pg})$ ou $7,01 \times 10^{6}$ nanopartículas por célula.

Para realizar a quantificação das nanopartículas na célula mediante a técnica de RFM, faz-se necessário realizar uma visualização qualitativa das células marcadas. Isto foi necessário para assegurar-se que as nanopartículas acopladas estejam ligadas à superfície do antígeno das células-tronco fornecendo maior confiabilidade aos resultados quantitativos oriundos da RFM. O espectro de RFM mostrado na Figura 2.3 .8 correspondente a amostra de $\mathrm{CD}_{133^{+}}$que tínhamos comprovado uma forte na densidade eletrônica na periferia da célula. Além disso, a morfologia não foi conservada como comentado anteriormente. Em 
todas as células o sinal de RFM dos NSOF foi devido às nanopartículas acopladas aos anticorpos que por sua vez estavam ligados as células. A análise do sinal obtido para quantificação resulta em $1.64 \times 10^{-13} \mathrm{~mol}$ de ferro $(9,4 \mathrm{pg})$ ou $6,77 \times 10^{6}$ nanopartículas por célula, em boa concordância com os resultado obtidos com células bem marcadas (Figura 2.3.5. B). Portanto é necessária uma análise morfológica prévia ao da análise quantitativa por RFM.

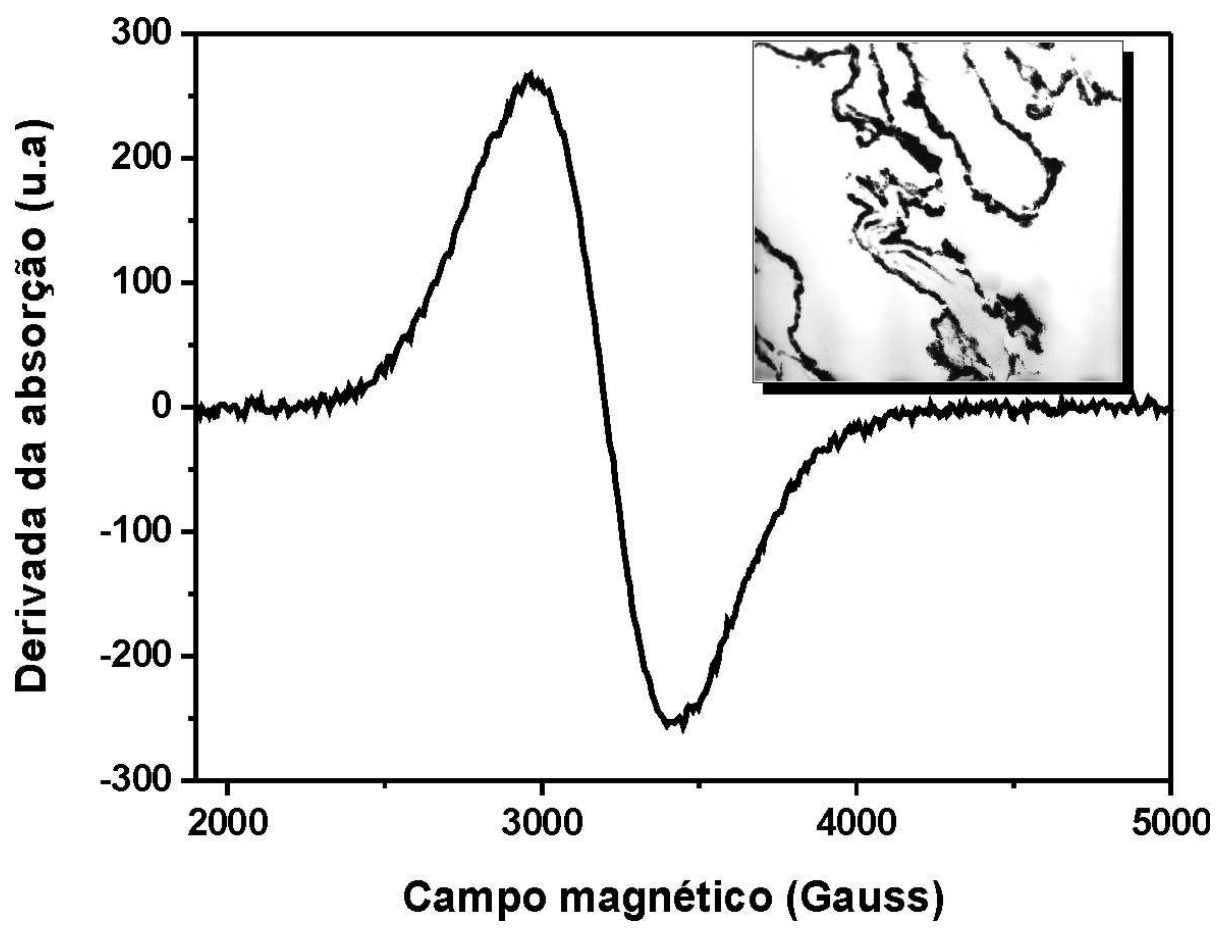

Figura 2.3.8 Espectro de absorção de RFM dos NSOF correspondente às celulas CD133+ que apresentam uma forte marcação eletrondensa na periferia da célula como é mostrada no inset, na micrografia 


\section{Conclusão}

A motivação principal dos estudos desenvolvidos neste trabalho foi aliar a Ressonância Magnética Eletrônica (RME), ou seja, RPE e RFM à investigação em nível molecular de sistemas de interesse biofísico.

$\mathrm{Na}$ primeira parte do trabalho usamos espectroscopia de RPE de marcadores de spin com o grupo repórter nitróxido aliada a um extenso processo de simulações espectrais baseadas no pacote de programas $\operatorname{NLSL}^{(19)}$ para investigar os efeitos dependentes da temperatura e pH da interação da nicotina sobre as propriedades físico-químicas de modelos de membrana constituídos separadamente, por dois dos principais fosfolipídios do chamados surfatantes pulmonares DPPC e POPC. Este estudo objetivou investigar o tipo de interação desempenhada pela nicotina em pH ácido de básico. Para tal usamos marcador de spin com o grupo repórter em diferentes posições da cadeia acila do fosfolipídio palmitoil-steroil(n-DOXIL)glicerolfosfatidilcolina [n-PCSL; $n=5$ e 16] para monitorar as mudanças na estrutura dinâmica da cadeia hidrofóbica dos fosfolipídios. Os resultados apontam que em pH ácido a nicotina interage na região da cabeça polar e tem ação penetrante em meio básico. Um resultado interessante é aquele que mostra que a nicotina perturba internamente a fase gel do DPPC no sentido de desestabilizá-la. Isto foi verificado através do uso indireto de ajuste espectral dos espectros experimentais medidos na presença do marcado 16-PCSL, que apresentou uma composição de duas componentes espectrais no intervalo de temperatura $30-40^{\circ} \mathrm{C}$ independentemente da presença 
de nicotina. Neste no intervalo de temperaturas onde se observou a coexistência de duas componentes um tratamento mais detalhado foi feito com base no modelo tradicional de van't Hoff para processos químicos envolvendo dois estados termodinâmicos.

Os gráficos de van't Hoff para as amostras sem e com nicotina apresentaram um comportamento linear dentro do intervalo de temperatura onde coexistem duas componentes nos espectros de RPE (Figura 1.3.10). Do coeficiente angular desses gráficos foi calculado os valores da variação de entalpia de transferência de um fosfolipídio da região associada à componente 2 (fluid-like) em relação à região da componente 1 (gel-like): $\Delta \mathrm{H}=\mathrm{H}_{2}-\mathrm{H}_{1}$. Obtivemos, desta maneira, $\Delta \mathrm{H}_{\mathrm{sem}}=+7,5 \mathrm{kcal} / \mathrm{mol}$ e $\Delta \mathrm{H}_{\mathrm{com}}=+16,0 \mathrm{kcal} / \mathrm{mol}$ para as amostras sem e com nicotina, respectivamente. Os valores de $\Delta \mathrm{H}$ determinados são positivos, indicando que o processo de transferência de uma molécula de fosfolipídio da fase gel-like para fluida é entalpicamente desfavorável. Além disso, $\mathrm{O}$ valor de $\Delta \mathrm{H}$ na presença de nicotina é aproximadamente o dobro daquele determinado na sua ausência.

Como o DPPC é o maior constituinte dos surfatante pulmonares e sua função biológica está diretamente ligada à diminuição da tensão superficial dos líquidos formados na superfície dos alvéolos pulmonares, a desestabilização em sua fase gel, portanto, fase fisiologicamente importante pode levar ao aparecimento de doenças respiratória em tabagistas. Vale lembrar que o experimento foi realizado em uma solução ácida onde a nicotina encontra-se predominantemente monoprotonada.

Este estudo não é conclusivo tendo em vista que deve-se realizar experimentos das amostras investigada neste trabalho nos $\mathrm{pH}^{\text {'s }}$ que não foram possível realizar até o presente momento e com o POPG nas mesmas condições 
de medidas. Ademais um sistema interessante para ser investigado seria a composição lipídica de todos os fosfolipídios na presença e ausência de nicotina.

Na segunda parte, nós investigamos no sentido de quantificar célulastronco de cordão umbilical marcado com nanopartículas superparamagnéticas de óxido de ferro (NSOF), previamente preparada no laboratório de nanotecnologia do Instituto Israelita de Ensino e Pesquisa Albert Einstein (IIEPAE). Este trabalho é resultado de uma colaboração entre nosso grupo e o grupo do Dr. Lionel Gamarra Contreras, atualmente pesquisador do Hospital Israelita Albert Einstein (São Paulo). Especificamente, O estudo foi no sentido de analisar quantitativamente, mediante a técnica de Ressonância Ferromagnética (RFM), a concentração de NSOF após marcação das células tronco CD133. Primeiro nós apresentamos a metodologia sugerida para a análise quantitativa de NSOF nas células tronco $\mathrm{CD}_{133^{+}}$através da técnica de RFM. A metodologia para a quantificação dos NSOF, trabalho a ser publicado. Seguido, caracterizamos uma suspensão coloidal de NSOF, ${ }^{(24)}$ através da técnica de RFM, este material é usado como marcador celular. Os experimentos de RFM são realizados da mesma maneira que experimentos tradicionais de RPE, exceto pelo fato de as amostras conterem monodomínios da ordem de alguns nanômetros. As medidas foram feitas com variação da temperatura para que ganhássemos informação acerca das propriedades superparamagnéticas da amostra e da dependência com a temperatura de parâmetros como a largura de linha pico-a-pico, fator g e número de spins (Artigo aceito para publicação e exposto no apêndice $A$ desta tese.) Por último, aplicamos o método de quantificação das células como mostra o artigo publicado e exposto no apêndice $B$.

Como perspectivas futuras, sugerimos após completar a série de experimentos de interação de nicotina em sistemas modelos de surfatantes 
pulmonares, investigar complexos surfatantes sintéticos disponíveis a fim de correlacionarmos os tipos de interação investigadas nos dois sistemas. Em se tratando de células-tronco, outros sistemas interessantes poderiam ser investigados principalmente em sistemas In vivo. 


\section{REFERÊNCIAS}

1. EATON, G. R. Foundations of modern EPR. Singapore: World Scientific, 1997. p. 548

2. GORCESTER, J. FREED, J. H. Two-dimensional fourier-transform electron-spinresonance spectroscopy. Journal of Chemical Physics, 85, n. 9, p. 5375$5377,1986$.

3. BERLINER, L. J. Spin Labeling Theory and Applications II. New York: Academic Press Academic Press, 1979.

4. CREUWELS, L. A. J. M. VAN GOLDE, L. M. G.; HAAGSMAN, H. P. The pulmonary surfactant system:biochemical and clinical aspects. Lung, v. 175, n. 1, p. 1-39, 1997.

5. NAGA, K.; et al. Interactions of serum with lung surfactant extract in the bronchiolar and alveolar airway models. Respiratory Physiology \& Neurobiology, v. 157, n. 2-3, p. 411-424, 2007.

6. SUVASREE, M.; et. al. Physicochemical studies on goat pulmonary surfactant. Biophysical Chemistry, v. 134, n. 1-2, p. 1-9, 2008.

7. LYRA, P. P.R.; DINIZ, E. M. A. The importance of surfactant on the development of neonatal pulmonary diseases. CLinics, v. 62, n.2, 181-190, 2007.

8. JOBE, A. H. Why Surfactant works for respiratory distress syndrome. NeoReviews v.7, n.2, p.e95-e106, 2006.

9. RICHARD, H. Sustained alterations in postnatal respiratory function following sub-optimal intrauterine conditions. Reproduction, Fertility and Development, v.7,n. 3, p.431-441, 1995.

10. WIRTZ, H.R.W.; SCHMIDT, M. Acute influence of cigarette smoke on secretion of pulmonary surfactant in rat alveolar type II cells in culture. European Respiratory Journal, v. 9, n.1, p.24-32, 1996. 
11. ROSEMBERG, J. Nicotina droga universal. p. 16-18. <http://www.inca.gov.br/tabagismo/publicacoes/nicotina.pdf> acesso em 25/03/2008.

12. ROSEMBERG, J. Nicotina droga universal. p. 72-78. < http://www.inca.gov.br/tabagismo/publicacoes/nicotina.pdf > acesso em 25/03/2008.

13. SU, T.; et al. Human Cytochrome P450 CYP2A13: Predominant Expression in the Respiratory Tract and Its High Efficiency Metabolic Activation of a Tobaccospecific Carcinogen, 4-(Methylnitrosamino)-1-(3-pyridyl)-1-butanone ${ }^{1}$.Cancer Research, v. 60, n. 11, p. 5074-5079, 2000.

14. BRAIN, D.; et al. Structure of the human lung cytochrome P450 2A13. The Journal of Bilogical Chemistry, v. 282, n. 23, p. 17306-17313, 2007.

15. ROSEMBERG, J. Nicotina droga universal. p. 79-82. < http://www.inca.gov.br/tabagismo/publicacoes/nicotina.pdf > acesso em 25/03/2008.

16. BURR, M.; KOSHLAND, D. E. Jr. Use of "reporter groups" in structure-functions studies of proteins. Proceedings of the National Academy of Sciences. $v$. 52,n. 4, p.1017-1124, 1964.

17. EARLE, K. A.; BUDIL, D. E. Calculing slow-motion ESR spectra of spin-labeled. In: SHULAMITH, S. Advanced ESR methods in polymer research. New York: John Willey \& Sons, Inc. 2006. p. 53-83.

18. FREED, J. H. Theory of slow tumbling ESR spectra for nitroxides. In: BERLINER, L. J. Spin labeling: theory and applications. New York: Academic Press, 1976. p. 53-132.

19. BUDIL, D. E. et. al. Nonlinear-least-squares analysis of slow-motion EPR spectra in one and two dimensions using a modified levenberg-marquardt algorithm. Journal of Magnetic Resonance, v. 120, n.2, p. 155-189, 1996.

20. SCHNEIDER, D. J. FREED, J. H. Calculating slow motional magnetic resonance spectra: a user's guide. In: BERLINER, L. J.; REUBEN, J. Biological magnetic resonance. New York: Plenum Publishing, 1989. p. 1-76. v.8 
21. KUBO, R. A. Stochastic theory of lineshape. In: SHULER, K. E. Stochastic processes in chemical physics, advances in chemical physics. New York: Wiley, 1969. p. 101-127.

22. FREED, J. H. BRUNO, G. V.; POLNASZEK, C. F. Electron spin resonance lineshapes and saturation in the slow motional region. Journal of Physical Chemistry. v. 75, n. 22, p. 3385-3399, 1971.

23. FREED, J. H. ESR relaxation and lineshapes from the generalized cumulant and relaxation matrix viewpoint. In: MUUS, L. T.; ATKINS, P. W. Electron spin relaxation in liquids. New York: Plenum, 1972. p. 165-191.

24. GLARUM, S. H. MARSHALL, J. H. ESR of the Perinaphthenyl Radical in a Liquid Crystal. Journal of Chemical Physics, v. 44, n. 8, p. 2884-2890, 1966.

25. CAMPBELL, I. D. DWEK, R. A. Biological Spectroscopy. Menlo Park: The Benjamin/Cummings Publishing Company, 1984.

26. RISKE, K. A. et. al. Temperature and ionic strength dependent light scattering of DMPG dispersions. Chemistry and Physics of Lipids, v. 89, n. 1, p. 3144, 1997.

27. BASSO, L. G. M. Interações de fármacos fnti-malária com modelos de membrana. 2009150 p.Tese (Mestrado) - Instituto de Física de São Carlos, Universidade de São Paulo, São Carlos, 2009.

28. EARLE, K. A. et. al. 250-GHz Electron spin resonance studies of polarity gradients along the aliphatic chains in phospholipid membranes. Biophysical Journal, v. 66, n. 4,3-1221, 1994.

29. NAIR, M. K. et al. Biomembrane permeation of nicotine: Mechanistic studies with porcine mucosae and skin. Journal of Pharmaceutical Sciences, v. 86, n.2, p. 257-262, 1997.

30. HUANG, C-H, LI, S. Calorimetric and molecular mechanics studies of the thermotropic phase behavior of membrane phospholipids .Biochimica et Biophysica Acta, V. 1422, n. , p. 273-307, 1999.

31. KOYNOVA, R.; CAFFREY, M. Phases and phase transitions of the phosphatidylcholines. Biochimica et Biophysica Acta, v. 1376, n.1, p. 91145, 1998. 
32. WITTERBORT, R. J.; SHIMIDT, C. F.; GRIFFIN, R. G. Solid-state carbon-13 nuclear magnetic resonance of the lecithin gel to liquid-crystalline phase transition. Biochemistry, v. 20 n. 14, p. 4223-4228, 1981.

33. MARSH, D. Molecular motion in phospholipid bilayers in the gel phase: long axis rotation. Biochemistry, 1980, 19 (8), 1632-1637

34. RISKE, K. et. al. Lipid Bilayer Pre-Transition as the Beginning of the Melting Process: a Periodic Melting. Biochimica et Biopysica Acta, v. 96, n.3, p.458a-458a, 2009.

35. WITTEBORT, R. J. et a. Carbon-13 Nuclear Magnetic Resonance Investigations of Phase Transitions and Phase Equilibria in Pure and Mixed Phospholipid Bilayers?. Biochemistry, v. 21, n. 14, p. 3487-3502, 1982.

36. SCHWARTZ, J. L. Methods of smoking cessation. Medical Clinics of North America, v. 76, n. 2, p. 451-476, 1992.

37. SANTAREN, J. et. al. Thermal and 13C-NMR study of the dynamic structure of 1-palmitoyl-2-oleyl-sn-glycero-3-phosphocholine and 1-oleyl-2-palmitoyl-snglycero-3-phosphocholine in aqueous dispersions". Biochimica et Biophysica Acta, v. 687,n. 2, p. 231-237, 1982.

38. BANERGE, R. Surface Chemistry of the lung surfactant system: Techniques for in vitro evaluation. Current Science, v.82, n.4, 2002; p. 420-423, 2002.

39. DEVENDRAL, G.; SPRAGG, R. G. Lung surfactant in subacute pulmonary disease. Respiratory Research, v. 3, n. 1, p. 1-4, 2002.

40. SCOTT, J. E. The pulmonary surfactant: impact of tobacco Smoke and related compounds on surfactant and lung development. Tabacco Incduced Diseases, v. 2, n.1, p, 2-25, 2004.

41. BERNER, B.; et. al. A transdermal nicotine system: feasibility studies. Journal of Controlled Release, v. 20, n. 1, p. 13-20, 1992.

42. PAVAN, L. F. et al. Ultrastructural characterization of $C D 133^{+}$stem cells bound to superparamagnetic nanoparticles: possible biotechnological applications. Journal of Microscopy, v. 231, n. 3, p. 374-383, 2008. 
43. GAMARRA CONTRERAS, L. F. Síntese e caracterização de nanopartículas superparamagnéticas de óxido de ferro com aplicação ao estudo dacinética de eliminação e biodistribuição em ratos 2006129 p. Tese (Doutorado) - Instituto de Física, Universidade de São Paulo, São Paulo, 2006

44. BEAN, C. P.; LIVINGSTON, J. D. Superparamagnetism. Journal of Applied Physics, v.30, n.4, p.120S-129S, 1959.

45. BATLLE, X.; LABARTA, A. Finite-size effects in fine particles: magnetic and transport properties. Journal of Physics D: applied physcics, v.35, n.1, p. R15-R42, 2005.

46. FRANKEL, J.; DORMAN, J. Spontaneous and induced magnetization in ferromagnetic bodies. Nature, v.126, n.1, p.274-275, 1930.

47. BANGS, L. B. New developments in particle-based immunoassay: introduction. Pure and Applied Chemistry, v.68, n.10, p. 1873-1879, 1996.

48. DENIZOT, B., et. al. Phosphorylcholine coating of iron oxide nanoparticles. Journal of Colloid and Interface. Science, v.209, n. 1, p. 66-71, 1999.

49. WILLARD, M. A.; et. al. Chemically prepared magnetic nanoparticles. International Materials Reviews, v. 49, n.3-4, p. 125-170, 2004.

50. GAMARRA, L. F.; et al. Kinetics of elimination and distribution in blood and liver of biocompatible ferrofluids based on $\mathrm{Fe} 3 \mathrm{O} 4$ nanoparticles: an EPR and XRF study. Materials Science and Engineering C, v.28, n.4, p. 519-525, 2008.

51. BERRY, C. C.; CURTIS, A. S. G. Functionalisation of magnetic nanoparticles for applictions in biomedicine. Journal of Physics D: applied physics, v.36, n. 1, p. R198-R206, 2003.

52. PANKRUSKA, Q. A. et al. Aplications of magnetic nanoparticles in biomedicine. Journal of Physics D: applied physics, v.36, n.6, p.R167-R181, 2003.

53. SAFARIK, I.; SAFARIKOVA, M. Magnetic nanoparticles and biosciences. Manotshefte Für Ceime, v. 133, n.61, p.737-759, 2002.

54. KATO, K.; RADBRUCH, A. Isolation and characterization of CD34+ hematopoietic stem cells from human peripheral blood by high-gradient magnetic cell sorting . Cytometry, v.14, n 4, p.384-392, 1993. 
55. LANGER, R. New methods of drung delivery. Science, v. 249, n. 4976, p.1527-1533, 1990.

56. GAMARRA, L. F. et al. In vitro study of CD133 human stem cells labeled with superparamagnetic iron oxide nanoparticles. Nanomedicine, v. 4, n. 1, p. 330-339, 2008.

57. GAMARRA, L. F. et al. Quantitative ferromagnetic resonance analysis of CD133 stem cells labeled with iron oxide nanoparticles. Journal of Physics: condenced matter, v. 20, n. 204150, p. 1-6, 2008.

58. BULTE, J.W, KRAITCHMAN, D. L. Iron oxide MR contrast agents for molecular and cellular imaging. NMR in Biomedicine, v. 17, n.7,p 484-499,2004.

59. FRANK, J. A.; et al. Clinically applicable labeling of mammalian and stem cells by combining superparamagnetic iron oxides and transfection agents. Radiology, v.228, n.1, p. 480-487, 2003.

60. $\mathrm{HE}, \mathrm{G}$. et al. In vivo imaging of bone marrow mesenchymal stem cells transplanted into myocardium using magnetic resonance imaging: a novel method to trace the transplanted cells. International Journal of Cardiology, v. 114, n.1, p. 4-10, 2007.

61. JENDELOVÁ, P. et al. Imaging the fate of implanted bone marrow stromal cells labeled with superparamagnetic nanoparticles. Magnetic Resonance in Medicine, v.50, n.4, p. 767-776, 2003.

62. GAZEAU, F. et al. Blood clearance of dextran magnetite particles determined by a noninvasive in vivo ESR method. Magnetic Resonance in Medicine, $v$. 22, n.2, p. 435-442, 1999.

63. IANNONE, A. et al. Blood clearance of dextran magnetite particles determined by a noninvasive in vivo ESR method. Magnetic Resonance in Medicine, v.22, n.2, p. 435-442, 1991.

64. WILHELM, C. GAZEAU, F.; BACRI, J. C. Magnetophoresis and ferromagnetic resonance of magnetically labelled cells. European Biophysics Journal, v.31, n.2 p.118-125, 2002. 
65. WANG, Y. X. J. et al. Supermaramangnetic iron oxide contrast agents: physicochemical characteristics and applications in MR imaging. European Radiology, v.11, n.11, p.2319-2331, 2001.

66. MOLHO, P. Ferrofluido. In: DU TRÉMOLET DE LACHEISSERIE, E.; GIGNOUX, D.; SCHLENKER, M. Magnetism Matherials \& Applications, New York: Springer, 2005, p. 337-351.

67. CHARLES, S. W.; POPPLEWELL. Ferromagneitc liquids. In: WOHLFARTH, E. P. Ferromagnetic Materials a handbook on the properties o magnetically ordered substances. Amesterdan: North-Holland Physics Publishing,1986, p.509-557. v.2

68. QU, E.; MORAIS, P.C. An oxide semiconductor nanoparticle in aqueous medium: a surface charge density investigation. The Journal of Chemical B, v.104, n. 22, p. 5232-5236, 2000.

69. QU, E.; MORAIS, P.C. Oxide semiconductor nanoparticle in aqueous mdedium: a superface charge density investigation. The Journal of Chemical Physics, v.111, n. 18, p. 8588-8594, 1999.

70. LIU, W.; ZHONG, W.; DU, Y. W. Magnetic nanoparticles with core/shell structures. Journal of Nanoscience and Nanotechnology, v.8, n.6, p. 2781-2792, 2008.

71. ZHANG, L. et al. Nanoparticles in medicine: therapeutic applications and developments. Cinical Pharmacology \& Therapeutics, v.83, n.5, p. 761769, 2008.

72. EONG, U. et al. Superparamagnetic colloids: controlledsynthesis and niche applications. Advanced Materials, v.19, n. 1, p. 33-60, 2007.

73. DU TRÉMOLET DE LACHEISSERIE, E.; ROCHETTE, P. Magnetism and the Life Sciences. In: DU TRÉMOLET DE LACHEISSERIE, E.; GIGNOUX, D.; SCHLENKER, M. Magnetism: matherials \& applications, New York: Springer, 2005, p. 425-439.

74. GAMARRA, L. F. et al. Biocompatible superparamagnetic iron oxide nanoparticles used for contrast agents: a structural and magnetic study. Journal of Magnetism and Magnetic Materials, v. 289, n. 3, p. 439-441, 2005. 
75. BULET, J. W.M.; KRAITCHMAN, D. L. Iron oxide MR contrast agents for molecular and cellular imaging. NMR In Biomedicine, v.17, n.7, p. 484-499, 2004.

76. BELLIN, M. F. MR contrast agents, the old and the new. European Journal of Radiology, v. 60, n.3, p. 314-323, 2006.

77. WEINMANN, H. J.; et al. Tissue-specific MR contrast agents. European Journal of Radiology,v. 46 , n.1, p. 33-44, 2006.

78. MIRAGLIA, S.; et al A novel five-transmembrane hematopoietic stem cell antigen: isolation, characterization, and molecular cloning. Blood, v. 90, n.12, p. 5013-5021, 1997.

79. MIRAGLIA, S.; GODFREY, W.; BUCK, D. A response to CD133 hematopoietic stem cell antigen: human homologue of mouse kidney prominin or distinct member of a novel protein family? Blood, v.91, n.11, p. 4390-4391, 1998.

80. BIDLINGGMAIER, S.; ZHU, X.; LIU, B. The utility and limitations of glycosylated human CD133 epitopes in defining cancer stem cells. Journal of Molecular Medicine, v.86, n.9, p.1025-1032, 2008.

81. CORBEIL, D.; et al The human AC133 hematopoietic stem cell antigen is also expressed in epithelial cells and targeted to plasma membrane protrusions. The Journal of Biological Chemistry, v.275, n. 8, 5512$5520,2000$.

82. MARZESCO, A. M. et al. Release of extracellular membrane particles carrying the stem cell marker prominin-1 (CD133) from neural progenitors and other epithelial cells. Journal.of Cell Science. v. 118, n.13, p. 28492858, 2005.

83. BHATIA, M. CD133 expression in human stem cells. Leukemia, v. 15, $\mathrm{n}$. 11 , p.1685-1686, 2001.

84. FARGEAS, C. A. et al. Prominin-1 (CD133): from progenitor cells to human diseases. Future Lipidology, v.1, n.2, p. 213-225, 2006.

85. YIN, A. H. et al. AC133, a novel marker for human hematopoietic stem and progenitor cells. Blood, v.90, n.12, p.5002-5012, 1997. 
86. WYNTER, E. A. et al. $\mathrm{CD} 34^{+} \mathrm{AC} 133^{+}$cells isolated from cord blood are highly enriched in long-term culture-initiating cells, nod/scid-repopulating cells and dendritic cell progenitors. Stem Cells, v.16, n.6, p.387-396, 1998.

87. HANDGRETINGER, R. et al. Biology and plasticity of $C D 133^{+}$hematopoietic stem cell. Annals New York Academy of Sciences, v. 996, n. 5, p. 141$151,2003$.

88. GOUSSETIS, E. et al. A functional hierarchy among the CD34+ hematopoietic cells based on in vitro proliferative and differentiative potential of CD133+CD34 bright and CD133dim/CD34+humancord blood cells. Journal of Hematother Stem Cell Research. v.9, n. 1, p.827-840, 2000.

89. GILL, M. et al. Vascular trauma induces rapid but transient mobilization of VEGFR $2^{+} \mathrm{AC}_{133^{+}}$endothelial precursor cells. Circulation Researcch. v. 88, n. 1 , p. 167-174, 2001.

90. GEHLING, U. M. et al. In vitro differentiation of endothelial cells from CD133 positive progenitor cells. Blood, v. 95, n.10, p. 3106-3112, 2000.

91. WATT, S. M. et al. Functionally defined CD164 epitopes are expressed on CD34(+) cells throughout ontogeny but display distinct distribution patterns in adult hematopoietic and nonhematopoietic tissues. Blood, v. 95, n.10, p. 3113-3124, 2000.

92. POWELL, T.M. et al. Granulocyte colonystimulating factor mobilizes functional endothelial progenitor cells in patients with coronary artery disease. Arteriosecleorosis, Thrombosesis, and vascular Biology. v. 25, n. 2, p. 296-301,2005.

93. UCHIDA, N. et al. Direct isolation of human central nervous system stem cells. Proceedings of the National Academy of Sciences USA. v.97, n.26 ,p.14720-14725, 2000.

94. BARRAUD, $P$. et al. In vitro characterization of a human neural progenitor cell coexpressing SSEA4 and CD133. Journal of neuroscience research, v. 85, n.2, p. 250-259, 2007.

95. FAUTH, F. et al. CD133 expression on acute myeloid leukemia blasts: correlation to $\mathrm{FAB}$ and to CD34 expression and possible implications for peripheral blood progenitor cell purging in AML_Leukemia Research v. 25, n.1, p.191-196, 2001. 
96. ATHERTON, N. M. Principle of electron spin resonance. 2. ed. New York: Ellis Horwood, 1993. p. 35-129.

97. KITTEL, C. Physical Theory of ferromagnetic domains. Reviews of Modern Physics, v. 21, n. 4, p. 542-583, 1949.

98. KITTEL, C. Introduction to solid state physics. 4. ed. New York: John Wiley \& Sons, 1971. p. 528-574.

99. BERGER, R. et al. Temperature dependence of superparamagnetic resonance of iron oxide nanoparticles. Journal of Magnetism and Magnetic Materials , v. 234, n. 3, p. 535-544, 2001.

100. CHIKAZUME, S.; CHARAP, S. P. Physics of magnetism. New York: John Wiley \& Sons, 1964. p. 15-35.

101. ATHERTON, N. M.; Principle of electron spin resonance. 2. ed. New York: Ellis Horwood, 1993. p. 281-319.

102. SLICHTER, C. P. Principle of magnetic mesonance 3. ed. New York: Springer-Verlag, 1989. p. 145-215.

103. CHIKAZUME, S.; CHARAP, S. P. Physics of magnetism. New York: John Wiley \& Sons, 1964. p. 79-109.

104. VERVEY, E. J.; HAAYAMAN, P. W.; ROMEIJN, F. C. Physical properties and cation arrangement of oxides with spinel structures I. cation arrangement in spinels. Journal of Chemical Physics, v. 15, n. 4, p. 174-180, 1947.

105. MORAIS, P. C. et al. Preparation and characterization of ultra-stable biocompatible magnetic fluids using citrate-coated cobalt ferrite nanoparticles. Thin solid Films, v. 515, n.1, p. 266-270, 2006.

106. LACAVA, L. M. et al. Magnetic resonance of a dextran-coated magnetic fluid intravenously administered in mice. Biophysical Journal, v.80, n. 5, p. 2483-2486, 2001.

107. TEDESCO, A. C. et al. Investigation of the binding constant and stoichiometry of biocompatible cobalt ferrite-based magnetic fluids to serum albumin. 
Journal of Magnetism and Magnetic Materials, v. 272-276, n. 3, p. 24042405, 2004.

108. ALBORNOZ, C, JACOBO, S. E. Preparation of a biocompatible magnetic film from an aqueous ferrofluid. Journal of Magnetism and Magnetic Materials, v.305, n.1, p. 12-15, 2006.

109. LANGER, R. New methods of drug delivery. Science, v.249, n. 4976, p.15271533, 1990.

110. LAHNER, M.; HOLTER, W. Endotoxin-free purification of monocytes for dendritic cell generation via discontinuous density gradient centrifugation

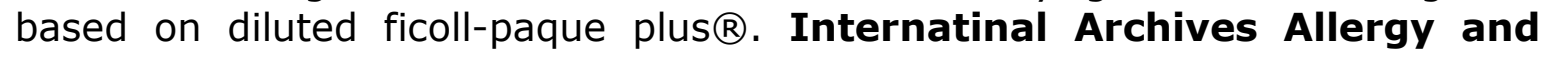
Immunology, v.128, n.1, p. 73-76, 2002.

111. GRISCOM, D. L. Ferromagnetic resonance of precipitated phases in natural glasses. Journal of Non-Crystalline Solids, v.67, n.1-3, p. 81-118,1984.

112. MARSART, R. et, al. Electron spin resonance investigation of $\mathrm{Mn}-\mathrm{Zn}$ ionic ferrofluid. Journal of Magnetism and Magnetic Materials, v. 201, n. 1-3, 73-76, 1999.

113. BERGER, R.; BISSEY, J. C.; KLIAVA, J. Lineshapes in magnetic resonance spectra. .Journal of Physics: condensed matter, v. 12, n. 44, p. 93479360, 2000.

114. CHIKAZUME, S.; CHARAP, S. P. Physics of magnetism. New York: John Wiley \& Sons, 1964. p. 321-355.

115. STUCKI, J. W.; BANWART,, W. L. Advanced Chemical Methods for Soil and Clay Mineral Research, Dordrecht: Reidel Publishing Co. Reidel Publishing, 1980

116. KINARRI, P.; UPADHYAY, R.V.; MEHTA, R. Magnetic properties of Fe-Zn ferrite substituted ferrofluids. Journal of Magnetism and Magnetic Materials, v.252, n. 1, p. 35-38, 2002.

117. NAGATA, K.; ISHIARA, A. ESR of ultrafine magnetic particles. Journal of Magnetism and Magnetic Materials , v. 104, n. 10, p. 1571-1573, 1992. 
118. RAY, C. S. et al. Mössbauer and EPR spectra for glasses and glass-ceramics prepared from simulated compositions of Lunar and Martian soils. Journal of Non-Crystalline Solids, v. 352, n. 32-35, p. 3677-3684, 2006.

119. HSEIH, C. T.; HUANG, W. L.; LUE, J. T. The change from paramagnetic resonance to ferromagnetic resonance for iron nanoparticles made by the solgel method. Journal of Physics and Chemistry of Solids, v. 63, n. 5, p. 733-741.

120. SHARMA, V. K.; WALDENER, F. Superparamagnetic and ferrimagnetic resonance of ultrafine Fe304 particles in ferrofluids. Journal of Applied Physics, v. 48, n. 10, p.4298-4301, 1977. 


\section{APÊNDICE A}

GAMARRA, L.F. et al. Magnetic characterization by SQUID and FMR of a biocompatible ferrofluid based on Fe304. Journal of Physics:condensed matter, v.21, 2009. In press. 


\section{Magnetic characterization by SQUID and FMR of a biocompatible ferrofluid based on $\mathrm{Fe}_{3} \mathrm{O}_{4}$}

\author{
L F Gamarra ${ }^{1,2}$, W M Pontuschka ${ }^{3}$, J B Mamani ${ }^{3}$, D R Cornejo ${ }^{3}$, \\ T R Oliveira ${ }^{3}$, E D Vieira ${ }^{4}$, A J Costa-Filho ${ }^{4}$ and E Amaro Jr ${ }^{1,2}$ \\ ${ }^{1}$ Instituto Israelita de Ensino e Pesquisa Albert Einstein, IIEPAE, 05651-901, \\ São Paulo, Brazil \\ ${ }^{2}$ Instituto de Radiologia, Faculdade de Medicina, USP, São Paulo, Brazil \\ ${ }^{3}$ Instituto de Física, Universidade de São Paulo, São Paulo, Brazil \\ ${ }^{4}$ Instituto de Física de São Carlos, USP, São Carlos, Brazil \\ E-mail: lgamarra@einstein.br
}

Received 17 July 2008, in final form 13 January 2009

Published

Online at stacks.iop.org/JPhysCM/21/000000

\begin{abstract}
Biocompatible superparamagnetic iron oxide nanoparticles of magnetite coated with dextran were magnetically characterized using the techniques of SQUID (superconducting quantum interference device) magnetometry and ferromagnetic resonance (FMR).

The SQUID magnetometry characterization was performed by isothermal measurements under applied magnetic field using the methods of zero-field-cooling (ZFC) and field-cooling (FC). The magnetic behavior of the nanoparticles indicated their superparamagnetic nature and it was assumed that they consisted exclusively of monodomains. The transition to a blocked state was observed at the temperature $T_{\mathrm{B}}=(43 \pm 1) \mathrm{K}$ for frozen ferrofluid and at $(52 \pm 1) \mathrm{K}$ for the lyophilized ferrofluid samples. The FMR analysis showed that the derivative peak-to-peak linewidth $\left(\Delta H_{\mathrm{PP}}\right)$, gyromagnetic factor $(g)$, number of spins $\left(N_{\mathrm{S}}\right)$, and spin-spin relaxation time $\left(T_{2}\right)$ were strongly dependent on both temperature and super-exchange interaction. This information is important for possible nanotechnological applications, mainly those which are strongly dependent on the magnetic parameters.
\end{abstract}

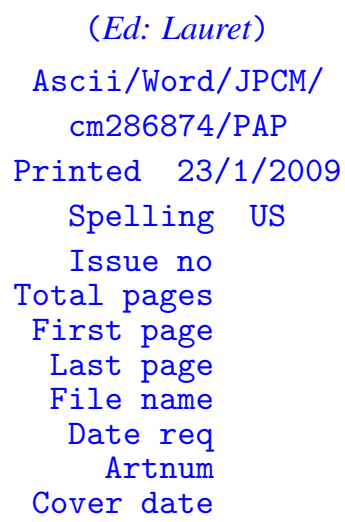

\section{Introduction}

Iron oxide nanoparticles are of considerable interest for applications in nanotechnology due to their inherent properties, such as superparamagnetism, high saturation fields, and extra anisotropy contributions or shifted loops after fieldcooling, which is attributed to finite size and large surface area [1]. Currently these nanostructured materials are applied in various fields such as magnetic storage, biomedicine, and catalysis [2-4].

The magnetic characterization of superparamagnetic iron oxide nanoparticles (SPIONs) having different physicalchemical configurations is fundamental in medical applications, including drug delivery [5], and hyperthermia cancer treatment $[6,7]$, among others. They are also used as image contrast agents in magnetic resonance imaging (MRI) $[8,9]$, where the principle of this application is based on the magnetic properties of the SPIONs. The physical properties of an assembly of magnetically ordered monodomains in a diamagnetic matrix depend on a number of parameters which characterize the magnetic compound and on the morphology of the nanoparticles. Such systems of superparamagnetic nanoparticles are currently being investigated by a large variety of techniques, where the main goals are to further explore the properties of these materials and to increase their potential for novel applications, taking into account that each potential application requires different properties of the nanoparticles.

The objective of this paper is to perform the magnetic characterization of a colloidal suspension of SPIONs recovered with dextran used as a contrast agent for MRI. The magnetic characterization was performed using the techniques of superconducting quantum interference device (SQUID) 
magnetometry and ferromagnetic resonance (FMR). The FMR analysis was carried out as a function of temperature in order to understand the superparamagnetic features exhibited by the SPIONs under investigation, as well as the temperature dependence of parameters such as the peak-to-peak linewidth, gyromagnetic factor, number of spins and spin-spin relaxation time.

\subsection{Ferromagnetic resonance}

Electron paramagnetic resonance (EPR) of the ferromagnetic particles, also known as FMR, is performed like any other EPR experiment, except that the samples contain approximately spherical aggregates of ferro or ferrimagnetic monodomains of the order of a few nanometers. Thus, the total magnetic momentum of each nanoparticle precesses about the direction of the total magnetic static field, which is the sum of the external static field, the internal contribution of the domain magnetization and the anisotropic magnetic field of the local lattice [10]. The FMR is adequate for the study [11] and detection of ferromagnetic nanoparticles $[12,13]$ even in the presence of soluble iron salts, which exhibit typical welldefined spectra.

The magnetic resonance theory of the superparamagnetic systems is described on the basis of a phenomenological equation of motion for a classical magnetic momentum $\boldsymbol{\mu}$ under ferromagnetic conditions of resonance $[14,15]$.

The magnetic fluids based on SPION present various relaxation phenomena, which are directly related to the orientation freedom degrees of the particle. The basic phenomenon of FMR is the microwave absorption, which is observed when the Larmor precession of the particles equals the frequency of the standing waves in the microwave cavity. The physical mechanism is essentially the same for ferromagnetic solids and magnetic suspensions. However, in ferrofluids, the FMR is considerably affected by two specific characteristics. The first one stems from the smallness of the particles and imparts a fluctuation component to the magnetic moment motion. The second originates from the mechanical mobility of the particles and results in a change in the distribution of their anisotropy axes under the influence of the external fields [16]. The underlying cause of both effects is the thermal noise, meaning that they are strongly temperaturesensitive.

Among the nanoparticles composed by spherical monodomains $(\sim 10 \mathrm{~nm})$, the reference value $K V$ of the magnetic anisotropic energy, where $K$ is the constant of anisotropy and $V$ is the particle volume, can be easily compared with the thermal energy $k_{\mathrm{B}} T$. Because of this, together with any regular movement, the magnetic momentum $\mu$ of the particle is submitted to considerable orientation fluctuations, including those that reverse their direction. This effect is known as superparamagnetism and it was predicted by Néel [17].

\section{Materials and methods}

The sample was a colloidal suspension of iron oxide superparamagnetic nanoparticles (Endorem ${ }^{\mathrm{TM}}$ _Guerbert, earlier trade name AMI-25, Laboratoire Guerbert, France) consisting of $126.500 \mathrm{mg}$ of $\mathrm{Fe}_{3} \mathrm{O}_{4}$ superparamagnetic nanoparticles contained in $8 \mathrm{ml}$ of water. The nanoparticles of $4.8-5.6 \mathrm{~nm}$ size are coated with low-weight dextran (7-9 kDa) [18] of hydrodynamic diameters between 80 and $150 \mathrm{~nm}$. Besides water, the solvent composition was $60.800 \mathrm{mg}$ of dextran, $2.714 \mathrm{mg}$ of citric acid, and $490.400 \mathrm{mg}$ of $\beta$-D-mannitol $\left(\mathrm{C}_{6} \mathrm{H}_{14} \mathrm{O}_{6}\right)$. The pharmacokinetics, toxicity, and relaxivity of these superparamagnetic iron oxide particles have been previously described [19-21]. The suspension is a ferrofluid applied as a contrast agent in MRI for the detection of liver lesions associated with an alteration in the reticular-endothelial system (RES) [9].

The magnetic characterization was performed by SQUID magnetometry and FMR. A commercial SQUID magnetometer was employed to perform static and dynamic measurements as a function of field, temperature, and driving frequency. Zero-field-cooling (ZFC) and field-cooling (FC) curves were recorded under applied magnetic fields up to $7 \mathrm{~T}$, between 5 and $250 \mathrm{~K}$ to avoid the melting of the solid matrix (solvent). The study using this technique was carried out with two types of ferrofluid samples: (a) as a colloidal suspension and (b) as a lyophilized ferrofluid in order to increase the concentration of nanoparticles, keeping their size unaltered. The samples were lyophilized on an Edwards lyophilizer, model E3M8Modulyo, operating at a temperature of $-50{ }^{\circ} \mathrm{C}$ and pressure of $8 \times 10^{-3}$ Torr, working with a vacuum pump. This process was carried out during a period of $27 \mathrm{~h}$, yielding a material free of humidity.

For magnetic measurements, as-prepared samples were conditioned in closed containers before quenching the magnetite/carrier mixture below its freezing point $(\sim 268 \mathrm{~K})$.

The FMR spectra were obtained using a Bruker ELEXSYS E580 spectrometer operating at X band $(9.2 \mathrm{GHz})$ and equipped with a rectangular microwave cavity operating in the $\mathrm{TE}_{102}$ mode. Experimental parameters were set to avoid saturation and distortion of the signal. To obtain the FMR spectra in the temperature range of $4-300 \mathrm{~K}, 3.5 \mathrm{mM}$ of SPIONs colloidal suspension sample in a volume of $10 \mu \mathrm{l}$ was used. The temperature was controlled by an ITC503 Oxford cryostat system.

\section{Results and discussions}

Magnetization curves (figure 1) obtained from SQUID magnetometry measurements, taken in ZFC and FC modes under an external field of $H=100$ Oe showed that the transition to a blocked state occurs at the temperature $T_{\mathrm{B}-\mathrm{F}}=$ $(43 \pm 1) \mathrm{K}$ for frozen ferrofluid. On the other hand, it can be clearly seen that the lyophilized ferrofluid sample had a higher blocking temperature $T_{\mathrm{B}}=(52 \pm 1) \mathrm{K}$. At the irreversibility temperature $\left(T_{\text {Irr }}\right)$ splitting of the ZFC and FC curves was observed when the larger particles were changed from the blocked state to the superparamagnetic state and vice versa. For the case of the lyophilized ferrofluid and the frozen ferrofluid sample, the following values $T_{\text {Irr-L }}=(97 \pm 1) \mathrm{K}$ and $T_{\mathrm{Irr}-\mathrm{F}}=(220 \pm 1) \mathrm{K}$ were observed, respectively. The changes in the temperatures $T_{\mathrm{B}}$ and $T_{\text {Irr }}$ showed the 


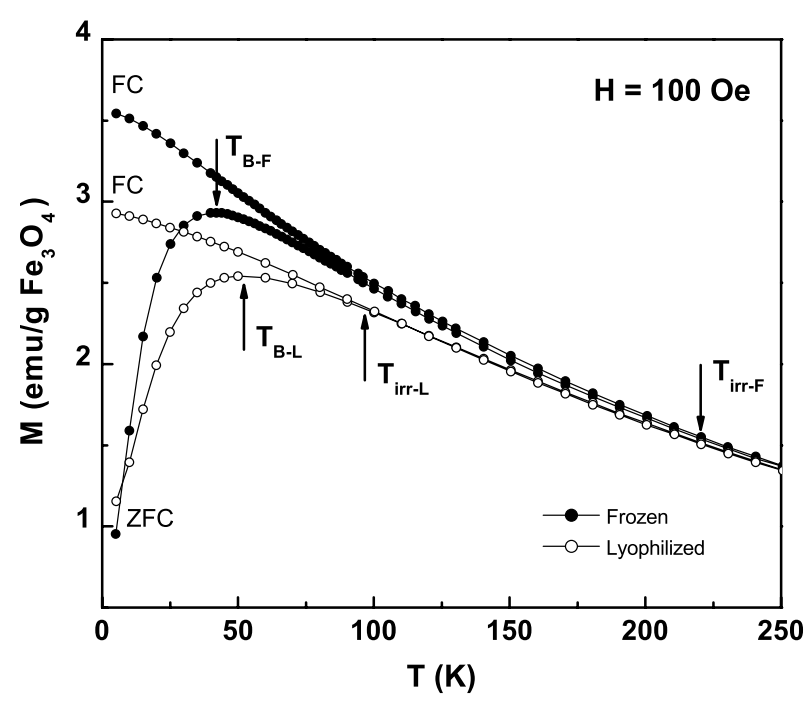

Figure 1. Magnetization curve for frozen $(\bullet)$ and lyophilized $(\mathrm{O})$ samples. Lower and upper branches correspond to ZFC and FC data, respectively. The arrows indicate the blocking temperature $T_{\mathrm{B}}$ and the irreversibility temperature $T_{\mathrm{Irr}}$.

effects of dipolar interactions, which tend to increase the energy barriers of individual particles. According to the size of monodomain particles, no indication of the Verwey transition was observed. By comparing samples with different average particle distances but identical particle distributions, we inferred that in concentrated systems the contribution from dipolar interactions can be of the same order as the anisotropy energy barriers of noninteracting particles.

Contributions to anisotropy energy can originate from intrinsic anisotropies of the particles (shape, magnetocrystalline, or stress anisotropies) or interparticle interactions (dipolar or exchange). Inasmuch as these two mechanisms contribute to modify the energy barrier, it is usually quite difficult to separate both kinds of effects. The conditions during the lyophilization assured that both samples have the same average particle size, particle distribution, and particle shape. Therefore, such an increase in anisotropy energy is not related to size/distribution effects but to the decrease of the average distance between particles.

Figure 2 shows the hysteresis cycles for the ferrofluid samples measured at temperatures of 5, 10, 20, 30, 50, and $70 \mathrm{~K}$. It is well known that after the initial magnetization, the sample acquires a remnant magnetization even after the removal of the external field. The field necessary to further reduce the remnant magnetization to zero is defined as the coercive field $H_{\mathrm{c}}$, which is calculated from the hysteresis curve (figure 2(a)). Figure 2(a) shows the existence of coercive field at temperatures below the blocking temperature. Thus, it is also observed that the material has a typical superparamagnetic behavior, i.e. with almost zero coercivity, because during the time elapsed in the measurement $\left(\tau_{\mathrm{m}}\right)$, the particles are in the superparamagnetic state at temperatures higher than the blocking temperature $\left(T_{\mathrm{B}}\right)$. As the temperature of the system decreases, the hysteresis appears and consequently the superparamagnetism disappears, where the thermal energy is no longer sufficient to overcome the potential barrier created

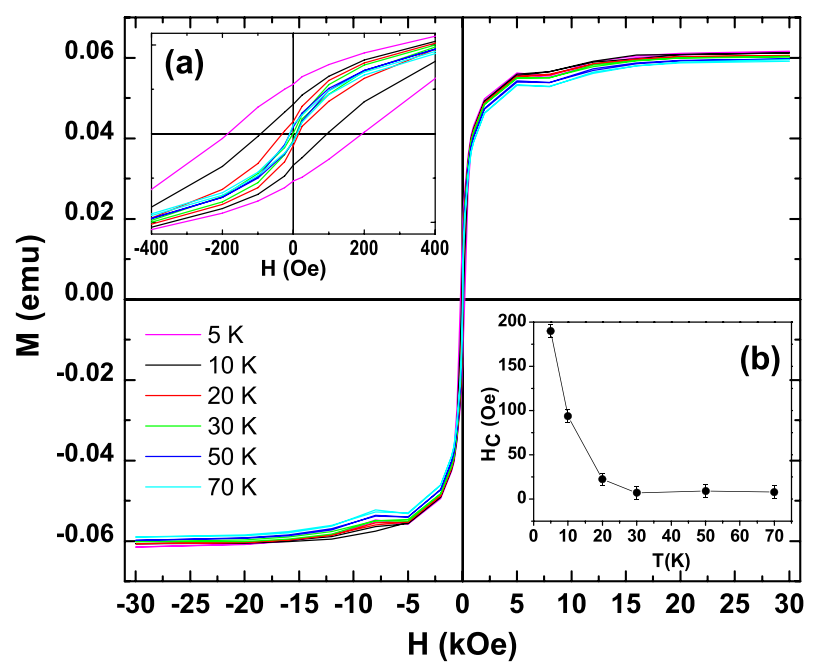

Figure 2. Hysteresis cycles of the ferrofluid at different temperatures. Inset (a): detail showing the reminiscent field with a field range from -400 to $+400 \mathrm{Oe}$. Inset (b): coercive fields measured in the blocking region of the ferrofluid sample.

by the anisotropic energy, thereby blocking their magnetic moments during the time $\tau_{\mathrm{m}}$.

The $M(H)$ curves shown in figure 2(a) indicate the development of a measurable coercive field below $T_{\mathrm{B}}$, reaching the field intensity $H_{\mathrm{C}}=190$ Oe for the temperature $T=$ $5 \mathrm{~K}$ (see figure 2(b)). The saturation magnetization $M_{\mathrm{S}}$ is almost reached for applied fields of the order of $30 \mathrm{kOe}$, suggesting no evidence of a magnetically hard particle surface, as found in other nanostructured iron oxide particles [22]. The ratio between the saturation and the remnant magnetization $R=M_{\mathrm{R}} / M_{\mathrm{S}}$ measured at $5 \mathrm{~K}$ is 0.27 , smaller than the theoretically expected $R=0.5$ value for noninteracting randomly oriented particles [23]. It has been suggested that $R>0.5$ and $R<0.5$ values should be expected for those systems with ferro and antiferromagnetic interactions, respectively, as proposed by Hadjipanayis et al [24]. Thus, the present $R=0.27$ value indicates that the interparticle interactions are of antiferromagnetic nature.

The FMR spectrum at room temperature of ferrofluid is shown in figure 3 . The typical ferrofluid spectra consisted of a broad line. The characteristic FMR absorption line of precipitated fine grains, composed by ferro-or antiferromagnetic monodomains $[25,26]$, is also observed in pairs of iron ions $\left(\mathrm{Fe}^{3+}\right.$ and $\left.\mathrm{Fe}^{2+}\right)$ and/or clusters formed in glassy matrices [27]. From the lineshape analysis it was possible to determine the magnetocrystalline anisotropic constant of first order $K_{1}=(1.2 \pm 0.2) \times 10^{5} \mathrm{erg} \mathrm{cm}^{-3}$, following a method described in the literature [25]. This value was determined by using the relations $H_{a}=2 K_{1} / M_{\mathrm{S}}$ and $H_{\mathrm{S}}=(4 \pi / 3) M_{\mathrm{S}}\left(\operatorname{erg~G} \mathrm{cm}^{-1}\right)$, where $H_{\mathrm{S}} \approx 2 \mathrm{kG}$ [25]. It was considered that the SPIONs chemical composition is $\mathrm{Fe}_{3} \mathrm{O}_{4}$ [25], consisting of monodomains of spherical geometry [26]. $\quad M_{\mathrm{S}}$ is the magnetization saturation of the cubic crystal and $H_{\mathrm{S}}$ is the saturation field of a spherical SPION. The derivative of FMR absorption shows a maximum $H_{\text {max }}$, a minimum $H_{\text {min }}$, and a maximum of negative slope 


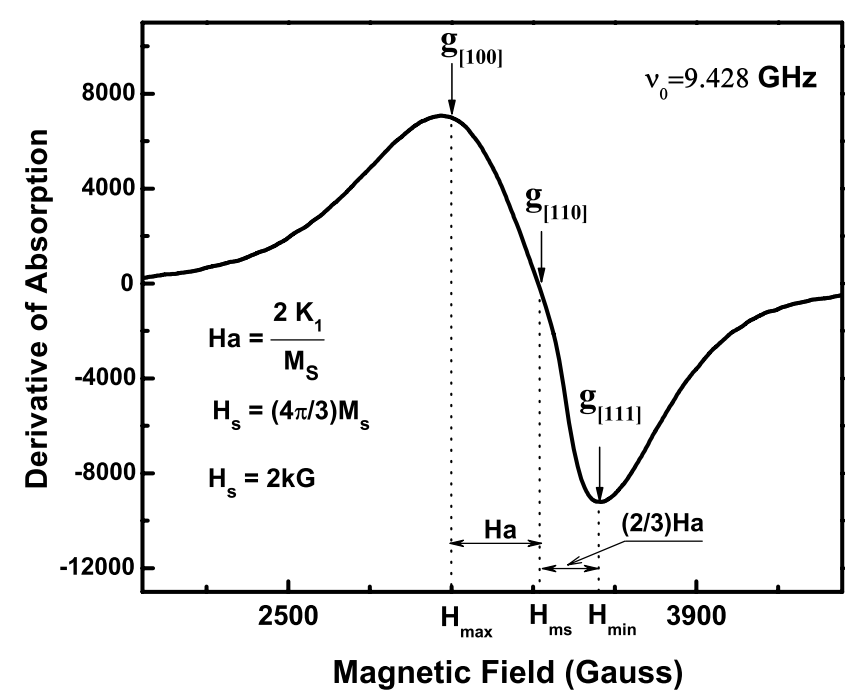

Figure 3. FMR spectrum of SPIONs recorded at room temperature.

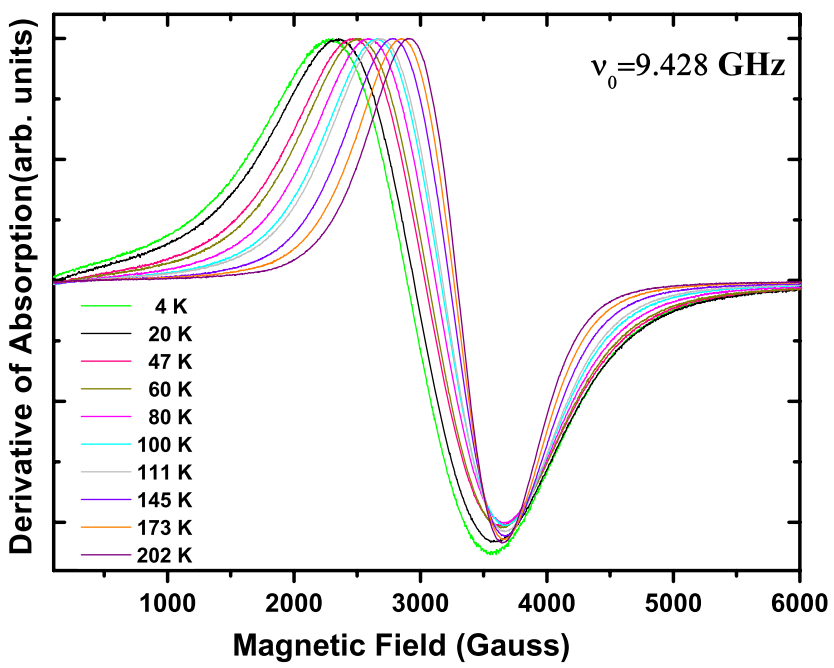

Figure 4. Temperature dependence of the ferrofluid FMR spectra obtained in the range of $4-300 \mathrm{~K}$.

$H_{\mathrm{ms}}$ whose values of effective $g$ are $g_{[100]}=(2.22 \pm 0.01)$, $g_{[110]}=(1.98 \pm 0.02)$, and $g_{[111]}=(1.89 \pm 0.01)$, respectively. The $H_{a}$ value was obtained from the field separation between the wing positions of $H_{\max }$ and $H_{\min }$, equal to $5 / 3$ of $H_{a}$, as shown in figure 4. The $H_{0}=H_{\max }-(2 / 3) H_{a}$ was obtained from the value of $g_{0}=\left(h v /\left(\beta H_{0}\right)\right)=(2.01 \pm 0.02)$, with $v=9.428 \mathrm{GHz}$, where $h$ is the Planck's constant, $v$ is the spectrometer microwave frequency and $\beta$ is the Bohr magneton.

FMR measurements were carried out at varying temperatures from $4 \mathrm{~K}$ up to room temperature as shown in figure 4. In general, the spectra were asymmetric and the peak-to-peak amplitude of the derivative of absorption remained constant through the entire temperature range. However, a lineshape change was observed as temperature increased, leading to successively narrower lines. This is due to the fact that in a ferromagnetic randomly oriented dispersion, the absorption linewidth turns out to be a monotonic function of temperature.

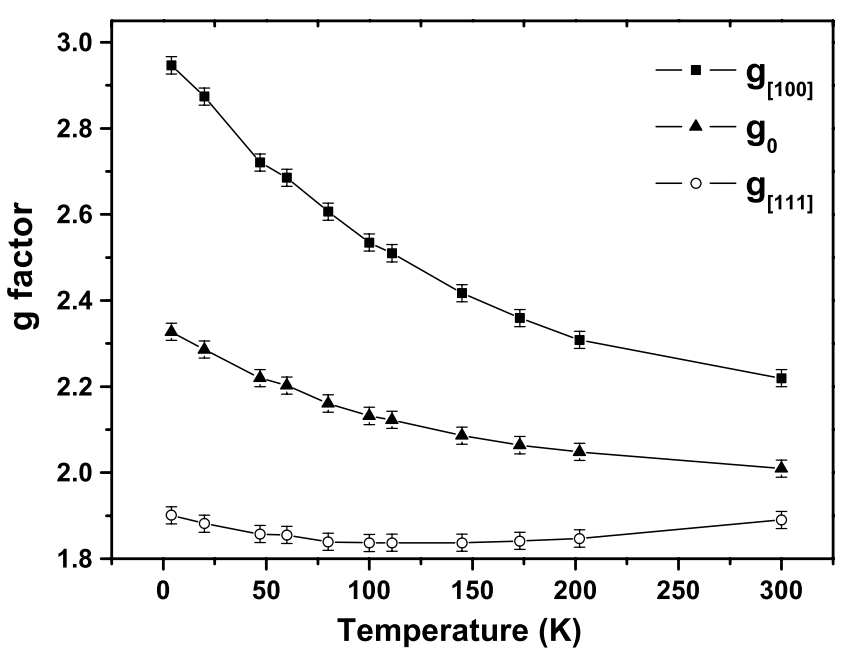

Figure 5. Temperature dependence of the gyromagnetic factors $g_{[100]}, g_{0}, g_{[111]}$ of SPIONs.

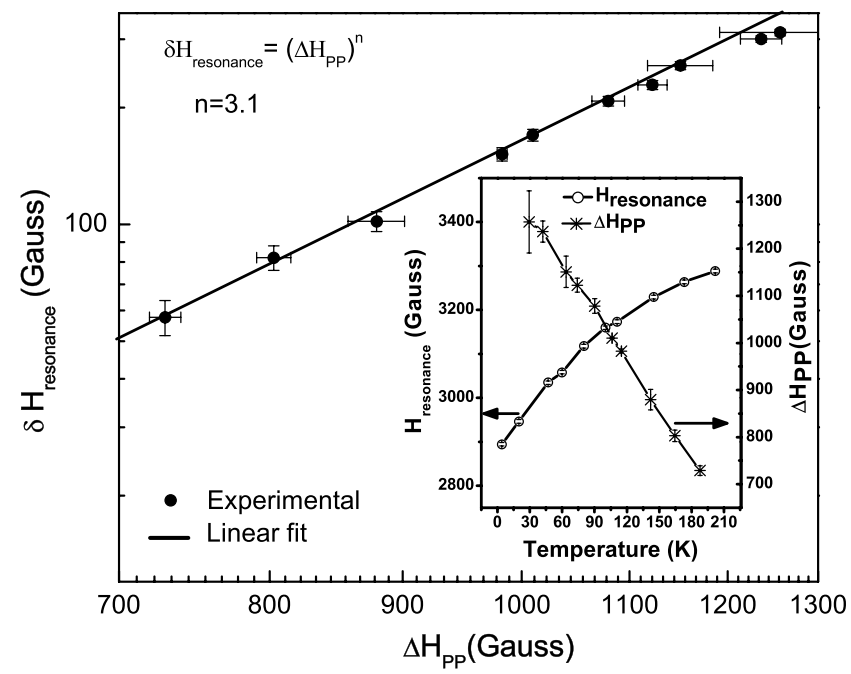

Figure 6. Relationship between $\delta H_{\text {resonance }}$ and $\Delta H_{\mathrm{PP}}$, showing an exponent $n$ of order 3 . In the inset, the variation of $H_{\text {resonance }}$ and $\Delta H_{\mathrm{PP}}$ as a function of temperature is illustrated.

At low temperature, the linewidth is large due to the particle dispersion in the direction of the anisotropic field. As the temperature increases, there is a tendency of isotropic magnetic moments to be formed, thus reducing the linewidth [28].

The gyromagnetic factors $g_{[100]}, g_{0}$ of SPIONs decreased monotonically with temperature, and in the case of $g_{[111]}$ it starts with a slight decrease, reaching a minimum at $150 \mathrm{~K}$ and then increases slowly, as shown in figure 5.

In figure 6 , the shift of the resonance field $\left(\delta H_{\text {resonance }}=\right.$ $\left.\left[H_{\text {resonance }}\right]_{300 \mathrm{~K}}-\left[H_{\text {resonance }}\right]_{T}\right)$ is plotted versus the peak-topeak linewidth $\left(\Delta H_{\mathrm{PP}}=H_{\min }-H_{\max }\right)$ of the FMR spectrum (derivative of the microwave absorption), and a straight line was obtained assuming that the function is $n$th power of $\Delta H_{\mathrm{PP}}$. The inset shows the decrease of resonance field with the increase in temperature. $H_{\text {resonance }}$ is plotted versus $\Delta H_{\mathrm{PP}}$ and it also shows the dependence of $\Delta H_{\mathrm{PP}}$ with the associated temperature. The curve $H_{\text {resonance }}(T)$ increase with the increase 


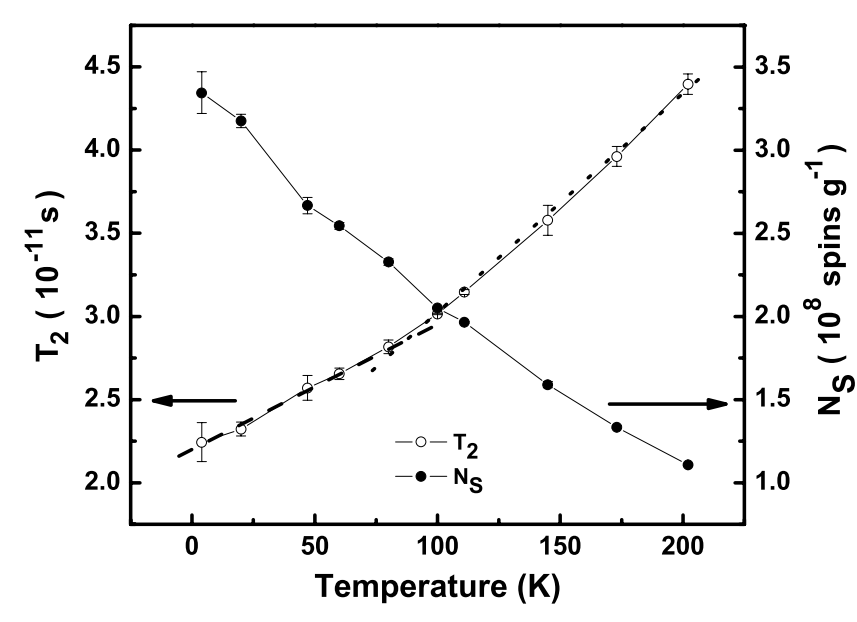

Figure 7. The spin-spin relaxation time $\left(T_{2}\right)$ and the spin number as a function of temperature of ferrofluid.

in temperature, whereas $\Delta H_{\mathrm{PP}}$ decreases with the increase in temperature, as expected for the FMR of superparamagnetic particles [29, 30]. Therefore, it is expected that the resonance line broadening should be associated with the magnetization blocking of the $\mathrm{Fe}_{3} \mathrm{O}_{4}$ nanoparticles.

The variation of $\Delta H_{\mathrm{PP}}$ can be explained using a two-level system and assuming thermal equilibrium. The FMR linewidth is given by [31]:

$$
\Delta H_{\mathrm{PP}}=L \tanh \left[\frac{\Delta E}{2 k T}\right], \quad L=\frac{5 g \beta S n}{D^{3}}
$$

where $n$ is the number of magnetic centers, $g$ is the gyromagnetic factor, $D$ is the average intergrain distance, $S$ is the effective spin of the magnetic centers and $\Delta E$ is the energy barrier. Therefore, $\boldsymbol{L}$ remains unchanged and the main contribution to $\Delta H_{\mathrm{PP}}$ would be $\Delta E$. The weakening of the magnetic coupling is the possible reason for the observed decrease in the linewidth $[30,32]$.

In general, for a system of superparamagnetic particles with statistical distribution of shapes and sizes, there is a simple relationship between $n$, the exponent of $\delta H_{\text {resonance }} \sim$ $\left(\Delta H_{\mathrm{PP}}\right)^{n}$, and the structural organization of the particles [33]: $n=2$ for partially oriented and $n=3$ for randomly oriented particles. To examine this power relationship, the data were plotted as shown in figure 6 on a double logarithmic scale. From the adjusted slope of $n \sim 3(3.1)$, it is concluded that the behavior of the magnetite nanoparticles is superparamagnetic, isolated, and randomly oriented.

The number of unpaired electron spins in the sample is proportional to the area under the absorption of FMR, determined by $\left(\Delta H_{\mathrm{PP}}\right)^{2} \Gamma$ where $\Gamma$ is the peak-to-peak height [34]. It is seen in figure 7 that the number of spins decreased with the increase of temperature.

The spin relaxation process is characterized using a time constant which is a function of the static magnetic field and is dependent on the rate of absorption and dissipation of the microwave energy. The spin-spin relaxation process is the energy difference $\Delta E$ transferred to the neighboring electrons.
The relaxation time $T_{2}$ can be determined from the peak-topeak linewidth according to the following equation, expressed in units $\mathrm{s}^{-1}$ :

$$
\frac{1}{T_{2}}=\frac{\sqrt{3} g \beta \Delta H_{\mathrm{PP}}}{\hbar},
$$

where $\hbar$ is the Planck's constant divided by $2 \pi$.

Figure 7 shows the variation of $T_{2}$ with temperature. The dipole-dipole interaction between the particles and the super-exchange interaction between the magnetic ions through oxygen ions are the two predominant factors which determine the resonance parameters: the gyromagnetic $g$-factor and $\Delta H_{\mathrm{PP}}$. Strong dipolar interactions result in high values of $\Delta H_{\mathrm{PP}}$ and $g$-factor. In addition, a strong super-exchange interaction produces small values of $\Delta H_{\mathrm{PP}}$ and $g$-factor [35]. The increase of temperature should increase the motion of electrons, causing a stronger super-exchange interaction between the cations through oxygen ions and thus a decrease in $\Delta H_{\mathrm{PP}}$ and $g$-factor. Consequently, $T_{2}$ increases with the increase in temperature. Another interesting observation is the change of the $\log \delta H$ slope with temperature, as shown in figure 7 , with evidence of two types of relaxation rates. The change in the relaxation rate of the superparamagnetic iron oxide at $T=75 \mathrm{~K}$ can be related with the change of magnetic susceptibility [36]. The immediate interpretation is the change from a partially oriented to a randomly oriented spin behavior. It is closely analogous to the behavior of a glass crossing the glass transition temperature $T_{\mathrm{g}}$, but this phenomenon needs further investigation.

\section{Conclusion}

From the ZFC and FC magnetization measurements, the transition to a blocked state was observed at the temperature $T_{\mathrm{B}}=(43 \pm 1) \mathrm{K}$ for frozen ferrofluid and at $(52 \pm 1) \mathrm{K}$ for the lyophilized ferrofluid samples, showing the effects of dipolar interactions in distributions of samples with identical size. The magnetization results as a function of the external field showed that for temperatures $T>T_{\mathrm{B}}$ the hysteresis cycle did not exhibit coercivity, indicating the superparamagnetic behavior of the material. However, on cooling below the blocking temperature, the magnetization of the sample increased and the hysteresis cycle became symmetric, showing a phase transition from the superparamagnetic to the ferromagnetic state.

The analysis of the FMR spectra of the ferrofluid measured in the range of temperatures 4-300 K confirmed the superparamagnetic state above $T_{\mathrm{B}}$ and the strong dependence of the parameters $\Delta H_{\mathrm{PP}}, g$-factor, $N_{\mathrm{S}}$, and $T_{2}$ on temperature. It is known that this behavior of the measured parameters is strongly governed by super-exchange interaction.

\section{Acknowledgments}

This work was supported by Instituto Israelita de Ensino e Pesquisa Albert Einstein and the Brazilian agencies FAPESP and $\mathrm{CNPq}$. 


\section{References}

[1] Batlle X and Labarta A 2002 J. Phys. D: Appl. Phys. 35 R15

[2] Weller D, Sun S H, Murray C, Folks L and Moser A 2001 IEEE Trans. Magn. 372185

[3] Bulte J W, Douglas T, Mann S, Frankel R B, Moskowitz B M, Brooks R A, Baumgarner C D, Vymazal J, Strub M P and Frank J A 1994 J. Magn. Reson. Imaging 449

[4] Bell A T 2003 Science 2991688

[5] Voltairas P A, Fotiadis D I and Michalis L K J 2002 Biomechanics 35813

[6] Jordan A, Scholz R, Wust P, Fahling H, Krause J, Wlodarczyk W, Sander B, Vogl T and Felix R 1997 Int. J. Hyperth. 13587

[7] Shinkai M, Yanase M, Suzuki M, Honda H, Wakabayashi T, Yoshida J and Kobayashi T 1999 J. Magn. Magn. Mater. 194176

[8] Jordan A, Scholz R, Wust P, Fahling H and Felix R 1999 J. Magn. Magn. Mater. 201413

[9] Wang Y X J, Hussain S M and Krestin G P 2001 Eur. Radiol. 112319

[10] Shilov V, Raikher Yu L, Bacri J C, Gazeau F, Perzynski R and Stepanov V I 1998 Phys. Rev. B $6011902-5$

[11] Gazeau F, Shilov V, Bacri J C, Dubois E, Gendron F, Perzynski R, Raikher Yu L and Stepanov V I 1999 J. Magn. Magn. Mater. 202 535-46

[12] Iannone A, Magin R L, Walczak T, Federico M, Swartz H M, Tomasi A and Vannini V 1991 Magn. Reson. Med. 22 435-42

[13] Wilhelm C, Gazeau F and Bacri J C 2002 Eur. Biophys. 31 118-25

[14] Raikher Y L and Stepanov V I 1992 Sov. Phys. 75764

[15] Raikher Y L and Stepanov V I 1994 Phys. Rev. B 506250

[16] Raikher Y L and Stepanov V I 1995 J. Magn. Magn. Mater. 14934

[17] Néel L 1949 Ann. Geophys. 599

[18] Laniado M, Chachuat A and Verträglichkeitsprofil von ENDOREM 1995 Radiologe 35 (Suppl. e) S266

[19] Halavaara J T, Lamminen A E, Bondestam S, Standertskjoeld-Nordenstam C G and Hamberg L M 1994
[20] Weissleder R, Engelstad B L, Bacon B R, White D L, Jacobs P and Lewis J 1989 AJR 152167

[21] Majumdar S, Zoghbi S S and Gore J C 1990 Invest. Radiol. 25771

[22] Stoner E C and Wohlfarth E P 1948 Phil. Trans. R. Soc. 240599

[23] Goya G F, Berquo T S, Fonseca F C and Morales M P 2003 J. Appl. Phys. 943520

[24] Hadjipanayis G, Sellmyer D J and Brandt B 1981 Phys. Rev. B 233349

[25] Griscom D L 1984 J. Non-Cryst. Solids 6781

[26] Ray C S, Reis S T, Pontuschka W M, Yang J B, Sene F F, Giehl J M, Kim C W and Sen S 2006 J. Non-Cryst. Solids 3523677

[27] Reis S T, Faria D L A, Martinelli J R, Pontuschka W M, Day D E and Partiti C S M 2002 J. Non-Cryst. Solids 304189

[28] Massart R, Zins D, Gendron F, Rivoire M, Mehta R V, Upadhyay R V, Goyal P S and Aswal V K 1999 J. Magn. Magn. Mater. 20173

[29] Stucki J W and Banwart W L 1980 Advanced Chemical Methods for Soil and Clay Mineral Research (Dordrecht: Reidel)

[30] Kinnari P, Upadhyay R V and Mehta R V 2002 J. Magn. Magn. Mater. 25235

[31] Tronconi A L, Moris P C, Pelegrini F and Tourinho F A 1992 J. Magn. Magn. Mater. 12290

[32] Kinnari P, Upadhyay R V, Mehta R V and Srinivas D 2002 J. Appl. Phys. 882799

[33] Nagata K and Ishihara A 1992 J. Magn. Magn. Mater. 1571 104-7

[34] Raber J F 1980 Experimental Methods in Polymer Chemistry—Physical Principal and Applications (New York: Wiley) p 332

[35] Li L, Li G, Smith R L and Inomata H 2000 Chem. Mater. 123705

[36] Wu K H, Chang Y C, Chen H B, Yang C C and Horng D N 2004 J. Magn. Magn. Mater. 278156 


\section{Queries for IOP paper 286874}

Journal: JPhysCM

Author: $\quad$ L F Gamarra et al

Short title: Magnetic characterization by SQUID and

FMR of a biocompatible ferrofluid based on $\mathrm{Fe}_{3} \mathrm{O}_{4}$

\section{Page 1}

Query 1:

Author: Please be aware that the colour figures in this article will only appear in colour in the Web version. If you require colour in the printed journal and have not previously arranged it, please contact the Production Editor now.

\section{Page 3}

Query A:

Author: If figures 2 and 4 are not to be printed in color, please note that it would be difficult to understand the details in them.

\section{Page 6}

Query 2:-

Author: [19, 20]: Please check the journal titles.

Reference linking to the original articles

References with a volume and page number in blue have a clickable link to the original article created from data deposited by its publisher at CrossRef. Any anomalously unlinked references should be checked for accuracy. Pale purple is used for links to e-prints at ArXiv. 


\section{APÊNDICE B}

GAMARRA, L.F. et al. Quantitative ferromagnetic resonance analysis of CD133 stem cells labeled with iron oxide nanoparticles. Journal of Physics:condensed matter, v.20, n.204150, p.1-6, 2008. 


\title{
Quantitative ferromagnetic resonance analysis of $C D 133$ stem cells labeled with iron oxide nanoparticles
}

\author{
L F Gamarra ${ }^{1}$, L F Pavon ${ }^{1}$, L C Marti ${ }^{1}$, W M Pontuschka ${ }^{2}$, \\ J B Mamani ${ }^{2}$, A J Costa-Filho ${ }^{3}$, E D Vieira ${ }^{3}$, C A Moreira-Filho ${ }^{1,4}$ \\ and $\mathbf{E}$ Amaro $\mathbf{J r}^{1,5}$ \\ ${ }^{1}$ Instituto Israelita de Ensino e Pesquisa Albert Einstein, IIEPAE, \\ São Paulo 05651-901, Brazil \\ 2 Instituto de Física, Universidade de São Paulo, São Paulo 05315-970, Brazil \\ ${ }^{3}$ Instituto de Física de São Carlos, Universidade de São Paulo, São Carlos 13560-970, Brazil \\ ${ }^{4}$ Instituto de Ciências Biomédicas, Universidade de São Paulo-USP, São Paulo, Brazil \\ ${ }^{5}$ Instituto de Radiologia, Faculdade de Medicina, Universidade de São Paulo 05403-001, \\ Brazil \\ E-mail: lgamarra@einstein.br
}

Received 4 April 2008

Published 1 May 2008

Online at stacks.iop.org/JPhysCM/20/204150

\begin{abstract}
The aim of this work is to provide a quantitative method for analysis of the concentration of superparamagnetic iron oxide nanoparticles (SPION), determined by means of ferromagnetic resonance (FMR), with the nanoparticles coupled to a specific antibody ( $A C 133)$, and thus to express the antigenic labeling evidence for the stem cells $C D 133^{+}$. The FMR efficiency and sensitivity were proven adequate for detecting and quantifying the low amounts of iron content in the $C D 133^{+}$cells $\left(\sim 6.16 \times 10^{5} \mathrm{pg}\right.$ in the volume of $2 \mu$ l containing $4.5 \times 10^{11}$ SPION $)$. The quantitative method led to the result of $1.70 \times 10^{-13} \mathrm{~mol}$ of $\mathrm{Fe}(9.5 \mathrm{pg})$, or $7.0 \times 10^{6}$ nanoparticles per cell. For the quantification analysis via the FMR technique it was necessary to carry out a preliminary quantitative visualization of iron oxide-labeled cells in order to ensure that the nanoparticles coupled to the antibodies are indeed tied to the antigen at the stem cell surface and that the cellular morphology was conserved, as proof of the validity of this method. The quantitative analysis by means of FMR is necessary for determining the signal intensity for the study of molecular imaging by means of magnetic resonance imaging (MRI).
\end{abstract}

\section{Introduction}

The use of superparamagnetic iron oxide nanoparticles (SPION), coupled to a specific antibody, has been successfully applied to label antigenic probes in molecular imaging, especially magnetic resonance imaging (MRI) [1-3].

The cell in culture labeling with SPION, together with MRI, provides a non-invasive method for study of the destinations of cells transplanted in vivo $[4,5]$. The cells may be labeled using contrast agents on the basis on nanoparticles, during their incubation in a culture, before their transplantation into tissue.

Superparamagnetic (magnetic fluid) contrast agents with a superparamagnetic core consisted of crystalline structures based on iron oxide, described by the general formula $\mathrm{Fe}_{2}^{3+} \mathrm{O}_{3} \mathrm{M}^{2+} \mathrm{O}$, where $\mathrm{M}^{2+}$ is a divalent metal ion such as iron, manganese, nickel, cobalt or magnesium. For the synthesis of the contrast agents, small $\mathrm{Fe}_{2}^{3+} \mathrm{O}_{3} \mathrm{Fe}^{2+} \mathrm{O}$ (magnetite) crystals are mainly employed [6]. Preparatory processes are of paramount importance-before the acquisition of molecular images based on MRI of the stem cells labeled with SPION. The process can be divided into the following parts: quantitative evaluation and qualitative expression of the antigens [3, 7], labeling efficiency [3, 8, 9], SPION toxicity [8-10], cell viability [3, 9], proliferation [3, 8, 9] and differentiation assays [8], qualitative visualization of iron oxide-labeled cells [3], iron content quantitative analysis [11, 12], among others. 
There are several techniques for performing iron content quantitative analyses $[11,12]$, such as that using ferromagnetic resonance (FMR) which is the electron paramagnetic resonance $(\mathrm{EPR})$ of small ferromagnetic particles. The only difference is that the electron spins interact among themselves in the lattice. This leads to a ferromagnetic or ferrimagnetic order in the nanoparticles, assumed to be composed of magnetic monodomains and having nearly spherical shape. Thus, the total magnetic momentum of each nanoparticle is precessing over the direction of the total static field, which is the sum of the external static field, the internal contribution of the domain magnetization and the anisotropic magnetic field of the local lattice [13]. The magnetic fluids based on SPION present physical mechanisms that are essentially the same for ferromagnetic solids and magnetic suspensions. However, in the ferrofluids the FMR is affected considerably by two specific characteristics. The first one stems from the smallness of the particles, and imparts a fluctuational component to the magnetic moment motion. The second originates from mechanical mobility of the particles and results in a change of their anisotropy axis distribution under the influence of the external fields [14].

For the molecular imaging purposes, a great deal of interest has been focused on CD133 stem cell labeling. This antigen may be expressed in a variety of tissues including the kidney, pancreas, placenta, fetal liver [15], skeletal muscles and human neural tissue. This vast number of tissues suggests an equal number of possible clinical applications, including, among other interesting possibilities, the utilization of the progenitor stem cells $C D 133^{+}$in tissue engineering. The antigen $C D 133$ is an integral glycoprotein of a $97 \mathrm{kDa}$ membrane that belongs to a molecular family of proteins 5$T M[15,16]$. In the human body, the monoclonal antibodies $A C 133$ may be bonded together in different epitopes, but they were originally demonstrated to react with a cellular surface antigen expressed in human stem cells and in various cellular progenitors, including those derived from the hematopoietic system [15].

The aim of the present work is the quantitative analysis of the SPION $\left(\mathrm{Fe}_{3} \mathrm{O}_{4}\right)$ concentration by means of FMR, where the nanoparticles are coupled to a specific monoclonal antibody (AC133) expressing the antigenic labeling evidence of the stem cells $C D 133^{+}$of the human blood and umbilical cord. The study is completed using the techniques of flow cytometry and transmission electron microscopy (TEM).

We first carried out a study to determine whether the cells were actually expressing the trans-membrane glycoprotein antigen $C D 133$, selected by affinity chromatography. The second point was to establish the efficiency of the selection procedure. The TEM analysis was used to detect the presence of antibodies coupled with SPION attached on the cellular membrane.

\section{Materials and methods}

The CD133 cell labeling was achieved by an in vitro protocol using the monoclonal antibody anti-CD133 coupled to magnetic beads composed of SPION- $-\mathrm{Fe}_{3} \mathrm{O}_{4}$ (Miltenyi
Biotec). These nanoparticles (average diameter of $9.0 \pm$ $0.3 \mathrm{~nm}$ ) are found in a colloidal suspension of a ferrofluid, or magnetic fluid with the iron content of $200 \mu \mathrm{g} \mathrm{ml}^{-1}$. Umbilical cord blood was obtained from volunteer donors $(n=5)$ after the registering of their written consent (CEP-IEPAE No. 105/02). Mononuclear cells were purified by density gradient centrifugation (Ficoll-Paque ${ }^{\mathrm{TM}}$ Plus (GE Healthcare)), according to a modified method published previously [17]. The $C D 133^{+}$cell population was purified using anti-CD133 mAbcoupled magnetic beads (Miltenyi Biotec) according to the manufacture's instructions.

After $C D 133^{+}$cell separation, the cell population was characterized by flow cytometry using the following monoclonal antibodies (Becton Dickinson, San Jose, CA, and Miltenyi Biotec): $C D 34$ (clone: 581) FITC-conjugated, $C D 45$ (clone: 2D1) PerCP Cy-5.5-conjugated and $C D 133 / 2$ (clone: $A C 141)$ APC-conjugated and the respective isotype controls $I g G 1$ FITC-conjugated, $\operatorname{Ig} G 1$ PerCP Cy-5.5-conjugated and I $g G 1$ APC-conjugated.

Cells were incubated with antibodies at $4{ }^{\circ} \mathrm{C}$, in the dark for $30 \mathrm{~min}$, and then washed with PBS and fixed with $1 \%$ paraformaldehyde. A total of 105 fluorescent cellular events were acquired in the FACSARIA flow cytometry (BD Bioscience) and analyzed using FACSDIVA software. Briefly, the analysis was performed by gating the cell population for forward scatter (FSC) versus side scatter (SSC) followed by gating only the $C D 45^{+}$cells. Within the $C D 45^{+}$cell population, cells were analyzed for expression of $C D 34$ and CD133 markers.

After $C D 133$ cell separation, the cell population was fixed in $2.5 \%$ glutaraldehyde in $0.2 \mathrm{M}$ cacodylate buffer for $2 \mathrm{~h}$ at $4{ }^{\circ} \mathrm{C}$. Later the routine procedure for TEM was carried out, including washes, post-fixation, contrasting, dehydration and inclusion in pure resin until complete polymerization was achieved. Semithin and ultrathin sections were obtained with the aid of a Porter Blum ultramicrotome. The ultrathin sections were placed on copper grids and photographed using a transmission electron microscope, PHILIPS CM 100.

The quantification of the average iron content per cell, expressed as the average number of SPION per cell, was attained by means of the technique of FMR. The characteristic FMR of a ferrofluid compound, containing magnetite particles, is observed as a broad line at about $g=2.1$. Since the resonance spectrum is recorded as the derivative of absorption, the number of resonant spins is proportional to the double integral of the signal, yielding the area under the absorption curve, measured over increasing values of the applied magnetic field, sweeping the complete interval where the resonance occurs. The constant of proportionality is determined using the calibration curve, constructed by weighing known amounts of ferrofluid which are directly correlated with the FMR signal intensities equal to the areas under the absorption curves, expressed in arbitrary units.

The calibration curve shown in figure 1 was constructed using different concentrations of the commercial ferrofluid Endorem (Endorem ${ }^{\mathrm{TM}}$ - Guerbert; earlier trade name $A M I$ 25, Laboratoire Guerbert, France). The concentrations covered a range of $2.6 \mu \mathrm{M}-0.6 \mathrm{mM}$ contained in the volume of $2 \mu \mathrm{l}$. 


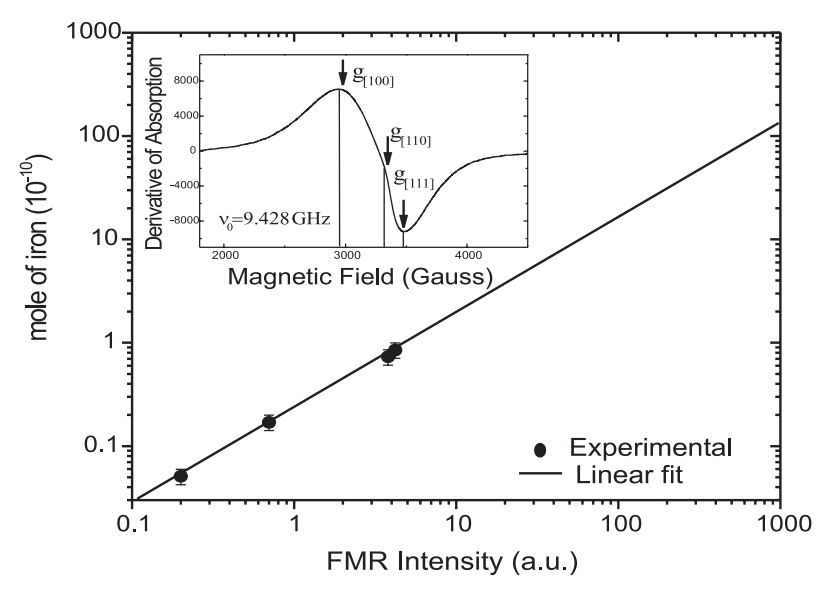

Figure 1. Calibration curves of the FMR of the nanoparticle concentration related to the area under the $g=2.1$ resonance absorption curve. The inset shows a typical FMR spectrum of the $g=2.1$ line of magnetite contained in the ferrofluid Endorem ${ }^{\mathrm{TM}}$ used in the data acquisition for the building of the curve calibration.

A typical FMR spectrum of the commercial ferrofluid is shown in the inset of figure 1 .

The FMR line intensity was determined from the area under the absorption line (double integral of the resonance at $g=2.1$ ), which is proportional to the iron particle concentration per $\mathrm{mm}^{3}$. This calibration curve is shown in figure 1 (solid line). The FMR derivative of the absorption spectrum is used to calculate the calibration curve, obtained at room temperature (inset in figure 1). The absorption lineshape is typical of a convoluted cubic crystal powder pattern of the FMR of fine-grained precipitates of ferromagnetic or ferrimagnetic single domains [18], also seen when iron ion $\left(\mathrm{Fe}^{3+}\right.$ and $\left.\mathrm{Fe}^{2+}\right)$ dimers and/or clusters are precipitated in glasses [19]. From this curve a positive firstorder magnetocrystalline anisotropy constant $K_{1}=(1.2 \pm$ $0.2) \times 10^{5} \mathrm{erg} \mathrm{cm}^{-3}$ was determined from the relation $H_{\mathrm{a}}=$ $2 K_{1} / M_{\mathrm{s}}$, taking into account that the nanoparticles are of magnetite. $M_{\mathrm{s}}$ is the maximum saturation magnetization of the crystal, equal to $H_{s} /(4 \pi / 3) \operatorname{erg} \mathrm{G}^{-1} \mathrm{~cm}^{-3}$ and $H_{S} \approx$ $2 \mathrm{kG}$ for magnetite. The nanoparticles were assumed to be monodomains of spherical shape. From the maximum $\left(H_{\max }\right)$, minimum $\left(H_{\min }\right)$ wings and maximum negative slope $\left(H_{\mathrm{ms}}\right)$ of the FMR spectrum, respectively, the effective $g$ values are $g_{[100]}=2.28 \pm 0.01, g_{[110]}=2.02 \pm 0.02$ and $g_{[111]}=1.94 \pm 0.01$. The value of $H_{\mathrm{a}}$ is obtained from the field separation between the positions of $H_{\max }$ and $H_{\min }$ wings (equal to $(5 / 3) H_{\mathrm{a}}$ ). From $H_{0}=H_{\max }-(2 / 3) H_{\mathrm{a}}$ the value of $g_{0}=\left(h v /\left(\beta H_{0}\right)\right)=2.12 \pm 0.02$ is obtained, where $v=9.428 \mathrm{GHz}, h$ is Planck's constant, $v$ is the spectrometer frequency and $\beta$ is the Bohr magnetron.

The derivative of the absorption of the FMR was obtained using a Bruker EMX homodyne spectrometer, operating in the $\mathrm{X}$ band, at the frequency of $9.428 \mathrm{GHz}$, using a rectangular $\mathrm{TE}_{102}$ cavity with $100 \mathrm{kHz}$ modulation.

\section{Results and discussion}

In our sample $98 \%$ of the cells were expressed by $C D 45$, which characterizes their hematopoietic source (data not shown). After the selection of $C D 45^{+}$events, the expression of $C D 34$ (progenitor marker) was analyzed; it was found that $82 \%$ of all $C D 133^{+}$selected cells also express $C D 34$ (figure 2(A)) indicating their progenitor phenotype. The specificity of the test was considered adequate from the negative result found in the isotype control (figure 2(B)). The efficiency of $C D 133$ selection after flow cytometry analyses was $83.6 \%$.

The ultrastructural analysis highlighted the presence of electron dense granules in the cell surface. This demonstrates the presence of AC133 monoclonal antibodies bound to SPION expressed in the cell membrane $\left(C D 133^{+}\right.$; figures 3(A), (B), (E)) which does not occur in the cells of the control group (figure $3(\mathrm{G})$ ), since these cells do not express the antigen $C D 133\left(C D 133^{-}\right)$.

The $C D 133^{+}$cells have a round morphology and an active nucleus that occupies almost the whole cell (figures 3(A) and (B)).

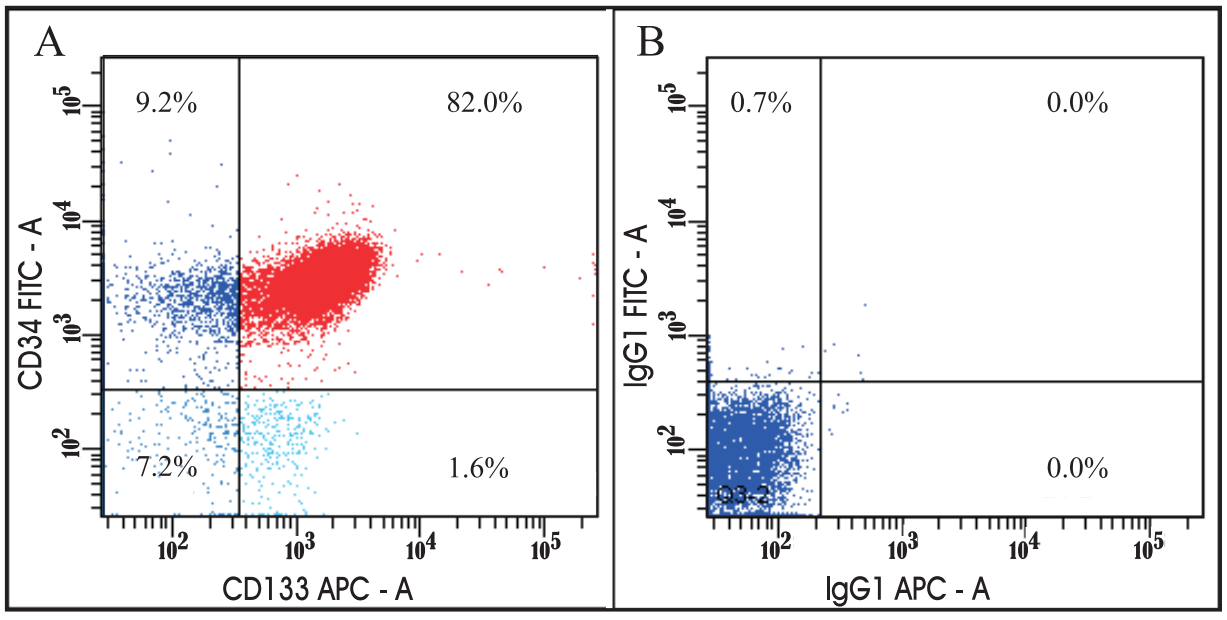

Figure 2. (A) The flow cytometry graph shows $C D 133^{+} / C D 34^{+}(82.0 \%), C D 133^{-} / C D 34^{+}(1.6 \%)$ and $C D 34^{+} C D 133^{-}(9.2 \%)$. (B) The isotype control graph shows that there was no non-specific staining.

(This figure is in colour only in the electronic version) 

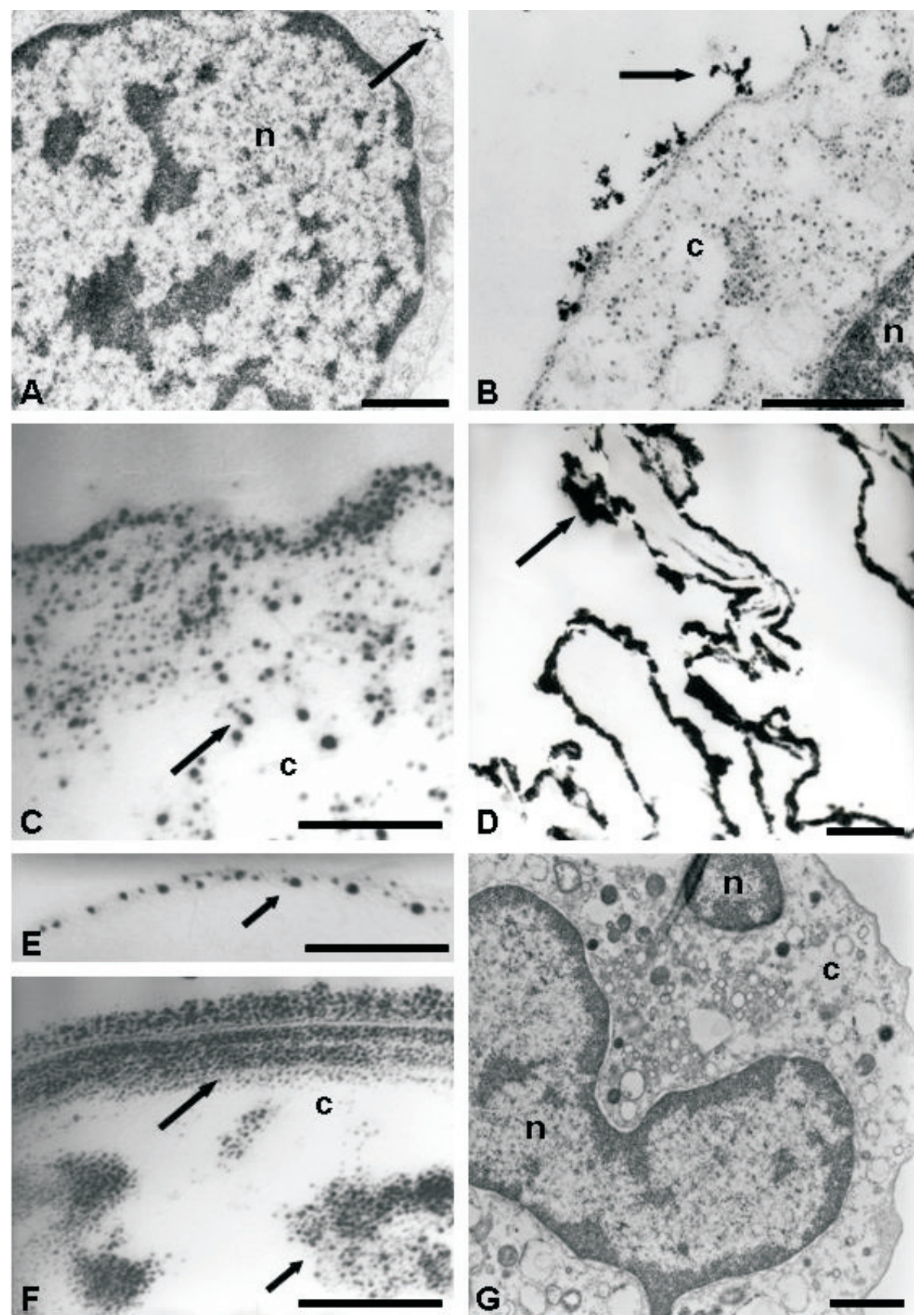

Figure 3. ((A)-(F)) TEM of $C D 133^{+}$stem cells. (G) TEM of $C D 133^{-}$stem cells (control). $\mathrm{n}=$ nucleus, $\mathrm{c}=$ cytoplasm, arrow $=$ electron dense granules. Scale: $((A),(G)) 1 \mu \mathrm{m}$; (B), (C), (E), (F)) $0.25 \mu \mathrm{m}$; (D) $0.5 \mu \mathrm{m}$.

The SPION were also observed in the cell cytoplasm (figure $3(\mathrm{C})$ ). These nanoparticles bound to the antibodies expressed in the cellular membrane were more probably incorporated into the cell through the endocytosis process (pinocytosis). They can be visualized using TEM as electron dense particles (figure 3(C)).

Preliminary experiments performed by our group showed a strong marking, electron dense in the periphery of the cellular content, but the morphology of cell $C D 133^{+}$was not preserved (figure 3(D)), probably due to insufficient fixation of the material for $2.5 \%$ glutaraldehyde in $0.2 \mathrm{M}$ cacodylate buffer.
The TEM also revealed an excess of nanoparticles electron dense in the cellular membrane, as well as in the cytoplasm (figures 3(C), (F)).

First, we obtained the FMR spectrum only for the magnetic beads (see figure 4) of the antigenic label, i.e., monoclonal antibody anti-CD133, coupled to the SPION (Miltenyi Biotec). The resonance was observed at $g=2.1$, indicating the presence of multiple $\mathrm{Fe}^{3+}$ spins interacting and showing a superparamagnetic behavior [20, 21], which characterizes the presence of agglomerates. This signal consists of a strong absorption, broadened by the exchange interaction between the $\mathrm{Fe}^{3+}$ spins. A control sample with 

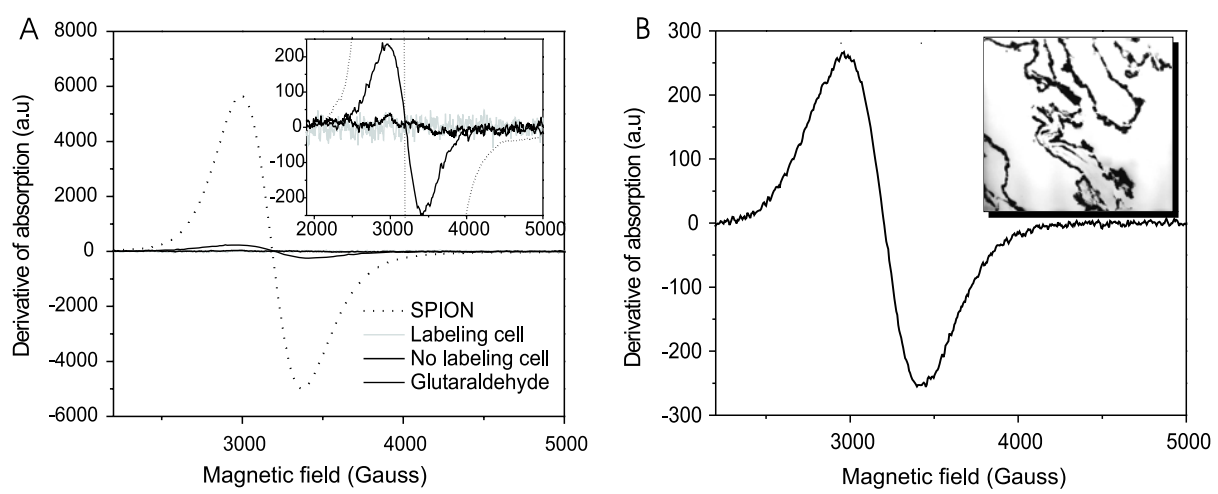

Figure 4. (A) FMR spectra, showing the derivative of the absorption curve of the isolated label, labeled cells, non-labeled control cells and the glutaraldehyde. In the inset the resonance is compared with the enhanced spectrum of a control sample. (B) FMR derivative of the absorption spectrum of SPION attached to the $C D 133^{+}$cells that exhibit high electron densities in the cell periphery, as shown in the TEM image of the inset.

CD133 control cells with no label was measured by means of FMR and no resonance could be observed (see figure 4(A)).

Subsequently an FMR spectrum of the labeled $C D 133^{+}$ cells $\left(0.64 \times 10^{5}\right.$ labeled cells contained in the volume of $\left.2 \mu \mathrm{l}\right)$ showed the resonance at $g=2.1$ (see figure 4(A)). This again demonstrated the presence of SPION in the cells immersed in the fixer glutaraldehyde $2.5 \%$, attached to the cells as shown in figure 4(A).

In order to be sure that the nanoparticles were not present in the fixer, the latter was separated from the labeled cells by $1200 \mathrm{rpm}$ centrifugation, for $10 \mathrm{~min}$, and the floating substance was carefully removed. The FMR spectrum of the fixer in the glutaraldehyde was taken and the absence of SPION was confirmed (inset of figure 4(A)). This result was already expected from the TEM morphological study, where it was observed that the antibody coupled to the nanoparticles was found tied to the $C D 133^{+}$cells.

The quantification of the average iron content per cell was determined from the area under the FMR absorption curves of the labeled cells (figure 4(A)), by interpolation of the calibration curve of figure 1 . The iron content per cell was $1.70 \times 10^{-13} \mathrm{~mol}(9.5 \mathrm{pg})$ or $7.0 \times 10^{6}$ nanoparticles per cell.

For the quantification by means of FMR of the number of nanoparticles per cell, it was necessary to carry out a qualitative visualization of iron oxide-labeled cells. This was necessary in order to ensure that the nanoparticles coupled to antibodies were attached to the surface antigen of the stem cell, providing confirmatory information.

The FMR spectrum (figure 4(B)) of the $C D 133^{+}$sample confirmed a strong labeling of dense electron regions in the periphery of the cell (see the inset of figure 4(B)). Moreover, we have observed that the morphology was not conserved, as explained previously. For all cells the FMR signal of SPION was due to the nanoparticles coupled to the antibodies which in turn are bonded into the cells. The analysis of the signal obtained for the quantification gives the result of $1.64 \times 10^{-13} \mathrm{~mol}$ of iron $(9.4 \mathrm{pg})$ or $6.8 \times 10^{6}$ nanoparticles per cell, in good agreement with the values obtained with well labeled cells, for example, those of figures 3(B) and (G). It is then necessary to perform a morphological analysis before performing the quantitative FMR measurements.

\section{Conclusion}

The FMR method is an efficient technique for the quantification of the iron concentration in stem cells. In this work, FMR has allowed us to quantify the SPION concentration in the $C D 133^{+}$cells of small samples (volume of the order of $\mu 1$ ). In practice, for ferromagnetic particles, an area unit can be accurately measured, being equal to the number of $4.5 \times 10^{11}$ nanoparticles contained in the volume of $2 \mu \mathrm{l}$ or about $6.16 \times 10^{5} \mathrm{pg}$ of iron.

The information obtained from the FMR spectra of the $C D 133^{+}$stem cells is similar to that obtained from the cells where the morphology was not conserved. Thus, in order for the FMR quantification method be valid, it is necessary to perform a preliminary test of a qualitative visualization of iron oxide-labeled cells (TEM), in order to make sure that the nanoparticles coupled to the antibodies are effectively tied to the antigen located at the surface of the stem cell, and that the morphology of the cell was preserved.

\section{Acknowledgments}

This work was financed by Instituto Israelita de Ensino e Pesquisa Albert Einstein (IIEP) and CNPq. We are grateful to Lab. de Microscopia Eletrônica, UNESP de Rio Claro, SPBrazil, and Monika Iamonte for technical support.

\section{References}

[1] Bulte J W M and Kraitchman D L 2004 NMR Biomed. 17484

[2] Weissleder R and Ntziachristos V 2003 Nat. Med. 9123

[3] He G, Zhang H, Wei H, Wang Y, Zhang X, Tang Y, Wei Y and Hu S 2007 Int. J. Cardiol. 1144

[4] Bulte J W, Douglas T, Witwer B, Zhang S C, Strable E, Lewis B K, Zywicke H, Miller B, Van Gelderen P, Moskowitz B M, Duncan I D and Frank J A 2001 Nat. Biotechnol. 19 1141-7

[5] Jendelov P, Herynek V, De Croos J, Glogarov K, Andersson B, Hjek M and Sykov E 2003 Magn. Reson. Med. 50 767-76

[6] Wang Y J, Hussain S M and Krestin G P 2001 Eur. Radiol. 112319 
[7] Ahrens E T, Flores R, Xu H and Morel A P 2005 Nat. Biotechnol. 23983

[8] Zhang Z, van de Bos E J, Wielopolski P A, Jong-Popijus M, Bernsen M R, Duncker D J and Krestin G P 2005 MAGMA 18175

[9] Zhang Z, van de Bos E J, Wielopolski P A, Jong-Popijus M, Duncker D J and Krestin G P 2004 MAGMA 17201

[10] Vinardell M P 2005 Toxicol. Highlight 88285

[11] Jendelov P, Herynek V, Urdzíkov L, Glogarov K, Kroupov J, Andersson B, Bryja V, Burian M, Hjek M and Sykov E 2004 J. Neurosci. Res. 76232

[12] Billotey C, Wilhelm C, Devaud M, Bacri J C and Bittoun J 2003 Magn. Reson. Med. 49646

[13] Shilov V, Raikher Y L, Bacri J C, Gazeau F, Perzynski R and Stepanov V I 1998 Phys. Rev. B 60 11902-5
[14] Raikher Y L and Stepanov V I 1995 J. Magn. Magn. Mater. 14934

[15] Miraglia S, Godfrey W, Yin A H, Atkins K, Warnke R, Holden J, Bray R A, Waller E K and Buck D W 1997 Blood 90 5013-21

[16] Miraglia S, Godfrey W and Buck D 1998 Blood 91 4390-1

[17] Lehner M and Holter W 2002 Int. Arch. Allergy Immunol. 12873

[18] Griscom D L 1984 J. Non-Cryst. Solids 6781

[19] Reis S T, Faria D L A, Martinelli J R, Pontuschka W M, Day D E and Partiti C S M 2002 J. Non-Cryst. Solids 304189

[20] Gamarra L F, Brito G E S, Pontuschka W M, Amaro E, Parma A H C and Goya G F 2005 J. Magn. Magn. Mater. 289 439-41

[21] Sharma V K and Waldner F 1977 J. Appl. Phys. 484298 
